Portland State University

PDXScholar

$1-1-2005$

\title{
Teacher Learning: Documentation, Collaboration, and Reflection
}

William A. Parnell

Portland State University

Follow this and additional works at: https://pdxscholar.library.pdx.edu/open_access_etds Let us know how access to this document benefits you.

\section{Recommended Citation}

Parnell, William A., "Teacher Learning: Documentation, Collaboration, and Reflection" (2005). Dissertations and Theses. Paper 743.

https://doi.org/10.15760/etd.743

This Dissertation is brought to you for free and open access. It has been accepted for inclusion in Dissertations and Theses by an authorized administrator of PDXScholar. Please contact us if we can make this document more accessible: pdxscholar@pdx.edu. 


\section{DISSERTATION APPROVAL}

The abstract and dissertation of William Arthur Parnell for the Doctor of Education in

Educational Leadership: Curriculum and Instruction were presented October 10, 2005, and accepted by the dissertation committee and the doctoral program.

COMMITTEE APPROVALS:
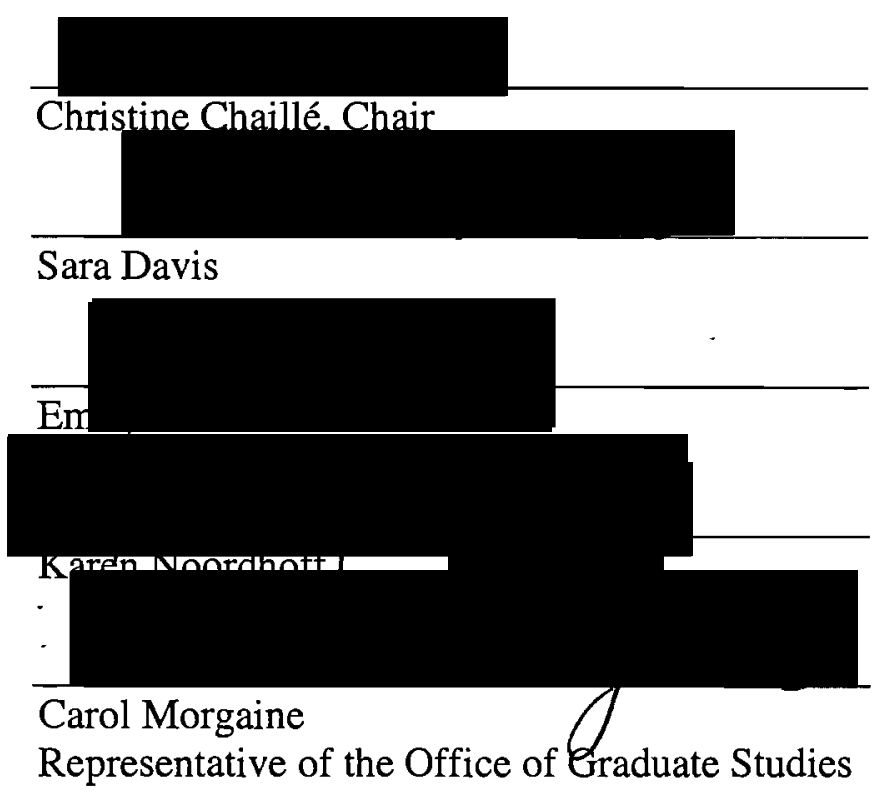

DOCTORAL PROGRAM APPROVAL:

Carol Mack, Interim Dean

Graduate School of Education 


\begin{abstract}
An abstract of the dissertation of William Arthur Parnell for the Doctor of Education in Educational Leadership: Curriculum and Instruction presented October 10, 2005.
\end{abstract}

Title: Teacher Learning: Documentation, Collaboration, and Reflection

Inspired by the Municipal preprimary schools of Reggio Emilia, Italy, two art studio teachers and a researcher have explored experiences and meaning in the atelier. When studio teachers document children's thinking through digital photographs, transcribed audio tapes, quotations of a child's verbal thoughts, and copies of their work, an indescribable moment in teacher thinking interweaves with the child's learning. As teachers capture children's representations, investigate, interpret, and share their ideas with colleagues and community-an underlying question emerges. What are studio teachers' experiences of teaching-learning in the atelier as they utilize documentation, collaboration, and reflection as a way to inform their practices? From this question, reader and researcher start a journey together into a six-month phenomenological study of studio teaching experiences. As a core member in the teaching team, the studio teacher resides in the atelier to bring teaching and 
learning together in a profound way, to bridge classroom experiences with representative arts, and to facilitate the community's learning about teaching-learning.

The methods used to inform this study include observations, in-depth interviews, electronic journaling, description, photos, and interpretation of studio work. Overall, this study's methods inform the phenomenological research and construct an in-depth look at experiences in the artist's studio.

The results of this research are retold through narratives focusing on experiences and meaning-making in the studios. Stories such as living with the cracked egg; isolation in the studio: gifts for others; rough stones polishing one another; and many others, utilize photographs to enhance meaning through picturesque artifacts. Essential themes, conclusions, and implications appear in the webbing of experiences and are explored in the final chapter. The themes include conceptual frameworks such as life eats entropy, serendipity and synergy and more. Conclusions are drawn and findings are made connecting studio experiences to participant voice, disequilibrium, listening, engaging, stepping back, and slowing time; demonstrating documentation as learning, revisiting, representation, and manageability; making meaning of collaboration as struggle, communication, and reconstruction; and reflecting back as purposeful and an act of teaching-learning. Overall, this research study exposes techniques, ideas, and wonderings from two studio teachers' and a researcher's experiences in the atelier. 


\author{
'TEACHER LEARNING: \\ DOCUMENTATION, COLLABORATION, AND REFLECTION
}

\author{
by \\ WILLIAM ARTHUR PARNELL
}

A dissertation submitted in partial fulfillment of the requirements for the degree of

DOCTOR OF EDUCATION

in

EDUCATIONAL LEADERSHIP: CURRICULUM AND INSTRUCTION

Portland State University

(C)2005 
Table of Contents

List of Tables $\quad v$

List of Figures $\quad$ vi

Chapter One: Introduction and Research Topic 1

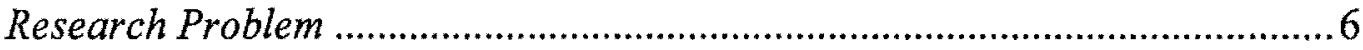

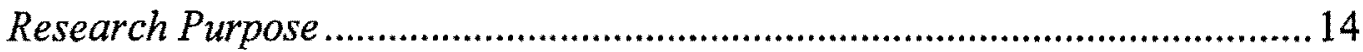

Fundamental Research Question and Underlying Provocations ...................15

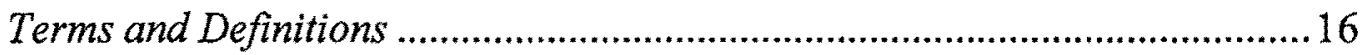

Chapter Two: Review of the Literature and Underpinning Theoretical Frameworks 18 History and Context of Reggio Emilia's Municipal Preprimary Schools and Infant-Toddler Centers: Schools Built Brick by Brick ...................................19 Intersubjectivity, Educational Research, and Social Constructivism .............25

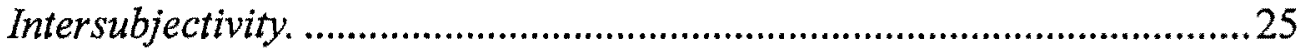

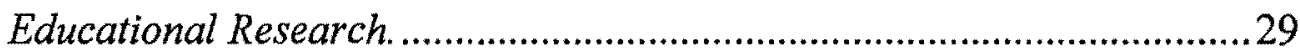

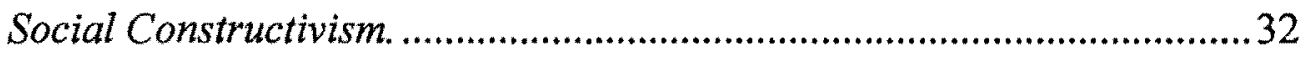

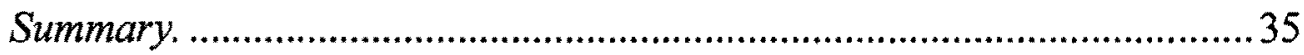

The Intersection of Teaching and Learning: Educational Influences ..............36

Teacher Work and Development: Documentation, Collaboration, and

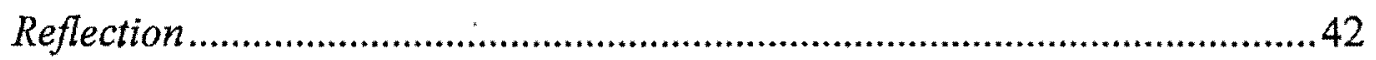

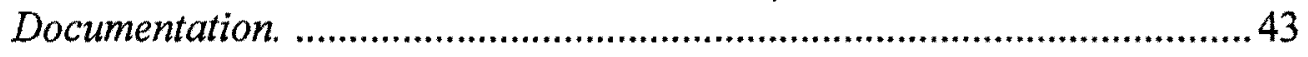

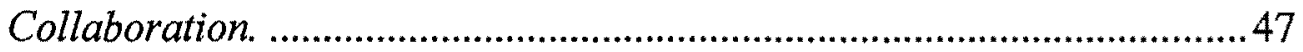

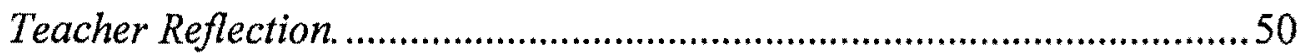


Summary. 52

Learning for the Teacher: Metaphor and Meaning 53

Impetus for Teaching and Renewal ..........................................................58

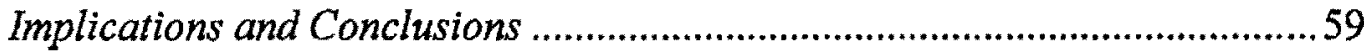

Chapter Three: Approach and Methods $\quad 62$

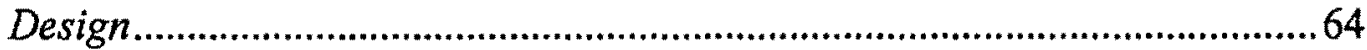

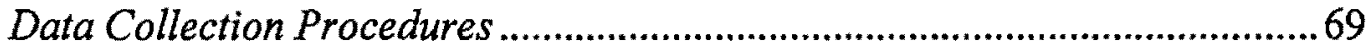

Observation, Field Notes, and Photographs. .......................................... 71

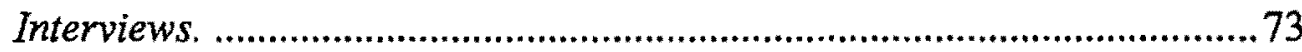

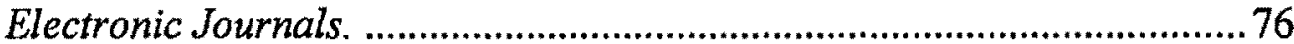

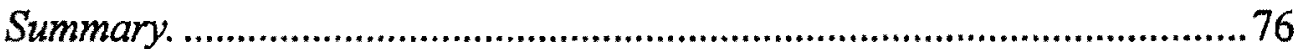

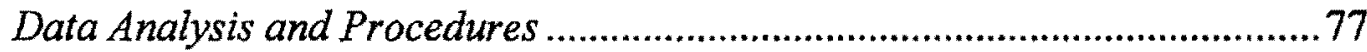

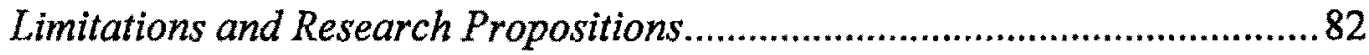

Validity, Ethics, and this Research Capacity. ......................................... 82

Theoretical and Practical Significance. ....................................................8 86

Chapter Four: Research Results and Discussion $\quad 88$

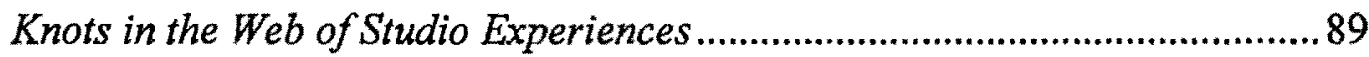

The Value of Intentional Listening. ...........................................................91

Meltdown in the Midst of Beauty...............................................................94

Light at the end of Week Two's Tunnel. ..................................................96

Atelierista Frustration in the Work ..........................................................99

Engaging Children in the Studio: Laboratory of Learning Experiences. 101

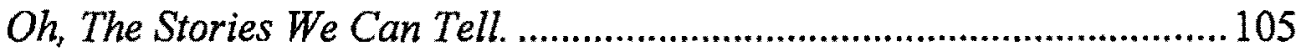




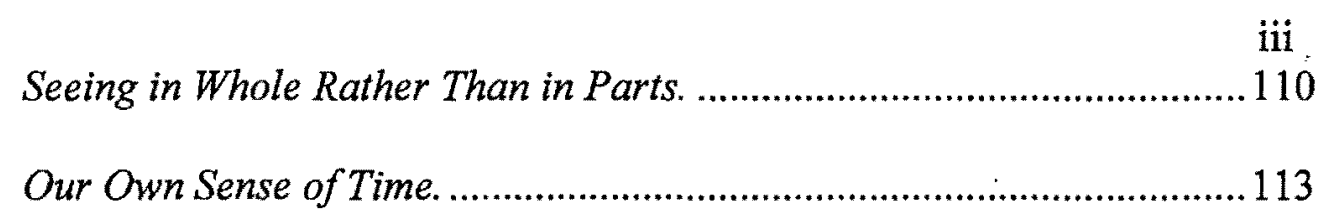

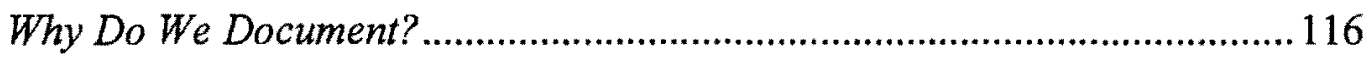

What Happens to our Experiences as we document them? The Eyes of an

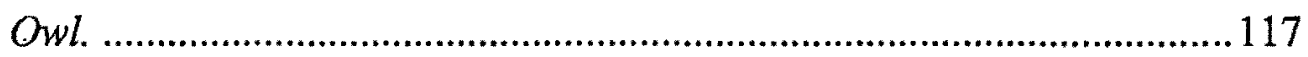

Hidden Meanings in documentation: Understanding Symbols. ...............119

Documenting the Documenter: Silly Gestures. ...................................... 121

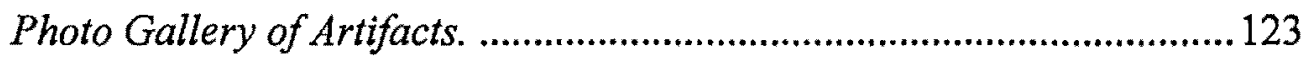

The Meaning of Pedagogical Collaboration ...............................................128

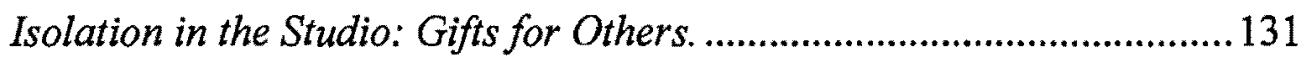

Rough Stones Polishing One Another: Teachers and Children as Co-

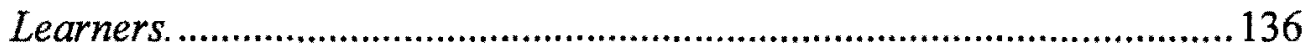

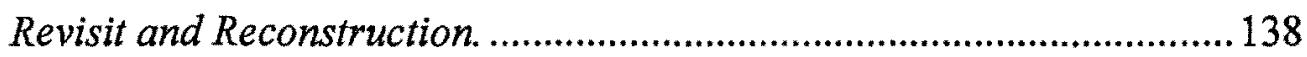

Community Involvement: Parents, Teachers, and Other Children. ........ 140

Reflecting Back: The Meaning of our Atelier Experiences as a Discussion.143

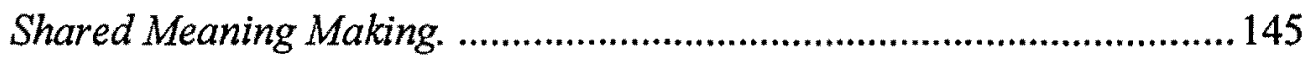

Endings, Beginnings, and Continuations. ............................................. 147

Summary: Review of the Research Questions and Results............................ 148

Chapter Five: Themes, Conclusions, and Future Implications 154

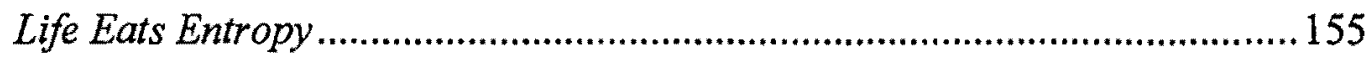

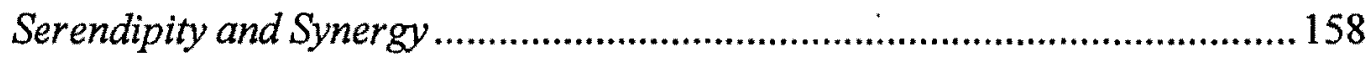

The Image of the Child as a Connection to All Images in School ..................161

Engagement in the Studio-Engagement in the Classrooms............................ 163 


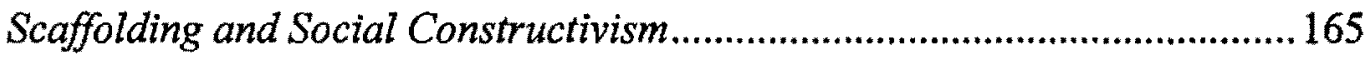

Intersubjectivity, Phenomenology, and the Meaning of Wholes ................... 168

The Role of the Atelierista, Pedagogista and School Organization............. 172

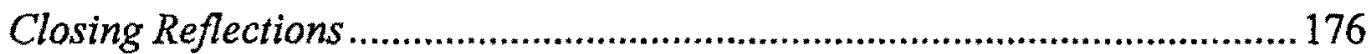

$\begin{array}{ll}\text { References } & 178\end{array}$ 


\section{List of Tables}


List of Figures

Figure 1. Susan's house with levels and beds. .95

Figure 2. Children drawing together in Marsha's studio. .95

Figure 3. Merna makes a family party. 101

Figure 4. Representing birds migrating from the Winged Migration movie. 104

Figure 5. Sharing egg drawings in Marsha's studio. 107

Figure 6. Suzy suggesting that children look at Thomas's drawing. 109

Figure 7. Drawing an owl with tremendous concentration. 112

Figure 8. Sophie flying her owl creation toward the camera. 118

Figure 9. First drawing of the peak of Merna's house which shows the mysterious round near the top. 120

Figure 10. Gestures Making Meaning in the Ateliers. 126

Figure 11. Suzy holding Susan to comfort her as Susan gives way into Suzy's arms.

Figure 12. Frustrated Merna looking on as Susan tantrums. 137

Figure 13. Merna and Susan's hands working together to complete their teacher's face in clay. 138 
Chapter One: Introduction and Research Topic

Imagine a place where teachers and parents are profoundly interested in children's thinking and imagination and they work together to create sacred learning spaces for children and others. In this place, provoking children into theory building and believing in the capabilities of young children's learning processes as theory and not as misinterpretation creates aliveness, uniqueness, and rich contextual experiences. In this place, a reciprocal relationship exists between the schools for young children and most everyone in the city. The children's work is taken seriously in the township and the viewpoint of children as full participatory citizens in community life is revered. What this means is that as a visitor you begin to notice pieces of the children's work, gifted with care, on every street in the city. And you meet seemingly unconnected people who volunteer their time and talent to the schools as you journey through the city shops, restaurants, and open markets. Everywhere you go, you are asked if you are visiting their schools for young children and told stories about how some individual has contributed to the children's world in a beautiful, aesthetic, and artful way.

This city is not a dream, conjured on these pages. This city exists and is alive with the energy of the children. Mind you, it is not without struggles and hardships, but it exists in our time as a gift to the world of childhood. This mindful and exceptional way of thinking about children comes from the energy generated out of this Italian city, Reggio Emilia. The educational coordinators (pedagogiste) and art studio teachers (atelieriste) of this city's experience ask that the rest of the world develop their own sense of being with children, capture and celebrate their own 
experiences of children's learning and work, and that their name, "Reggio Emilia," be spoken softly and only as inspiration for our own creations with children (Carla Rinaldi, personal communication, October 19,2001). Reggio Emilia is not a trademark name or a "way" of copying good practices with children. Instead, Reggio Emilia is a small city in northern Italy, carving out its own unique and important experiences with the children, most notably through their centerpiece of pedagogical exploration, which is called "the atelier" or art studio in each school. The reflective practitioners, studio teachers, pedagogical coordinators, and community of this city are continuously awakening to the idea that children matter, their work is important enough to share with others, and that children have rights on this little planet. A planet which is too full of other agendas and of people who have for years drowned out the teachers, parents, and children's voices.

Reflective practitioners such as those in Reggio Emilia are dedicated to investigation and reinvention of their own teaching practices, and this mission shows up throughout their many school spaces; the classroom, art studio, central piazza, ReMida (recycled-materials) center, and many more. In the Reggio Emilia preprimary schools and infant-toddler centers, treasuring the inseparability of teaching and learning and the search for meaning is the way preprimary teachers, children, and families flourish. "I once again touch on the question of the unfinishedness of the human person, the question of our insertion into a permanent process of searching. In this context I explore again the problem of ingenuous and critical curiosity and the epistemological status of curiosity" (Freire, 1998/2001, p. 21). Freire points to an experience in teaching where one remains curious and learning. Curiosity and 
learning materialize in this unique city called Reggio Emilia, where the values of collaboration, responsiveness, and responsibility to critically analyze teacher and children's thinking and work are foundations in the Municipal infant-toddler centers and preprimary schools for young children. These values inform teacher awareness, development, and insight. For those of us not teaching directly in Reggio Emilia, this "Reggio-inspired" way invites us to develop research around a unified construct of teaching-learning, a construct defined by Hesslefors-Arktoft (1996) "as a dynamic meeting which aims toward transforming understandings of things" (Focusing Pupil Experiences section, para. 5).

As Freire (1998/2001) advocates, "Whoever teaches learns in the act of teaching, and whoever learns teaches in the act of learning" (p. 31). The unification of teaching and learning into a single concept is no stranger to several cultures as displayed in their vocabulary. In the Maori and Hawaiian languages there exists only one word for the meaning of teaching and learning. In Hawaiian the word a'o means both to teach and to learn and in Maori the word ako means both to learn and to teach (Sydney Gurewitz Clemens, personal communication, December 29, 2004). These cultural expressions, which demonstrate the meaning behind the words "to teach and to learn," promote an intersection in their meaning for us. This meeting-place or intersection profoundly influences the research engagement found on these pages. Exploring the teaching-learning idea further, a conceptual framework emerges for this research study. Teaching and learning are tied together and aid in the formation of liberatory education. This educational viewpoint is one in which schools do no harm, where students attempt to uncover their own subjectivity, and where teachers act as 
learners. Likewise, the Reggio way radiates questions vis-à-vis what teachers learn and the impact this has on children, the classroom and studio environment, and intentional co-learning communities in schools.

When the studio teachers document children's thinking through digital photographs, transcribed audio tapes, quotations of their verbal thoughts, and copies of children's work, an indescribably precious moment in studio teacher thinking interweaves with the child's learning. Furthermore, as studio teachers capture classroom work, make investigations and interpretations, and collaboratively share their ideas with colleagues and community - a fundamental and primary question emerges. What are studio teachers' experiences of teaching-learning in the school's art studio as they utilize documentation, collaboration, and reflection as a way to inform their practices? From this question we start our journey together-reader and researcher-into the lives of two art studio teachers and a researcher participant to study the experiences of studio teaching and meaning behind documentation, collaboration, and reflection in intentional teaching-learning spaces. This designed space is developed through the artist's studio (the atelier), which is adjacent to children's classrooms. As a core member in the teaching team, the atelierista (studio teacher) resides in the atelier (studio) to bring teaching and learning together in a profound way, to bridge classroom experiences with graphic arts, and to facilitate the community's learning about teaching-learning —creating a meta-cognitive learning field. In this way, the atelierista is a meta-cognitive mediator.

The atelierista has to be well versed in graphic arts and able to help children in the formation of their thoughts, ideas, and inquiry into matters that can be dissected, 
digested, transformed, manipulated, and understood through creative processes. Imagine a teacher who listens to children discussing cats. A child says that cats have eyes that see into her soul. The teacher's record of this perceptive consideration solicits an inquiry. The teacher asks the child how she/he can represent such an idea in drawing, through sculpture, or by dance and drama. A child's imagination, creativity, thinking, and representation begin the journey. The studio teacher (atelierista) works to capture such fleeting but profound moments: a child's precious thoughts, ideas, actions, feelings, and (self) expressions. Then, the atelierista transforms the classroom based on the children's and teacher's considerations. Vea Vecchi, a thirty-year atelierista in Reggio Emilia, denotes her perceptions of the atelierista's role in the following way.

Working together, guiding the children in their projects, teachers and I have repeatedly found ourselves face to face-as if looking in the mirror-learning from one another, and together learning from the children. This way we were trying to create paths to a new educational approach, one certainly not tried before, where the visual language was interpreted and connected to other languages, all thereby gaining in meaning. (Edwards, Gandini, \& Forman, 1998, p. 141)

Expression and meaning-making take place in the atelier. The atelier bears the markings and traces of children's learning - their thinking made visible. Clay figurines molded by children's hands, the best paints carried in mason jars with highquality brushes of varying sizes and beautiful markings on canvas, shiny sequins sewn into fabric, and glass windows beaming with light onto displays of children's work 
exist in a space alive with learning journeys. The studio resonates with children's graphic, visual, and verbal languages, teacher's impressions, and community interests. The atelier teaches through its environment, by capturing and demonstrating both the value of learning and participants' voices. This thoughtful space facilitates metacognition; our ability to learn about our own learning patterns. It grounds educators in a culture of teaching through the field of learning, consisting of documentation, the materials, the crackling energy of thoughts, ideas, and work.

\section{Research Problem}

The problem in contemporary U.S. education is that parents, teachers, and children of early childhood schools are continually faced with poorly developed images of the teacher. These images are socially constructed and reinforced by mass media such as books, magazines, movies, and television. At present, the existing metaphors for "teacher" are surfacing as an area of inquiry in early childhood educational research (Guidici, Rinaldi, \& Krechevsky, 2001; Curtis \& Carter, 2000). This socially constructed non-professional image has informed and affected the teacher's ability to teach well and the learning opportunities present for children. This area of inquiry demands that educators re-look at their images which affect their role and identity in schools and which influences children's and teachers' co-learning opportunities.

The early childhood teacher is presently seen in U.S. society as babysitter, caretaker, and omniscient giver of knowledge pouring their "right way of thinking" into empty heads. In an alternate picture, there exists a more profound and underdeveloped teacher researcher image. This image calls forth a trustworthy, 
knowledgeable, child development expert; facilitator, listener, and observer; and guide of the child's own learning experiences. A researcher image is lacking in our current era of standardization where teachers practice not through constructivist ideology, but by "giving" children answers with decontextualized knowledge and an attempt to show children the "right way" to process information in order to survive and compete in schools and eventually in society. Since society in general, and more specifically the educational establishment, shapes the teacher's work-life through regulation, policy, and culture, the image and role of teacher is embedded in place and time within the school. Educational establishments are now pressured by the political world to meet standards and be more quantitatively accountable. This pressure promotes a teacher image of expert giver of knowledge and a banker and storehouse of information.

This question of how the image of the teacher influences teaching-learning is vastly important because it affects "political and economic choices that can influence the entire educational system, and also the social system" (Giudici, Rinaldi, \& Krechevsky, 2001, p. 40). Human relationships are at stake when teachers of young children are mired in images which propel them toward acting in certain manners and preclude children's creative learning potentials. These relationships extend outward from the young child to others in the classroom, into the home, and into the broader community forum. These images can ultimately influence teaching-learning at a broad level.

Literature on Reggio philosophy suggests that teachers strengthen the practical application of early childhood teaching by employing methods of documentation, 
collaboration, and reflection and that these methods expand the early childhood teacher role and image into a teacher researcher (Edwards, Gandini, \& Forman, 1993; Guidici, Rinaldi, \& Krechevsky, 2001; Katz \& Cesarone, 1994). The big ideas in these Reggio-inspired methods consist of capturing and thinking about learning experiences, such as through observation, reflection, and a pedagogy of listening; analyzing children's graphic language expressions (clay work, painting, sculpture, artistic creations, and the like) in collaboration with others; and a process of making children's work visible through a well-planned and carefully selected design of documentation. Overall, research shows that teachers who utilize reflective teaching methods (documentation and collegial collaboration) and a meta-cognitive framework (teaching about the how and why of learning) in the art studio environment, establish a particularly rich educational image of teaching-learning and of teacher within the school-life context (see Cadwell, 1997; Edwards, Gandini, \& Forman, 1993; Edwards, Gandini, \& Forman, 1998; Erlich \& Bhavnagri, 1994; Gandini, Cadwell, Hill, \& Schwall, 2005; Hertzog, 2001; Sassalos, 1999). This context begins in the atelier and extends into the school and larger community through the documented experiences and collegial collaboration on the children's work.

Using a Reggio-inspired approach, teachers from other towns, cities, and countries tend to transform the images of the teacher, child, and community into capable and strong researchers who profoundly study and inquire about the world around them (Giudici, Rinaldi, \& Krechevsky, 2001). This is accomplished through an overt process of collaboration and reflection on children's learning experiences and turning them into documented encounters between co-learners (teacher and child, 
child and child) or learner and materials (environments, etc). The classroom and school becomes an excited and energetic laboratory of learning for every person who enters (Gandini, Cadwell, Hill, \& Schwall, 2005). In this way, teaching-learning experiences begin to reshape the early childhood classroom from incidental "day-care" to thoughtful schools of wonder, inquiry, and elaborate learning places.

The research problem and challenge in seeing the teacher as a researcher and co-learner and not a baby-sitter, is exacerbated in the culture and classrooms of American preschools. Current U.S. images of the child and the early childhood teacher create a dejected image of what it means to teach this age. Again, teachers are often viewed as mere "babysitters" and bankers of knowledge (Freire, 1998/2001), not educators and researchers. Moreover, in San Francisco at the National Campus Child Care Coalition caucus in 1998 , Anita Olds stated that our Government spends $\$ 87.00$ per year on every child under the age of five in the United States. For every child over the age of five, our Government spends $\$ 8700.00$ per year (Personal Communication, March 21, 1998). In the United States the evidence shows that collectively we are not considering the needs of teachers and young children in early childhood education (see Dahlberg, Moss \& Pence, 1999). Such a disparate pattern is in conflict with research that shows early intervention and preschool groundwork as predictors of student success in elementary school years (Xiang \& Schweinhart, 2002; Lee \& Burkam, 2002; Karoly, et al., 1998; and Administration for Children and Families, 2001). In other words, if our preprimary schools offer the best materials, care, and thinking a culture of teaching has to contribute, they consider the needs of our youngest citizens 
in a more profoundly connected way to learning, context, and experiences in school settings.

Responding to the standardization rhetoric, more parents are pressuring early childhood schools to teach with particular practices. Imagine touring parents through school and hearing such questions as, "do you teach the alphabet so my child learns to read before real school," and "I want my child to read by age four so she is prepared for kindergarten; do your teachers provide sit down lessons and tests for this?" All the while, parents feel confused by mixed messages about these standards and accountability which whisper to them the "right" schooling methods for their child's later success in life. This success by "instructional" methods contributes to a poor image of the teacher and misses basic tenets of preprimary school teaching practices. Research on child development and classroom management suggests that teachers must give ample teaching time to social and emotional development as well as to cognitive growth to achieve a balanced and high quality developmentally appropriate classroom atmosphere (Charlesworth, 1999). Moreover, constructivist practices demonstrate that learning is achieved through play and exploration which should be fun and contextualized experiences for all children (Cadwell, 2003; Charlesworth, 1999; Van Hoorn, Nourot, Scales, \& Alward, 2002).

To achieve a deep level of classroom teaching-learning, a teacher's teaching conjures very different images than one of knowledge-bearer who dispenses the valueladen information to seated students who are expected to individually "soak up" the right answers. Instead, the teacher image consists of facilitator and co-learner sitting around the roundtable of learning - collecting, reflecting upon, and collaborating 
about children's many represented languages. Rather than the traditional hierarchical image of gatekeeper of knowledge projecting from the front of a class to "emptyheaded" students, this alternative and innovative image is vital to the early childhood classroom. Teaching practice fundamentally shows up differently to aid children in the construction of - and ownership in - their own meaning-making of the world around them.

Again, the images that institutional and parental pressure impart on a teacher as bearer of the knowledge and filler of the empty vessels convey that the teacher is an omniscient messenger. Instead, more viable images exist for teachers such as facilitator, observer of the child's learning interests, guide along the pathway of life and learning with the child, one who helps the child uncover her own learning endeavors along side of, rather than for, the child. As Swetnam (1992) acknowledges, "Problems arise from the misrepresentation of who teaches, where they teach, how they teach, and what demands are placed on teachers, thereby creating an alarming distortion with consequences serious enough to warrant the concern of all education professionals" (p. 30). This profound issue of teacher image not only affects teacher practice, but has serious consequences for teacher identity and the profession of teaching as a whole.

An essential factor to exploring the image of the teacher and how this has helped to shape early childhood teaching identity is the aspect of how childhood teachers envision themselves influencing the classroom teaching and learning tone. In a Reggio-inspired approach, teachers attempt to dismantle traditional images such as omniscient knowledge-bearer into more profoundly connected roles-social 
collaborator collecting work, asking questions, reflecting, and learning along side of children — with teaching as a way of learning and self-development. This more thoughtful way of imaging the teacher ultimately benefits children by contextualizing their learning experiences through the documentation, collaboration, and reflection processes. The attempt to redefine images of the teacher is not currently well-received in a politically charged, numbers-based educational era where parents influence and pressure largely privatized, tuition-based, and customer-oriented early childhood schools. Within this political context, parents are bringing messages to schools that standards, performance-based outcomes, and test accountability are the correct methods used to compete, make children smart, and prepare them for their future educational experience.

In contrast, the Reggio school of thought inclusively values the rights of children, teachers, and families, which demonstrates the interconnection and overt social nature of the Reggio Approach. Each member of the group engages and participates with the learning community and is respected as a human-a subject, not object. In comparison, the U.S. early childhood educational model has yet to lay claim to the rights of teachers, children, and families as a community of learners. Americans value independence and rigorous competence in individual learning, which I believe leads us to devalue community education experiences. Competition leads to understaffed and stressed teachers, overtaxed parents, and poorly designed preschools that "corral" children and prepare them for their next instructional and academic level of engagement. 
The significance of the teacher image problem lies squarely in what Freire (1998/2001) terms "the banking model," which is currently held as the political standard and forces teachers into an instructor image. The banking model imagines the teacher as a storehouse of knowledge and the child as an empty vessel needing a deposit of information. "The banking model tries to control thinking and action and inhibits our creative powers. It tries to maintain the submersion of consciousness. In it we are merely spectators, not re-creators" (Freire, 1998/2001, p. 62). This image leaves children filled with meaningless facts and figures that are neither contextualized nor significantly rooted in experiences to inform life-practices. A more thoughtful model is suggested by Curtis and Carter (2000) as a round-table of co-learning, termed "subject-centered" learning by Parker Palmer (1998). As Palmer (1998) states:

At the center of this communal circle, there is always a subject-as contrasted with the object at the top of the objectivist ladder. This distinction is crucial to knowing, teaching, and learning: a subject is available for relationship; an object is not. When we know the other as a subject, we do not merely hold it at arm's length. We know it in and through relationship, the kind of relationship Barbara McClintock had with the corn plants that she studied. (pp. 102-103) Palmer's model locates the subject in the center of the round-table and the learning surrounds each participant around the table. Each voice plays a critical role in the teaching-learning atmosphere and knowledge is self-and-socially constructed. Context becomes essential to the learning field in order to build meaning and experience into cultural understanding. Guidici, Rinaldi, and Krechevsky (2001) suggest this phenomenon to represent an intersubjective field of learning where each 
participant grows in their own understanding of the world through contact and interaction with another around a subject matter. In turn, the other participants shift to more profound levels of understanding along the learning journey.

If those of us utilizing the knowledge and understandings of the Reggio Approach share with other practitioners our history, context, experiences, and stories of how this "inspired" practice manifests in our classrooms (not located in Reggio Emilia), I believe that we can break free from our currently lived metaphors such as "baby-sitter" and "banker of knowledge." These metaphors constrict our way of thinking about teaching and learning as top-down instruction. Joining those persons in a Reggio-inspired approach reformulates our teaching-learning experiences into an educational environment filled with co-learning and co-construction of knowledge. Research Purpose

The purpose of this research has been to experience the work of two longtime Helen Gordon Child Development Center studio teachers through the viewpoint of a researcher participant. These studio teachers and the researcher are deeply inspired by the Municipal preprimary educational system of Reggio Emilia, Italy and we hoped to explore studio teaching experiences in the atelier and the meaning of teaching-learning work, documentation and reflections in the atelier, and collegial collaborationsmeetings about children's learning. This study was cultivated over the course of six months. Additionally, this research aspired to capture, share, and enlighten, through the significant life-stories of the studio teachers and researcher participant, the meaning and experiences of the simultaneous act of teaching-learning and how these play out in the studio teacher's practices within the atelier. 
Fundamental Research Question and Underlying Provocations

The desire to study the experiences of studio teachers and their practices in their respective art studio teaching roles brings forth deliberation. Questions buzz in my ear and as I search to find the cornerstone of this research I am led to the fundamental question: What are studio teachers' experiences of teaching-learning in the atelier as they utilize documentation, collaboration, and reflection as a way to inform their practices? Informing this primary question are open-ended research provocations:

- When the studio teachers and the researcher engage in the atelier teachinglearning phenomenon, what do we experience?

- When the studio teachers and researcher participant capture children's learning, what is our meaning and understanding of documentation?

- When the studio teachers and researcher get together to discuss the children's learning and work, what is our experience and our meaning of collaboration?

- When we engage in teacher reflection, what are the studio teachers' experiences of the meaning of teaching-learning in the atelier?

These questions lead us toward an authentic exploration of the work-lives of the two studio teachers as well as in the direction of a close review of the literature. As we engage with the ideas of this research study we cultivate an expanded understanding of a Reggio-inspired studio teaching work-life. 
Terms and Definitions

This study focuses on studio teachers' experiences of teaching-learning in the atelier utilizing documentation, collaboration, and reflection as a way to inform teaching practices. In order to better map out the meaning in this research, we must first define key terms used throughout the paper: Atelier, Atelierista, Image of the Child, Image of the Teacher, Intersubjectivity, One-Hundred Languages of Children, Phenomenology, Reggio-inspired, and Teaching-Learning. These terms reference the overall context of this research study and are found throughout this body of writing.

Atelier. The art studio space inside of the school. A fundamental space for children and teachers to delve deeper into research through multiple and varied artistic mediums.

Atelierista $(m \& f, s)$. The studio teacher who serves as a fundamental member of the teaching team focusing on visual and representative arts, sometimes referred to as art studio teacher. The atelierista captures the thinking and research in the school, primarily inside of the studio and displays this work to engage others in the making of the research. Atelieristi (m, pl); Atellieriste ( $f, p l)$.

Image of the Child. A way of seeing the child in our mind's eye and how we interpret their capabilities. Society's view of the child and each individual's view of the child.

Image of the Teacher. A way of seeing the teacher which influences our interpretation of his/her role and identity inside and outside of the school. 
Intersubjectivity. Intersubjectivity is an idea of "thirdness" which exists inside and between each person mentally. It is a mutual sharing of meanings and a construction of shared contextualized understandings.

One-Hundred Languages of Children. A wide range of ways children can communicate and represent their understandings, feelings, and creative selves.

Phenomenology. An investigation of the meaning of the lived experience.

Reggio-inspired. Anyone who is not teaching in a municipally-governed Reggio Emilia preprimary school or infant-toddler center but is inspired by their principles and practices of early education and attempting to understand and practice utilizing these overarching philosophical viewpoints is Reggio-inspired.

Now that the research topic, problem, and purpose have been laid out, a question has been asked, and terms are defined, a plunge into the literature and underlying theoretical frameworks is essential to support this research endeavor. 
Chapter Two: Review of the Literature and Underpinning Theoretical Frameworks Much of the literature on the Reggio Emilia approach includes the history of the making of the schools as well as reasons why they came into existence. This historical insight plays a significant role in the development of the overall principles and practices of this approach to early education. Situated within a context of the Reggio-inspired experiences, the heart of this research rests in the Helen Gordon Center studios. The conceptual frameworks of Reggio-inspired teaching and instances of individual teacher's experiences and meaning-making about teaching-learning practices weave in and out of the cultural reflection of this study. Specifically, informing this research are six areas of literary investigation including:

(a) History and Context of Reggio Emilia's Municipal Preprimary Schools and Infant-Toddler Centers: Schools Built Brick by Brick;

(b) Intersubjectivity, Teacher Research, and Social Constructivism;

(c) The Intersection of Teaching and Learning: Educational Influences;

(d) Teacher Work and Development: Documentation, Collaboration, and Reflection;

(e) Learning for the Teacher: Metaphor and Meaning;

(f) And Impetus for Teaching and Renewal; These perspectives prevail in work and dialogue around the Reggio Approach and are highlighted in both American and Italian research and writing. We shall explore their meaning and context through the literature as well as later through the life-lens of the studio teachers and researcher participant taking part in this research study. 
In review, born out of the complex background of Reggio Emilia, Italy come our teaching-learning inspirations for this particular research study. The challenges of an underdeveloped teacher image and untapped teaching-learning practices call forth an investigation into Reggio-inspired studio teacher experiences. We shall explore the meaning and perspective of Reggio-inspired practices through the American and Italian literature as well as through the life-lens of the researcher and participants studying to grasp children's educational experiences and school-life. Ultimately, we can see how historical context; intersubjectivity, research, and social constructivism; educational influences; documentation, collaboration, and reflection; metaphor and meaning-making; and teacher renewal inform and play a part in early childhood teacher practice. Research methods are explained and then the research is conducted, investigated, analyzed, summarized, and interpreted. At the end of this research paper, conclusions are drawn and implications are made for future reséarch into this timely study of what studio teachers experience while teaching-learning and utilizing Reggioinformed practices of documentation, collaboration, and reflection. Most importantly and in order to move forward into understanding these conceptual frameworks, we must develop contextualized historical meaning undergirding the notion of "the Reggio Approach."

History and Context of Reggio Emilia's Municipal Preprimary Schools and InfantToddler Centers: Schools Built Brick by Brick

At the end of World War II, the people of the municipality of Reggio Emilia, Italy were in shock from their experiences of inhumane acts of aggression and violence performed on them by other human beings. They gathered together what 
little resources they had left and decided to place their future in the hands of educating their youngest. In Barazzoni's (1985/2000) work Brick by Brick, a book about the making of the Reggio Emilia preprimary schools, it is made clear that the loathing of fascism was directly leading the people of the municipality to develop a democratic society and to demand "the right to education for all the children" (p. 18). The township of Villa Cella, in the municipality of Reggio Emilia, sold off a tank that had been left in their devastated residence in order to gather enough money to build their first preprimary school. Parents and children gathered together and built this school brick by brick with "the women who scraped off the mortar from the bricks, scraping the skin itself from their fingers" (Barazzoni, 1985/2000, p. 20).

Before the making of the first schools in Reggio Emilia, early education was "caught in the tangled web of relations between church and state. The enormous power conflicts between the centuries-old Catholic Church and the young Italian state (formed in 1860) have affected many modern outcomes, including early childhood education" (Edwards et al., 1998, p. 18). The budding philosophy of the Reggio Emilia preprimary schools, which grew as the schools changed over time, had roots in Abbot Ferrante Aporti's schools from the city of Cremona. As Edwards (1998) states, "Teaching and learning were important there [in Cremona]" (p. 20). Edwards (1998) also points out that Froebel's Kindergarten and Maria Montessori were instrumental in pedagogical grounding of the emerging schools of Reggio Emilia at the time. In Giudici, Rinaldi, \& Krechevsky (2001), Howard Gardner writes:

Throughout history, a few schools have acquired legendary quality. Their ranks have included Plato's Academy, the Yasnanya Polanyi School set up on 
his estate by Court Leo Tolstoy, the Laboratory School at the University of Chicago presided over by John and Alice Dewey, and the collection of contemporary schools inspired by writings and example of Maria Montessori, Rudolf Steiner, and Jean Piaget. To these ranks I have no hesitation in adding the Municipal Infant-toddler Center and Preschools of Reggio Emilia, as inspired by the work of Loris Malaguzzi and as fashioned over the years by his circle of collaborators and colleagues. (p. 25)

There is no doubt that Loris Malaguzzi and his circle of collaborators and colleagues were influenced by the numerous pedagogical, psychological, and school missions that came before them (Edwards et al., 1993; Edwards et al., 1998; Giudici, Rinaldi, \& Krechevsky, 2001).

A most notable influence on Loris Malaguzzi was Bruno Ciari's Movement of Cooperative Education (MCE). "Ciari suggested many education innovations, both in his writings and through the meetings he organized for teachers in Bologna... Loris Malaguzzi participated in these lively debates" (Edwards et al., 1998, p. 21). Ciari's ideas of participatory committees of teachers, parents, and citizens, of co-teaching and collaboration without hierarchy, and of grouping children by age, but mixing ages in collaborative ways are only a part of the grounded philosophy influencing the early work and still emerging in Reggio Emilia, Italy today.

Over time, as the preprimary school mission grew and more preprimary schools developed in Reggio Emilia, challenges arose with funding and continued support. The outcome of the inevitable transformation of the schools is best described by Joanne Hendrick (1997) in First Steps toward Teaching the Reggio Way. "Some 
schools continued until 1967 (when they were handed on to the city government), thanks to the strength, initiative and imagination of workers, farmers, and a famous group of the time, the Union of Italian Women (UDI)" (p. 3). At this time, it was also Loris Malaguzzi who became "a leader and philosopher of that spontaneous initiative" (Hebert, 1997, p. 64) to municipally govern the schools. Malaguzzi took time away from teaching to get his degree in psychology and come back to support and lead the preprimary schools in their mission. According to Hebert (1997) in Schools for Everyone, "Malaguzzi brought these schools through three decades at an unprecedented level of excellence" (p. 64). It is his work with many other pedagogical coordinators that has recorded, strengthened, and sustained a high caliber of educational practice and pedagogy.

As described by Howard Gardner's essay in Edwards (1993), The Hundred Languages of Children, "without question, Malaguzzi...is the guiding genius of Reggio-the thinker whose name deserves to be uttered in the same breath as his heroes Froebel, Montessori, Dewey, Piaget" (Edwards, Gandini, \& Forman, 1993, p. x). Again in Edwards (1993), Gardner goes on to describe the current Reggio preprimary school system as unique and exceptional.

It is a collection of schools for young children in which each child's intellectual, emotional, social, and moral potentials are carefully cultivated and guided. The principal educational vehicle involved youngsters in long-term engrossing projects, which are carried out in a beautiful, healthy, love-filled setting. (p. $x)$ 
The Reggio Emilia approach is recognized as an exceptional model to early learning. In 1991 it was nominated in the American magazine Newsweek in the early childhood category as one of the top ten best schools in the world (see Edwards et al., 1993, p. xiii for complete data).

Today, there are over 22 preschools and 13 infant/toddler centers in the Reggio Emilia municipality. The Reggio Approach is being studied and practiced in over 80 countries across the world, such as China, Japan, France, Australia, Mexico, and the United States. According to the Reggio Children Newsletter, ReChild (2004), "From 1994 to 2004, Reggio Children has hosted more than 14,000 study tour participants from 80 different countries, though the requests have been even greater" (p. 7). Within the United States, the most prominent work has come out of the collaborative writing of essays in The Hundred Languages of Children between Italian and American . pedagogues. Another accomplishment comes out of the St. Louis Reggio Collaborative. Author of Bringing Reggio Home and a long-time atelierista in St. Louis, Missouri, Louise Cadwell (1997) has played a major role in the recreation of three schools that now serve as American mentor schools inspired by this approach. In 2000 , Reggio Children, an organization set up for the protection of the rights of children and their work, has collaborated with Project Zero from Harvard University to create the book Making Learning Visible. The outcomes of this work are yet to be seen, but have been explored by the ECAP Collaborative Reggio List Serve as a transformative and innovative way to capture children's learning, teacher thinking, and parent inclusion (see http://istarchives.crc.uiuc.edu/reggioaskeric/2003/Nov_2003/index.html for complete data). Other fascinating and 
important collaborations and writings have been birthed both through and alongside these various critical meetings of the minds and do not appear to be the last. Cadwell (2003) has recently published a second book capturing the St. Louis school's journey of over ten years of intense collaboration and study with two of the Reggio Children pedagogical coordinators, Carla Rinaldi and Amelia Gambetti. Additional significant research is appearing across the U.S. in regions such as Boulder, Colorado; Santa Monica, California; Miami, Florida; Virginia; Vermont; and elsewhere in the world. This work, filled with teaching-learning stories, holds implications for the future of pedagogy and epistemology in early childhood education.

In summary, witnessing the reframing of Reggio-inspired principles of teaching-learning practice emerges within the context guided by the history of the Reggio Emilia municipally governed preprimary schools and infant-toddler centers, which are heavily influenced by well-known psychologists and educational philosophers. The rich and engaging historical aspects of this approach serve as crucial characteristics of the writings and exploration of this model. The exchange of context and stories begins to change each person's way of thinking and teaching. This is done teacher to teacher, connecting with one another; just as the first teachers built their schoolhouse, constructing it brick-by-brick. Without the context of the making of these schools and similarly inspired schools in the United States, we cannot capture the flavor of the importance of grass roots campaigning, building, sustaining, and visioning for the rights of children, teachers, families, and communities to encompass high quality pedagogical experiences for young children. The more we encounter and 
grapple with an idea-in this case the vibrant historical context of Reggio Emilia-- the more we intertwine ourselves with it and the more it exchanges a part of itself with us. Intersubjectivity, Educational Research, and Social Constructivism

Intersubjectivity interplays with educational research paradigms and social constructivism to awaken Reggio-inspired practices. When we delve into the notion of intersubjectivity, recently promoted by Reggio educators, we find a relationship between valuing subjectivity or "the rich originality of each individual" (Giudici, Rinaldi, \& Krechevsky, 2001, p. 30) and researching children's meaning-making in group learning experiences. This construct leads us to critically investigate the reasons educational research exclusively appears through a qualitative perspective from Reggio educators. Moreover, when we examine educational research perspectives through the value-lens of intersubjectivity (becoming more of ourselves as we study and begin to know the other), social constructivism (learning processes in and through groups) stands out as a commonly explored theme and highly esteemed practice in Reggio-inspired schools. Therefore, the literature review on the Reggio Approach engages the interwoven nature of these three ideas by exploring and examining them in great detail. All the while, other thoughtful perspectives and original thinkers from these frameworks of study are gathered and interspersed into this review of the literature.

\section{Intersubjectivity.}

Intersubjectivity is the fabric of social becoming (Crossley, 1996). As Crossley asserts, intersubjectivity means, "The mutual sharing of meanings, behaviors, activities and events by actors in interactive situations" (Canfield, n.d., Glossary 
section). Berk and Winsler (1995) define intersubjectivity as "the process whereby two participants who begin a task with different understandings arrive at a shared understanding. Creates a common ground for communication as each partner adjusts to the perspective of the other" (p. 170). While these two definitions provide us with a basic understanding of intersubjectivity, the most pertinent to this study and more elaborate comes from Dr. Benjamin in the brochure from the Oregon Psychoanalytic Center (2005). She states that "the development of intersubjectivity is enhanced by the ideas of 'thirdness,' a mental space 'inside' and 'between us.' [She]... keeps an eye on the presence or absence of this space, noting its absence in the 'twoness' of impasses or power struggles" (Working Through Impasses with the Intersubjective Third, Brochure, para. 1). Philosophers and social scientists have studied the meaning of intersubjectivity as it relates to and interweaves our understanding of the world and others (see Heidegger, 1988; Findlay, 1977; and Williams, 1992). "Furthermore, it [intersubjectivity] is an interdisciplinary concept. It appeals to philosophers, sociologists, psychologists and political thinkers alike, seemingly offering them insights into both their specific discipline and the connections between that discipline and others (Crossley, 1996, p. viii). The meaning of intersubjectivity suggests that the more we relate with the world and beings in it, the more we understand and know ourselves and the two become interlinked. This important pedagogical framework extends from such philosophers as Coulter (1979), Habermas (1987a, 1991a), Hegel (1979), Heidegger (1988), Rosenthal and Bourgeois (1991) and others. The notion of intersubjectivity can be seen in the thinking of the late Loris Malaguzzi (1996) when he states: 
A child is born a first time, and then, through the long and difficult process of constructing his identity, it is as if he is born again. In this process, he gives himself a face, a body, gestures, movement, speech, thoughts, feelings, imagination, fantasy; in short, the awareness of being and the means of expressing his "me-ness" which are absolutely essential for becoming autonomous and distinguishing ourselves from other people and thingspeople and things we live and interact with and from which, little by little, we draw most of the raw material with which we create our own identity. To recognize ourselves and to be recognized. But a child's most sought-after goal is to recognize himself in others, and to find in others (objects and the natural world as well) parts of himself. (Reggio Children, 1996, p. 47) The writings of Carla Rinaldi, colleague to the late Loris Malaguzzi and Executive Pedagogical Consultant of Reggio Children International Center for the Defense and Promotion of the Rights and Potential of All Children clearly suggest and promote the importance of an intersubjective understanding. In Making Learning Visible (2001), she declares that school is "a place where a personal and collective culture is developed that influences the social, political, and values context and, in turn, is influenced by this context in a relationship of deep and authentic reciprocity" (Giudici, Rinaldi, \& Krechevsky, 2001, p. 38). Moreover, individual and collective growth through the community's contextualized experiences becomes central in the educational life of teaching and learning. Intersubjectivity is expressed as central, inseparable, and evolving. 
Intersubjectivity is not widely explored in early childhood didactic research and must emerge through the words, ideas, and thoughts of teachers who engage in reflection and action with pedagogical documentation-the crux of this research. In Rinaldi's words, intersubjectivity

...is vitally important for the future of humanity itself. The relationship between the individual and others, between Self and Other, is a key issue for our future. To choose whether our individual construction is independent from others or exists with and through other, means resolving not only the traditional pedagogical and psychological debate, but also the one regarding different images of the human being and humanity. It is a question of political and economic choices that can influence the entire educational system, and also the social system. (Giudici, Rinaldi, \& Krechevsky, 2001, p. 40) Overall, as we locally engage with learning explorations of children, collaborate as educators, and reflect on our own teaching practices, we grow in our understanding of education, life, and commitment to a better learning community. "Documentation stimulates the teacher's self-reflection and produces discussion and debate among the group of colleagues.... The group discussions serve to modify, at times radically, the teacher's thoughts and hypotheses about the children and interactions with them" (Edwards et al., 1998, p. 119). The value of intersubjectivity engages the early childhood teacher in a journey to discover the nature of how we come to know, which in turn serves to unravel the complexities of teaching-learning and reveal their inseparability. 
Educational Research.

As researchers studying educational research methods, Denzin and Lincoln (1994) assert that "questions of method are secondary to questions of paradigm" (p. 105 ) in the pursuit of educational research. Van Manen (1990) supports this case as he states:

One might make a partisan claim for the sphere in which hermeneutic phenomenological research is (or should be) conducted. In the sense that traditional, hypothesizing, or experimental research is largely interested in knowledge that is generalizable, true for one and all.... In contrast, phenomenology is, in a broad sense, a philosophy or theory of the unique; it is interested in what is essentially not replaceable. We need to be reminded that in our desire to find out what is effective systematic intervention (from an experimental research point of view), we tend to forget that the change we aim for may have different significance for different persons. (pp. 6-7)

While both qualitative and quantitative research methods are important to the development and formation of educational research, I contend that phenomenological research, methods, and approaches (explored in depth in the methods and approaches chapter) capture the essence of the intersubjective life of teaching-learning. To conduct lived-experience research and work toward an intersubjective understanding between participants and the researcher is phenomenological. "From a phenomenological point of view, to do research is always to question the way we experience the world, to want to know the world in which we live as human beings" (Van Manen, 1990, p. 5). While our research questions may guide us toward a 
specific method of research, such as a quantitative or qualitative design, if a researcher holds a belief structure where intersubjectivity is central and the individual story and voice is valued, the research question will lean toward a qualitative design.

Bateson's (1994) work on "Learning as Coming Home" in Peripheral Visions is revealing for this argument that our research is guided by our system of values which informs our research questions. "It is not that we do not value learning that comes as recognition, but that we have despaired of making it the paradigm of all learning" (p. 202). Her suggestion is poignant as she states that our culture is hopelessly led to believe in a pinnacle of learning which has come through "transmission of knowledge" or Freire's (1998/2001) banking model. In Freire's case, the teacher is left with an image of a banker doling out the knowledge as the validated and right way to teach. This image leaves children filled with meaningless facts and figures that are neither contextualized nor significantly rooted in experiences to inform life-practices. Intersubjectivity is not valued in this model; the teacher knows and passes on the knowledge to empty-headed children. The teacher is not seeking to learn through teaching when enmeshed in the banking model framework.

In contrast, Bateson (1994) suggests that evolutionary change has played a part in the development of our learning and knowledge and informs practice differently.

The human species has been honed through aeons of evolutionary change for readiness to learn, in small ways as well as in the dramatic ways I have been speaking of. Each new recognition of pattern... could offer a moment of homecoming, building toward an understanding and a capacity to participate in 
a complex social and biological world. It is in this sense that the model of learning as coming home can inform schooling. (p. 203)

Bateson (1994) alludes to a model for learning where schools create opportunities to learn and occasions for mutual understanding by teacher and student as a means of "coming home" in the learning field. Teachers revise their own sense of learning and what it means to be a teacher-learner as they look for moments of homecoming with their students. Thus, the intersubjective relationship between co-learners resides in the foreground of this type of learning experience where the power difference is minimized in the classroom and the teacher acts as a learner.

If learning is a coming home experience, an awakening, and a deliberate building upon our lived experiences then, our deepest desire is to know a subject and live inter-subjectively - to live with the "other." (Guidici, Rinaldi, \& Krechevsky, 2001) Intersubjectivity is the dance that exists between the various participants as well as between knower and that which can be known. In this intersubjective way of life, the relationship between the knower and that which can be known is defined and developed inside of the mind and thoughts of the knower and reflected in that which is known or is co-determined by the participants.

Others maintain the view that knowledge exists in our genes and that we are able to carry forth our ancestry's educational legacy as we move along in our own journey of life (see Hillman, 1996). In contrast, the radical constructivists believe we co-create a reality as we live, move, and breathe and that knowledge exists only as each of us constructs it (see Von Glaserfeld, 1995; Segal, 2001). The way we perceive the nature of knowledge and reality is a belief choice; it is a conviction. Once the 
choice is made, how a teacher believes about the nature of reality and knowing, the images of teacher are called forth differently and the meaning of classroom teaching is transformed. If a teacher believes in the intersubjective life and therefore, also believes in social constructivist teaching-learning, choices become clear and phenomenological research prevails as documented trails and traces of children's and teachers' lived-experiences.

\section{Social Constructivism.}

Piaget, Dewey, Vygotsky, and other scholars inform the discussion of teaching-learning experiences. There is an underlying message about constructing knowledge for each scholar that we cannot ignore. Whether knowledge is socially or individually constructed is not a debate in this research study (see Ernest, 1994; Lincoln \& Guba, 1985; Phillips \& Soltis 1998). Constructivism guides this study as a fluid exchange for and between learners. Sometimes learners are working with materials and thoughts with their own history and social context, constructing learning through their own life-lens. Other times they actively call upon the genius of others to aid in their construction of knowledge. These ways of building understanding sit on a continuum of social constructivism as presented by Ernest (1994), Denzin and Guba (1994), and others.

Even while learning on their own, some social constructivists believe that learners bear the cultural traces and intersubjective nature of life of others before them (Phillips, 1996; Taylor, Marineau, and Fiddler, 2000)-for this reason, learning is positioned in this paper as socially contextualized. Ernest (1994) states that "An awareness of the social construction of knowledge suggests a greater pedagogical 
emphasis on discussion, collaboration, negotiation, and shared meanings" (p. 12). Interaction and shared meaning are important factors in the framework of intersubjectivity, collaborative and qualitative research, and social constructivism. Intersubjectivity, phenomenological research and social constructivism help design this lived-research experience.

Piaget's early work was primarily grounded in a psychological view of the interaction between individual child and material, while Vygotsky's writings were rooted in the socio-cultural system of learning existing around and through the child. Later in Piaget's life, he comments on Vygotsky's view of his own theories about school learning.

[Vygotsky] reproaches me for viewing school learning as not essentially related to the child's spontaneous development. Yet it should be clear that to my mind it is not the child that should be blamed for the eventual conflicts, but the school, unaware as it is of the use it could make of the child's spontaneous development, which it should reinforce by adequate methods instead of inhibiting it as it often does. (Piaget, 1962/1995, p. 336)

I suggest that Piaget's commentary puts to good use the ideas explored in this research study — documentation, collaboration, and reflection - as a testing ground for reinforcing development. As the teacher becomes more aware of and acts on the child's ideas through documentation, collaboration, and reflection, the child benefits. The view of the nature of knowledge, teacher learning, and schooling practices is critical to Piaget's suggestion of school learning which concludes that as teachers we must practice differently or we will remain unaware of our teaching-learning tone. 
As Chaillé and Britain (2003) suggest in The Young Child as Scientist, "Social interaction facilitates children's theory building. In addition to exposing children to various ideas and perspectives, social interaction requires them to coordinate their own perspectives with those of others if the 'play' is to proceed" (p. 39). Clements (1997) thoughts add to the social interaction discussion:

Students do not construct knowledge alone, even though each has to modify his or her own ways of thinking and acting.... We must rethink social relations among students and between student and teacher. For example, constructivistoriented teachers must be skilled in structuring the social climate of the classroom so that students discuss, reflect on, and make sense. (p. 199) As well, in Why the Child's Construction of Relationships is Fundamentally Important to Constructivist Teachers, Rheta DeVries (2004) argues that "a teacher who is called 'constructivist' must think about the child's mental construction of relationships" ( $p$. 411). Clearly, there is a need for constructivist-minded teachers to examine, know, and reflect on their beliefs around teaching and learning theories in order to aid children in constructing knowledge in a social constructivist atmosphere.

Moreover, Denzin and Guba's (1994) constructivist paradigm purports that knowledge is both individually and socially constructed and the existence of the knower creates and molds their particular reality — their way of seeing life-in the social stratum. This notion is supported in their discussion of the four paradigms in the Handbook of Qualitative Research. In their analysis, as seen through the social constructivist view on methodology, "The variable and personal (intramental) nature of social constructions suggests that individual constructions can be elicited and 
refined only through interaction between and among investigator and respondents" ( $\mathrm{p}$. 111). It is through the social constructivist lens that we hope to "distill a consensus construction that is more informed and sophisticated than any of the predecessor constructions" (p. 111). Piaget (1970) believed similarly when he stated that "there is no longer any need to choose between the primacy of the social or that of the intellect: collective intellect is the social equilibrium resulting from the interplay of the operations that enter into all cooperation" (p. 114). In the end, teaching and learning become more complex as we build on negotiated learning experiences with others and through their ideas, which nourishes the intersubjective way of life. Even in Piaget's (1932) early work he makes it clear that "there are no more such things as societies $q u a$ beings than there are isolated individuals. There are only relations...and the combinations formed by them, always incomplete, cannot be taken as permanent substances" (p. 360). This radical notion of constructing knowledge and relationships promotes social constructivism and serves to illumine the image of children as cohabitants full of potential and able to share knowledge at the round-table of learning.

\section{Summary.}

Intersubjective understanding allows us to delve into life's rich context through constructed learning experiences. We can experience a subject because we desire to understand and know it fully. It overtakes our being, and feels like coming-home. This integration of self, subject, and other comes out of us in our own way-through our own life lens - to teach and learn in a more deeply connected way with children. The optimum moment is when we make meaning, exchange ideas, and grow. Dewey (1938/1963) describes this phenomenon best as he muses: 
We live from birth to death in a world of persons and things which is in large measure what it is because of what has been done and transmitted from previous human activities. When this fact is ignored, experience is treated as if it were something which goes on exclusively inside an individual's body and mind. It ought not to be necessary to say that experience does not occur in a vacuum. There are sources outside an individual which give rise to experience. (p. 39)

In these teaching-learning intersections of finding what was there, of passing through disequilibrium, and of integrating ideas into our thinking and actions, intersubjectivity, sharing our research and stories, and believing in a social constructivist framework become the inner beauty of our humanity. In this way, teaching-learning joins itself to the multiplicity of human and material relationships we encounter in each moment of life, as we slow down to celebrate our lived experiences.

\section{The Intersection of Teaching and Learning: Educational Influences}

In the literature on the Reggio Emilia approach, a divergence of thought exists regarding the underpinnings of theoretical influences in the preprimary schools of Reggio Emilia. At first glance, American and Italian educators agree that there are multiple theories and schools of thought influencing the Reggio Approach. These theoretical influences are clearly stated in Cadwell's (1997) Bringing Reggio Home, "Over the past 30 years, many different writers from different fields have contributed to the ever-evolving practice of the Reggio Approach. Among them are Urie Bronfenbrenner, Maria Montessori, Lev Vygotsky, Jean Piaget, Erik Erikson, David Hawkins, Humberto Maturana, Francisco Varela, Gregory Bateson, and Jerome 
Bruner" (p. 4). This multiplicity of theoretical inspiration is established similarly by Malaguzzi in The Hundred Languages of Children. "The works of John Dewey, Henri Wallon, Edward Chaparede, Ovide Decroly, Anton Makarenko, Lev Vygotsky, and later also Erik Erikson and Urie Bronfenbrenner were becoming known...this literature, with its strong messages, guided our choices" (Edwards et al., 1993, p. 52). Looking more closely, some American educators propose that the primary learning principle is socio-constructivist and comes from the influence of Lev Vygotsky (Berk \& Winsler 1995; Hendrick, 1997; New, 2000). All the while, the Reggio educators continue to name many primary contributors to their perspectives and caution us to keep our ever-widening eye on the practice itself. As described by Laura Berk (1995), Vygotskian principles are widespread throughout the Reggio Approach.

The Reggio Emilia system of early childhood education echoes central Vygotskian themes. Its reliance on small-group collaboration is highly compatible with a theory of development and education in which thought processes originate in social interaction. The teacher as a creator of activity settings designed to stimulate dialogue and co-construction of knowledge is reminiscent of the concept of scaffolding. Having children stay with the same teacher and the same set of peers for three years is consistent with Vygotsky's emphasis on history and the importance of understanding the development of children's social interactions and relationships over time. The practice of creating diverse symbolic representations of classroom activities and concepts through artistic and technological means exemplifies Vygotsky's belief in the 
use and internalization of cultural symbol systems as the major route to higher mental functions. Joint teacher-child decision making, adult and peer scaffolding of projects with integrative themes, and richly equipped settings that foster small group play are consonant with Vygotsky's ideas about experiences that promote self-regulation. (p. 145)

Ultimately, in this view of adult and peer scaffolding, teachers engage in the learning dialogue and scaffold with children in their understanding of the subject at hand. Again, Edward's (1998) work suggests that, "The emphasis of our educational approach is placed not so much on the child in an abstract sense, but on each child in relation to other children, teachers, parents, his or her own history, and the societal and cultural surroundings" (p. 115). This complex work emphasizes the elements of interconnectedness and socio-educational context as a primary way of educating young children. It is a way of rearing children-developing them from within-rather than instructing and filling them full of information from the outside.

Hendrick (1997) validates the proposition that Vygotsky is essential to the Reggio Approach. "It [the collaborative approach] is also influenced by Vygotsky's perspective emphasizing the use of guidance and modeling in a social setting" (p. 82). These principles and practices can be described through the Vygotskian lens, however as Malaguzzi states, "It is important for pedagogy not to be the prisoner of too much certainty, but instead to be aware of both the relativity of its powers and the difficulties of translating its ideals into practice" (Edwards et al., 1993, p. 51). Malaguzzi insists that "a unifying theory of education that sums up all the phenomena of educating does not (and never will) exist" (Edwards et al., 1993, p. 81). 
Reggio educators assert that their pedagogical influences are from more than the Vygotskian view. Malaguzzi states that Piaget was extremely influential in their preprimary schools' creation as an approach to learning. "Piaget was the first to give them [children] an identity based on a close analysis of their development, by observing and talking to children over extended periods of time" (Edwards et al., 1993, p. 76). At the same time Malaguzzi puts Piaget's theories at juxtaposition to later influences and further constructivist theory.

The theories of Piaget are clearly visible in our work, although certain differences are evident which are the fruit of both our practical experiences (where Piaget himself suggested that his psychological hypotheses be put to the test) and evaluation regarding the new generational perspective and dimension of children, the family, culture, custom, and scientific research itself, as well as our evaluation of the contributions that comparative pedagogy has made to the science of education. (Reggio Children, 1996, p. 30) Hendrick (1997) gives another perspective on Piaget and Reggio education. She clearly states the disconnection between the Reggio system of education and the way Piaget's theory came into being.

Within the perspective used in Reggio Emilia that the school is a system of social relationships where all participants interact as "inseparable and integrated subjects of education" (Rinaldi, 1992, p. 8), Malaguzzi's view of Piaget's constructivism - that it isolates the child-makes sense. However, it is important to remember that Piaget was a psychologist looking at the cognitive development of individuals. He was not looking at a system of 
education. When Reggio educators understood that Piaget's "main goal was to trace the genesis of universal invariant structures" (Malaguzzi, 1993b, p. 76), they became more interested in him. (p. 80)

Hendrick's (1997) view is pivotal in that she unmistakably describes Piaget's construct of a theoretical framework as different than the construct of a complex, historic, and socially-based system of education in Reggio Emilia. However, as both Hendrick and Malaguzzi point out, there is influence and historical significance of Piaget's ideas evidenced in the assemblage of the intricate educational system in Reggio Emilia.

Along the same line of thinking as the Piagetian influence in the Reggio Approach to education rests others who have influenced this model. Dewey is mentioned as an influence on the Reggio Approach, but is not expanded upon more than as one among a list of philosophers who did so. Only Hendrick (1997) describes and expands Dewey's influence. "Dewey's view of education as continual growth in a social direction is similar to the view held by Reggio educators" (p. 73) However, in the end, she believes that "Dewey's framework is in developing the organizational structures that sustain the implementation of these principles" (p. 76) is expanded by the Reggio educators. As for other philosophical underpinnings to the Reggio Approach, there are mentions of many folk. In as much as is relevant, these brief references have not been explored in the writings on the Reggio Approach, but are mentioned several times by Malaguzzi and others as important figures to the development of the array of points of view in the schools. 
Malaguzzi's expression of multiplicity of perspectives on learning is furthered by his lifelong colleague Carla Rinaldi when she expounds that "in educational practice, this means being open to the complex, conflictual, and unpredictable nature of human learning wherever it takes place, both inside and outside the institutional context directly involved in education and formation" (Giudici, Rinaldi, \& Krechevsky, 2001, p. 43). The Italian educator's thoughts about the underlying and complex principles of learning tend to stem from their intricate value of intersubjectivity. Through the use of the term subjectivity we can clearly understand "the correlational and reflexive aspects involved in the construction of the individual subject" (Giudici, Rinaldi, \& Krechevsky, 2001, p. 39). For Rinaldi, this value of intersubjectivity is a key issue to the future of humanity itself. Rinaldi states "to choose whether our individual construction is independent from others or exists with others and through others, means resolving not only the traditional pedagogicalpsychological debate, but also the one regarding different images of the human being and humanity" (Giudici, Rinaldi, \& Krechevsky, 2001, p. 40). Resolving this issue does not mean pointing to one philosophical learning perspective; however it does reinforce the American scholars' notion that Vygotsky's conceptual framework is strongly present in the Reggio Approach. Malaguzzi insists:

We do indeed have a solid core in our approach...that comes directly from the theories and experiences of active education and finds realization in particular images of the child, teacher, school, family, and community... and still [Adolphe] Ferriere, Dewey, Vygotsky, Bruner, Piaget, Bronfenbrener, and Hawkins are very much present for us. (Edwards et al., 1993, p. 81) 
In conclusion, the Reggio Approach has been influenced by many different theoretical perspectives on teaching-learning, primarily resting along an axis of constructivism, simultaneously from Piaget's perspective, "endogenous reconstruction and reflective abstraction" (Hendrick, 1997, p. 80) through Vygotsky's view "on the importance of learning in a social setting" (Hendrick, 1997, p. 80). The Reggio educators undoubtedly plan to keep an open mind on the subject of pedagogy and theory as they closely observe and listen to children. In contrast, I believe it is more comfortable for U.S. educators to seek out more explicit explanations in educational theory to describe and explain Reggio-inspired phenomenon. In seeking the trappings of empirical evidence, we are prone to suggest socio-constructivism as an explanation of this complex and historically-based community model of education. Due to the multifaceted historical structure, we must trust Malaguzzi's interpretation and use of a multiplicity of theoretical frameworks as both foundational and futuristic to the Reggio Emilia approach.

Teacher Work and Development: Documentation, Collaboration, and Reflection

The subject of teacher work, development, and knowledge is vast in educational literature (see Desforges, 1995; Fullan, 1991; Guskey \& Sparks, 1991; Joyce \& Showers, 1983; Lambert, 1988; Lieberman \& Miller, 1979; Sparks, 1983; Wideen \& Andrews, 1987). To narrow our focus of study in the area of teacher work and development, this review of the literature strongly suggests an emergent and Reggio-inspired belief-set informing teaching-learning practice and experience. The pedagogical practices of documenting, collaborating, and reflecting on zones of learning (children's work, the classroom environment and school, teacher impressions, 
parent influences) utilized to aid in teacher development, thread throughout the literature on the Reggio Emilia approach. The three particular practices are not clearly present as an "intersection of study" across the vast body of literature found on teacher development and knowledge outside of the Reggio Approach literature. These practices carry more particular threads of original scholarly influence such as thinking from John Dewey (1933) and Donald Schon (1987) to current early education researchers' concepts such as from Carolyn Edwards (1998), and Deb Curtis and Margie Carter (2000). Original concepts of pedagogical documentation, collaboration, and teacher reflection as well as current thinking around their influence on Reggioinspired practices are explored in this review.

\section{Documentation.}

It is through The Art of Awareness: How Observation Can Transform your Teaching, written by Deb Curtis and Margie Carter (2000) and inspired by the Reggio Approach, that I witness preschool pedagogy as an act of teaching and learning. "Teachers can develop themselves from closely watching the development of children" (p. xvi). Through using observation and listening as a guide to our teaching, we learn about the student's abilities, their learning, and ourselves. Children inform our practice of teaching and create potential moments for self-awareness. "If we listen to and watch them [students] closely, they will teach us to be more observant, inquisitive, and responsive in our work" (Curtis \& Carter, 2000, p. xii). Without learners, there would be no teaching; without keen awareness of teachers, the disparate relationship between teaching and learning would persevere. 
Documentation is a way of thinking about teaching and learning. It is not an after effect of the work produced and thought about. Documentation extends teachinglearning into a new realm where learning is central to the field of study in the classroom. Documentation leads classroom experiences into a meta-cognitive awareness as it is practiced within a context of a review of learning and a stopping place for reflection. Sharing documents, work, and thinking strengthens understanding of the learning and context behind classroom work.

Meta-cognition is centered on a focused study of the learning field. While this research study focuses on teacher learning-due to teacher reflection, classroom learning experiences for teachers and children, and documentation-meta-cognition is alive in the classroom atmosphere and children are experiencing this phenomenon to varying degrees of understanding (see Perfect and Schwartz, 2002 for full details). Flavell (1976) asserts that meta-cognition "refers to one's knowledge concerning one's own cognitive processes or anything related to them, e.g., the learning-relevant properties of information or data. For example, I am engaging in metacognition if I notice that I am having more trouble learning A than B; if it strikes me that I should double check $\mathrm{C}$ before accepting it as fact" (p 232). Furthermore, Blakely and Spence (1990) suggest, "In the creation of a metacognitive environment, teachers monitor and apply their knowledge, deliberately modeling metacognitive behavior to assist students in becoming aware of their own thinking" (Establishing a Metacognitive Environment section, para. 1). While examining a subject matter, the community of learners study and play with ideas about learning and this moves their growth beyond just the subject matter into learning about learning. In a meta-cognitive field, key 
questions linger in the atmosphere of learning. In early childhood settings, these questions can be addressed by the teacher, environment, and the group learning community. These questions can include such ideas as,

- What do I know about this subject, topic, and issue?

- What materials do I need?

- How much time will I need?

- Do I understand what I just heard or saw?

- What is my neighbor learning?

- How can we adjust our theories as we test them?

- How could I revise my plan if it is not working?

To achieve a classroom and school atmosphere where teaching-learning is a vital construct of learning, teachers must subscribe to a belief that developing a plan for learning with the community, monitoring that plan with each learner-participant, and spending time rethinking the plan with children, parents, and colleagues is critical to the environment. Thus, documentation must come from within the context or learning atmosphere, through the voice of the children, teacher and community. Livingston (1997) sums up the meta-cognition phenomenon well.

We engage in metacognitive activities everyday. Metacognition enables us to be successful learners, and has been associated with intelligence (e.g., Borkowski, Carr, \& Pressley, 1987; Sternberg, 1984, 1986a, 1986b). Metacognition refers to higher order thinking which involves active control over the cognitive processes engaged in learning. Activities such as planning how to approach a given learning task, monitoring comprehension, and 
evaluating progress toward the completion of a task are metacognitive in nature..."Metacognition" is often simply defined as "thinking about thinking." (para. 1)

In Reggio-inspired practices, documentation is thinking about thinking, talking about learning, revisiting the subject matter studied, and displaying it for further discussion and curious learning opportunities. Developed over time, this becomes a way for the learning field to communicate what is being learned, how, and why. Documentation can become a meta-cognitive process for children, teachers, and the community. Children revisit documented panels, create new stories about their prior learning with parents, friends, and co-learning teachers, and talk about past happenings while looking at their own languages on the walls of the school. As teachers we make learning visible, the field of learning becomes more valued and children and teachers are re-imaged in the system. They are viewed through the human stories that portray humanity's character, thinking, and feelings.

Documentation is a way to develop meta-cognition for children, teachers, and the larger community. To think about thinking and learn about learning are essentials in a modern early childhood education classroom. Capturing the moments in children's work and thinking and revisiting them create a unique field of educational energy, evoke a sense of wonder, and allow curiosity and clarity to emerge.

Once practiced and actualized as a part of teaching-learning practices, documentation and meta-cognition serve to change the image of the teacher, child, learning environment, and the school. Our minds expand and draw in the community 
and social thinking to awaken and reinterpret our human selves in new and inventive ways. Magical moments are achieved when we stop looking at the ants in our classrooms and begin to see the huge elephants we have before our very eyes.

In the end, documentation develops the reciprocal teaching-learning relationship, classroom awareness, and meaning-making processes. Documenting children's learning is mind expanding and carries limits and biases for teacher interpretation. "We are aware that the medium we choose for documenting the experience observed-in other words, for making it visible and sharable-contains limitations and sources of bias that can be favorable only when multiple documents, media, and interpretation are placed side by side" (Edwards et al., 1998, p. 121). Documents such as wall-panels, books, pictures, and the like, support communication and daily interaction for children, teachers, parents and community visitors. It is an ingenious way to "offer the teacher a unique opportunity to listen again, see again, and therefore revisit individually and with others the events and processes in which he or she was co-protagonists, directly or indirectly" (Edwards et al., 1998, p. 121). Documentation leads the teacher to further (self) reflection as well as collaboration with children, colleagues, parents, and others.

\section{Collaboration.}

"Sharing documentation is in fact making visible the culture of childhood both inside and outside the school to become a participant in a true act of exchange and democracy" (Edwards et al., 1998, p. 122). We not only collaborate with children and raise awareness in our own thinking as a teacher of the young child; we call out for others to participate with us in this journey. Parents, colleagues, and professionals in 
our community partake in the making and remaking of childhood. "Documentation offers the possibility for parents to share their awareness to value discussion and exchanges with the teachers and among their group, helping them to become aware of their role and identity" (Edwards et al., 1998, p. 122).

As we develop children's work into a visible and valued marker in time and place, conversations and collaborative discussions emerge and redefine the identity of the teacher. "Realizing the importance of building one's experience within the daily life of the school, through ongoing sharing and exchange with others, has underscored once again how essential it is for us to learn to take on responsibilities, with a constant effort to analyze and develop" (Giudici, Rinaldi, \& Krechevsky, 2001, p. $135)$.

Within the framework of sharing our teaching-learning analysis, development, and documents, Rodgers, Anderson, Conley, LeVasseur, and Turpin (1993) point out that an atmosphere of trust and safety must exist for collaboration to flourish. "In addition to creating a safe place to grow, I wanted to dissolve the membrane of isolation I knew new faculty operated behind. Despite an ethos of sharing at MAT [Master's of Arts in Teaching Program of the School for International Training], I have sometimes found that 'sharing' slides into advice giving, coaching, or even boasting" (p. 2). Rodgers, Anderson, Conley, LeVasseur, and Turpin (1993) suggest that the roles between players in collaboration should be defined as co-equal laborers working toward a common task. "I wanted to create an environment of fellow explorers where community would flourish" (p. 2). 
In the Reggio-inspired tradition, everyone-new teacher, mentor teacher, parent, child-comes to the table with something to add to the conversation and develop an intersubjective understanding. Each member provides a point of view ranging from fresh perspectives and new eyes to years of experience on a subject to document and analyze. Louise Cadwell (2003) describes her experiences with collaboration in the following way.

Perhaps, because we wanted this kind of reality, we had to "rub up against each other's rough edges" enough and to the point that it hurt-sometimes a lot, and sometimes repeatedly —in order to begin to polish each other. There have been periods of personal suffering and tears and tension and unhappiness. Now, it is hard to remember all the scenarios that brought these emotions on. Slowly, it has dawned on us that if we wanted this truth, we would have to lose some of our personal righteousness and the need to be right. (p. 100) Cadwell (2003) continues by adding that listening is a key ingredient to a collaborative process, adjusting is essential, and forgiveness and acceptance create strong collegial relationships.

In the final analysis, collegial collaboration can prove difficult but rewarding and the process requires reflective practice. "We shared with the students that teachers in Reggio Emilia schools view intellectual conflict as an enjoyable process, involving negotiation that leads to growth" (Bullard and Bullock, 2002, p. 14). If collaboration contains guidelines of listening and reflection, then as conflict arises, the collaborative process can continue successfully. "We encouraged students [teachers] to reflect on their conflicts (e.g., Are you listening to the voice of each member in your 
group?); suggested that they engage in dialogue, debate, and discourse; and trusted that they would work toward negotiated issues of concerns" (Bullard and Bullock, 2002, p. 14). Ultimately, a collaborative process of engaging in the school's documented work leads us back around in the circle to reflection on children's work and self-reflection on our work as we capture it.

\section{Teacher Reflection.}

Deliberate teacher reflection is a complex and time-requiring activity. As Valli (1997) states, "A reflective person is someone who thinks back on what is seen and heard, who contemplates, who is a deliberative thinker... a reflective person gives careful consideration to important matters and is open to voices, opinions, and advice of others" (p. 68). This is true of educators inspired by the Reggio Approach. Cadwell (2003) muses, "I also include stories from my life-memoir, which fits inside the puzzle of trying to make sense of these ideas in a personal context, not only a professional one" (p. 10). Through journaling, collecting data, telling stories, listening to others reflect your own ideas back to you, and retelling your ideas that reflective practice begins to take shape for those practicing a Reggio-inspired approach. "I will use my journals and our many collected notes, tapes, video clips, and photographs to recall the concrete, small details of real-life dramas in school and string them together through narratives" (Cadwell, 2003, p. 10).

Valli (1997) eloquently describes the historical nature and involvement in the elaboration of teacher reflection by John Dewey: "Most educators who write and do research about reflective teaching and teacher education acknowledge their debt to John Dewey" (p. 68). In Dewey's (1933) work, How We Think, he advocates, "The 
better way of thinking that is to be considered in this book is called reflective.thinking: the kind of thinking that consists in turning a subject over in the mind and giving it serious and consecutive consideration" (p. 3). Dewey (1933) describes reflective thinking not only as "a sequence of ideas, but a con-sequence--a consecutive ordering in such a way that each determines the next as its proper outcome, while each outcome in tum leans back on, or refers to, its predecessors" (p. 4). The practice of reflective thinking leads teachers into reflective teaching practices and an increased appreciation of synergistic teaching-learning moments-those times in learning when both child and teacher develop shared meaning in the same moment-a consequence of deliberate reflection and action.

In Schon's (1987) work, Educating the Reflective Practitioner, he lays out several types of reflective experiences. "Schon discusses many experiences of practices - architectural design, psychotherapy ("the patient as a universe of one"), engineering design, science based professions, town planning and management to try to found similarities and differences in the way different types of practitioners reflect in practice" (Silva, 2001, para. 7). Schon (1987) visits the synergistic component of learning as described through the use of reflective teaching practices. "Reflection-inaction becomes reciprocal.when the coach [teacher] treats the student's further designing as an utterance, a carrier of meanings like 'This is what I take you to mean' or 'This is what I really meant to say,' and responds to her interpretations" (p. 101). This way of communicating and reflecting back what we hear, see, and understand brings us closer to shared understanding and creates meaningful curricular and project experiences between teachers and children. 
Additionally, our ability to question and grapple with what exists before our very eyes is sharpened with reflective practices. As Schon (1983) states:

At the same time that the inquirer tries to shape the situation to his frame, he must hold himself open to the situation's back-talk. He must be willing to enter into new confusions and uncertainties. Hence, he must adopt a kind of double vision. He must act in accordance with the view he has adopted, but he must recognize that he can always break it open later, indeed, must break it open later in order to make new sense of his transaction with the situation. (p. 164)

Staying with this "double vision" experience commits reflective practitioners to notably assess their documentation and collaboration experiences. More deeply held understandings of children's thinking, a transformed image of the child, and ultimately a newly forged image of teacher are firmly held in this purposeful teaching-learning way. "If the inquirer maintains his double vision, even while deepening his commitment to a chosen frame, he increases his chances of arriving at a deeper and broader coherence of artifact and idea" (Schon, 1983, p. 164). As Schon (1983) is pointing out, tenaciously reflective practitioners (teachers) broaden and deepen their knowledge of the individual and group thinking by studying and collaborating on the artifacts and ideas generated through the educational project and process.

\section{Summary.}

In conclusion, I see documentation, collaboration, and reflection as three practical and honotable approaches teachers can utilize to sustain a high quality understanding of children's thinking, group work, and individual learning. Not only 
can teachers benefit through these traditions of teaching-learning but also children, families, and the school can advance their respective image carried in the general public. Children can be seen as full citizens from birth, bringing with them ideas and fresh understanding of the way the world works (Guidici, Rinaldi, and Krechevsky, 2001; Reggio Children, 2004). Families can be re-conceptualized into a strong unit of learners full of compassion and community-bearing gifts. The metaphor of teacher can be transformed into a researcher, studying the lives and thinking of children and their families. Finally, the school can be imagined as a place of wondrous possibilities, of beauty, of creativity, and as a journey into meaning-making. For a community of colearners, sitting head-to-head at the round table of learning with curiosity and inquisitiveness in their eyes is no small undertaking. I believe that to move toward this ultimate goal of documentation, collaboration, and reflection requires a lifetime commitment of education for the teacher-learner in us and in our youngest. Learning for the Teacher: Metaphor and Meaning

Moving away from the theoretical frameworks of learning and how they shape Reggio-inspired practice and toward the thoughtful essence of our mindsets as teachers and how metaphors inform our practices, two primary pedagogical metaphors in the Reggio Approach emerge. The first stems from how children are seen in their learning. This metaphor is contradictory to the Reggio Approach and reflects Locke's theory that our minds are at first a blank slate (see Phillips and Soltis, 1998, p.13). In this framework the picture in early childhood education exists as a child with an empty mind and a funnel coming from the top of their head. A teacher stands over the funnel pouring information into the child. This metaphor keeps a stronghold in the 
professional development of American teachers but is contradictory to the Reggio Approach (Dahlberg, Moss, and Pence, 1999; Reyes and Rios, 2003). Cadwell (1997) elicits well what is termed in the Reggio Approach as "the image of the child." She states "children are strong, rich, and capable. All children have preparedness, potential, curiosity, and interest in constructing their learning, negotiating with everything their environment brings to them" (p. 5). This image directly relates to how the teacher sees teaching-learning. If the child is viewed as strong and capable, possessing the inherent capacity for engaging in the world, then the teacher must be a strong listener and observer of the child to help them come more fully into the world. This is exemplified in The First Steps toward Teaching the Reggio Way when Rosalyn's teacher, Julie, begins to see her children differently and learns that she can capture their learning by being more attentive and by asking "many open-ended questions" (Hendrick, 1997, p.169).

If teachers think of children as limited, their inabilities are proven through assumptions and practices. Our practices hold teachers and children back from their learning potentials, the system becomes mired in passive learning techniques, and predictions become reality; thus creating the funnel on the child's head. Even in the best of circumstances, the strong image of the child is never fully realized by teachers. If the image were fully understood, teachers would not be overwhelmingly and pleasantly surprised by images we capture in the documentation of children's learning. Their surprise at a children's ability demonstrates their image of the child. In 2001 at a director's conference in St Louis, Carla Rinaldi stated that it isn't what children do as learning but the act of capturing this learning that is the amazing event (personal 
communication, October 19,2001 ). Children are always doing and producing in incredible ways; teachers are just not paying close enough attention to the image we hold of children. It is a metaphor demanding continuous exploration. Teachers can learn through this metaphor how to become better teacher-learners of young children. Moreover, quite often there exists an American assumption that the Reggio preprimary schools are arts based (Hendrick 1997; Hertzog, 2001) due to another central metaphor proposed by the Italian educators termed "the hundred languages of children." Some Americans have asked what the hundred languages are exactly. The statement is a metaphor which "refers to the wide range of ways children can communicate and represent their understandings, feelings, and creative selves" (Hendrick, 1997, p. 170). In preprimary years, languages show up as "spoken words, drawings, paintings, sculptures in clay, and other materials, block constructions, drama, movement, dance, music, computers, and more" (Hendrick, 1997, p. 170). They show up in 100 or more languages. Although these languages show up primarily through artistic expressions such as the language of clay or paint or in graphic representation through drawing, they also cut across the disciplines such as in the language of block-building and the language of mathematics. These languages help express what the children are learning and their interests in studies from long-term project work. "The Reggio Emilia experience demonstrates that preprimary schoolers can use many graphic media to communicate the information gained and ideas explored in project work" (Edwards et al., 1993, p. 20). The "hundred languages of children" reaches deeply into the education of young children and elicits sustainable 
practices for learning that, at a minimum, range from art and language to science, math, physical, and social studies education.

Full of pictures, artifacts, and voices of children, teachers and parents, and many narrated stories of community learning, the One-Hundred Languages of Children Exhibit has traveled the world for over twenty years, gifting itself as a "narrative of the possible" to educators willing to deeply listen. In its most intense year in 2001, the exhibit traveled the United States, Japan, Hong Kong, Australia, Chile, and Luxembourg. According to Reggio Children (2005):

Twenty years of touring, five editions of the European version and the duplication of the exhibit in 1987 for a North American version, many showings throughout Europe and across the ocean, hundreds of thousands of visitors of all nationalities: these figures have made "The Hundred Languages of Children" a fundamental point of reference for Italian and international pedagogical culture.

First conceived by Loris Malaguzzi and his closest associates, this exhibit is rooted in the forty years of experience of the educational institutions operated by the Municipality of Reggio Emilia. The exhibit bears witness to the originality and the extraordinary nature of the years of research that have led the Reggio infant-toddler centers and preschools to become a primary point of reference for those who work in early childhood education worldwide. (100 languages of children section, para. 1-2)

This 100 languages of children exhibit extends the metaphor of one-hundred languages into the professional development arena for teachers of young children. 
Along with each showing, there is a professional development seminar for local educators to engage in pedagogical and rigorous thinking around children's education, schooling, and the image of the child. These collaborations extend the teachers' learning through dialogue, disequilibrium, and reconstruction of the teachers' thinking and practice as it relates to the child's identity and rights to education.

"To speak to the world about children's infinite wealth of potential, their ability to wonder and investigate, their ability to co-construct their knowledge through active and original relational processes: this has always been the primary objective of the exhibit" (Reggio Children, 2005, 100 languages of children section, para. 3). The image of the child is at the forefront of these educational collaborations and onehundred languages of children exhibits. "The use of a variety of communicative media was motivated by the need to highlight as clearly as possible the image of the child and the evolution of the educational research" (Reggio Children, 2005, 100 languages of children section, para. 3 ). This need to highlight the image of the child through their documented and exhibited one-hundred languages is pervasive and critical to the development of teaching and learning.

Our two principle metaphors of how we view the child and what languages they utilize bring about many underlying assumptions and debates as to the child's capabilities in learning. The documentation process of capturing children's learning through using their work samples, words, and conceptual languages such as drawing and telling, demonstrates that we must hold the image of the child in its fullest capacity and that we must continue to explore the many languages children possess. 
This act strengthens the fight for human subjectivity and dignity in children's learning. principles.

Impetus for Teaching and Renewal

The literature on Reggio philosophy strongly influences our choices and what we look for and see in researching teaching-learning. It impacts the research which intends to engage with two twenty-year veteran teachers through their school experiences and meaning-making, and weaves together a picture of the human stories of teaching, documentation, collaboration, reflection and learning. As Beverly Erlich and Navaz Bhavnagri (1994) state in a teacher change case study:

Despite all of this voluminous new information being published and disseminated about the Reggio Emilia approach, there has been little to none [sic] research on documenting the shifts of a teacher's reflections when exposed to the Reggio philosophy. There is a need to document the process a teacher experiences. (p. 7)

Through teacher awareness, we can uncover the rich complexity in daily life with children and begin to construct new meanings for teacher development and growth. I hope that the qualitative and phenomenological nature of this study becomes essential and a life giving force to present and future teachers. Those who want to live a quality educational life where teachers, children and schools are visible and valued in every precious moment may closely examine this research and are challenged to find themselves within the emerging stories as well as to intersubjectively develop their understanding of this research study's results. 
Implications and Conclusions

Within the rich and complex historical nature of Reggio Emilia, Italy and their emerging school contexts, as inspired teachers, we must examine our own practices and thoughts about teaching and learning. In valuing intersubjectivity, research, and social constructivism, we uncover meaning in children's education: Making children's learning visible and developing teaching as an act of collaboration, reciprocity, and reflection shapes experiences around teaching-learning atmospheres. The studio teacher's role profoundly encourages the formation of this educational perspective and way of valuing children's work and thinking.

Documentation is central to the larger thinking and work of the schoolcommunity. It brings about a sense of meta-cognition in the field of learning, extending across time and space. To revisit our children's work is an act of kindness and respect and builds upon the unfolding educational projects in the school. Sharing a teacher's story and becoming vulnerable to interpretation and meaning-making plays a part in this Reggio-inspired principle for growth and learning through teaching.

Again, as Beverly Erlich and Navaz Bhavnagri (1994) assert, "There is a need to document the process a teacher experiences... [utilizing] a Reggio Emilia approach so that others may gain further insight from her reflections" (p. 7). The implications of this phenomenological-based research (emphasizing intersubjectivity and social constructivism) reach beyond my story as an educator. As an educational researcher, it asks me to delve into the lived-experiences of Reggio-inspired studio teachers influencing U.S. schools in a deeply contextual and profound way. 
Overall, the field of learning created out of the sweat equity and synergy of the devastated families in the municipality of Reggio Emilia deserves examination, witness, and our added storytelling. Reggio educators have developed a marvelous example of living and learning collectively. The principles and practices of Reggio Emilia preprimary schools, which are ever-evolving and rooted in rich historical contexts through multiple frameworks, propel me to reexamine the community in which I am situated. In Making Learning Visible (2001), Howard Gardner states that "we are inspired by the pedagogical research of our Reggio colleagues and yearn for policies and structures that support reconsideration of how best to investigate what works in teaching and learning" (Guidici, Rinaldi, \& Krechevsky, 2001, p. 334). Gardner's statement reinforces the need for this research study as a way to investigate and develop what works in teaching and learning within our community, culture, and understanding of early education.

I know that I will be forever changed through the discoveries in this body of work and hope to open eyes about the magnificence and possibilities that lie in the fertile ground of Reggio Emilia and other locations actualizing these practices. Again, in Making Learning Visible (2001), Gardner purports that continued research and inquiry are essential in our early childhood educational practices. "We must ask how best to continue our American experiments [stories] in pedagogical research, building our own traditions as well as those developed in Reggio" (p. 334). As U.S. citizens, I hope we continue to see the Reggio-inspired practices and collaboration around children's work and community significance. Ultimately, I believe Americans shall grow into new interpretations of children's learning and potentials. We are awakening 
61

to a new order of living and we shall develop a new socio-educational praxis which includes documentation and meta-cognition, collaboration, and reflection, as tools for learning and living to our fullest potential. 
Chapter Three: Approach and Methods

"Phenomenology has been referred to as a philosophy, a paradigm, a methodology, and equated with qualitative methods of research. Such wide usage can only create tangles of meaning" (Patton, 1990, p.68). The German philosopher Husserl and the French phenomenologist Merleau-Ponty had an early influence on phenomenological research. These early philosophers, including Jean-Paul Sartre, Heidegger, Kierkegaard, Hegel, and others, have paved a way for a more broadly viewed nature of an event. More recently, phenomenological research comes to life through the experience and meaning-making of lived-events. Van Manen (1990) believes that phenomenology is an investigation of the meaning of the lived experience. His vision of phenomenology illumines our path for this research study about two studio teachers' and the researcher participant's lived-experiences and their meaning-making in the studio.

Many examples of phenomenological research studies come from the field of nursing and the field of psychology (Byrne, 2001). Phenomenology is a human science research method and a philosophy of ways to experience and make meaning of reality. As McClellend, Dahlberg, and Plihal (2002) point out, "Phenomenological research describes the world as it is experienced prior to any theories devised to explain it. Such research demands openness from the researcher so that implicitly understood experiences, such as learning, can be articulated" (p. 4). One specific example of a phenomenological study, which resembles the research process and part of the design on these pages, comes through a study in nursing: 
Lived experiences of women who have undergone a breast biopsy. Perhaps you have noticed that patients undergoing this procedure experience many similar feelings, thoughts, and worries. You question what is the experience and meaning of undergoing a breast biopsy. Data collection would consist of interviewing patients who have undergone the procedure and consented to be interviewed. Interviews would be taped for transcription and analysis. Interview questions would explore patients' experiences and probe into their thoughts, feelings, concerns, and worries before and after surgery. Patients' narratives would provide helpful perspectives related to this experience and rich detail about their feelings and thoughts. After the tapes had been transcribed, they would be analyzed to identify prevailing themes by coding and categorizing the essential meanings of patients' responses. (Byrne, 2001, p. 969)

For the purposes of this research study, lived experience research has been "the starting point and ending point of phenomenological research" (Van Manen, 1990, p. 36). An essential aim of this phenomenological research study was to bring the lived experience of two art studio teachers and researcher (as I work with them) into focus through writing. Additionally, this study has attempted to distill the studio teachers' and researcher's experiences to their essence "in such a way that the effect of the text is at once a reflexive re-living and a reflexive appropriation of something meaningful" (Van Manen, 1990, p. 36). Another intention in this research process was to provoke the reader so that they could become "powerfully animated in their own lived experience" (Van Manen, 1990, p. 36). I believe Van Manen (1990) describes lived 
experience research best this way, "Lived experience is the breathing of meaning" ( $\mathrm{p}$. 36). We have breathed the context and meaning of studio teachers' and researcher's shared experiences on these pages in order to delicately and more precisely add our voice and story to the body of knowledge in early childhood education and bring about shared meaning through the lived experiences in the two ateliers (studios).

Erlich and Bhavnagri (1994) assert that a close examination of Reggio-inspired teaching experiences is a current, critical, and necessary endeavor. Their assertion has been central to this research study as we examine Reggio-inspired teaching experiences and bring them forth in this research study for others to see. The methods used in this study exhibit elements of documenting, collaborating on, reflecting about, and analyzing the studio teaching phenomenon. The methods and approach in this exploration included elements of research design, data collection procedures, data analysis, ethical dimensions, validity and significance. These topics are described in detail and offer a unique view of the studio teachers' work-lives and a comprehensive lived experience approach to further inform teaching-learning education.

\section{Design}

This research design is qualitative and phenomenological. It is a lived experience account of the two studio teachers and the researcher participant practicing a Reggio-inspired approach to early learning. Through this design, we have been guided to explore and describe a process of teaching-learning from a combined perspective where words such as our, we and us become valuable and where the researcher and participants review, discuss, and add input into the researcher's results and discussion chapter and themes, conclusions, and implications chapter. We have 
desired to slowly digest a Reggio-inspired culture of early childhood teaching and learning which specializes and engages in documentation, collaboration, reflection and learning, over a six-month period-three months to collect and gather data and three months to analyze and interpret the data. This study has portrayed studio teachers' and a researcher participant's teaching-learning experiences and attempted to bring teacher and researcher voices to the forefront of an educational experience.

Currently, this Reggio-inspired way is not widely practiced in the United States and is commonly misunderstood as a specific and unwavering methodology of early childhood teaching. Documenting and analyzing children's thinking as a way to inform a teacher's development, inspire professional and personal development, and enhance one's own learning is a pedagogical culture unto itself and does not belong only to teachers in Reggio Emilia. This practice is arduous and challenging, but can also be a gift to the self, the child, the community, and the world; it strives to shift the underrated perspective of the image held of childhood in the U.S. and of preprimary school teaching-learning through sharing this experience.

To focus the research study, the two Reggio-inspired Helen Gordon Child Development Center studio teachers' and the researcher participant's work-lives, thinking, and learning have been revealed through a phenomenological or lived experience approach. This approach nestles best within a cultural framework due to its heavy focus on linking American teacher-learners to an Italian educational approach to experiencing teaching-learning. As Yun (2000) purports, "Recent postmodern philosophies, such as phenomenology ... and the modern practices of the 'Reggio Emilia approach' and 'constructivist education' seem to share existential 
prioritization of the importance of the actual experiences" (p. 247). Our Reggioinspired studio teachers have utilized an approach to education-the Reggio Approach—which informs teaching-learning perspectives such as documentation, collaboration, and teacher reflection. I believe that the teaching-learning experiences of Reggio Emilia have offered a deeply complex meaning to their existence and work in the studio.

The individual's voice—each studio teacher's voice and that of the researcher participant - has been fundamental in this study. We have sought out intersubjective ("thirdness") understanding in lived experiences, brought each unique perspective to the forefront, and examined it in relation to "other," subject, and surroundings. We have also documented moments of shared meaning to demonstrate our learning and process of teaching-learning. In the research, the studio teachers' and researcher's experiences and meaning-making have been shown through the artistic and graphic languages and pictures that project thought and express the teaching-learning in the studio space. These recorded data have included many different forms of expression crafted from diverse interpretative media such as pictures, recorded thoughts, and children's displayed work revised by the atelierista into books, narratives, gallery, or exhibit.

Great care has been taken to directly utilize and represent the voices, experiences, and meaning of the two studio teachers and researcher participant within this study so that the gift of their learning can be passed into the mind of the reader and mixed with the reader's shared knowledge. Due to this great care, a fundamental personal perspective has been included at length in the write up of the experiences. 
The researcher participant's voice and a copious amount of ' $I$ ' and 'we' language is present in the results. This is purposeful and necessary in order to fulfill the requirements of the particular phenomenological questions asked in the study. The arduous process of selecting how much of the researcher participant's voice along with the studio teachers' articulations to include in the narratives was framed around two questions: (1) was this experience unique and yet inseparable from the overall events in the studio? And (2) was the meaning of the experience valuable to the research reporting to make sense of the events? In the end, the researcher-participant's and studio teachers' voices became critical in the results and discussion and helped to frame the themes, conclusions, and implications.

As we zoomed in on each experience to determine its value, it became necessary to ask the above two questions. Opportunities during collaboration sessions for checking in about the clarity of each narrative (developing a strong relationship between the meaning in the story and the text used to describe the story) became essential both with the participants as well as with the proof-readers of the text. These results and discussions have been written and rewritten many times over to create clarification and enhance the understanding at each point of interest.

Additionally, this research and text has been reviewed and rewritten many times in the spirit of further developing intersubjectivity (third mindedness) within the early childhood education readership and through the early childhood exploratory body of knowledge. Intersubjectivity, in this case, has been developed to serve as the fluid between reader and the lived experience, mediated through the research. It was 
created by the studio teacher's work samples (artifacts), the researcher's framework, and the reader's engagement in and interpretation of this work.

To develop results of studio teachers' and researcher participant's lived experiences and meaning-making, we have utilized the studio teacher's artifacts (through photographs), as well as the many observations, lived experience descriptions, and interpretations in this study. The descriptions have led us to explore the studio teachers' and researcher's journey. As researcher, my choices of methods were used to demonstrate the experiences in this study. Furthermore, interpretation of the data was akin to connecting the dots between experiences. Clarifying the data has become essential to its analysis so revisiting the text and pictures time and again was crucial to the results. I demonstrated interpretive significance through narrating the experiences with text and pictures which has guided the research toward a shared understanding of perspectives and meaning about the studio teachers' and researcher participant's work, their encounters with teaching-learning, and what meaning these encounters and understandings have brought to their experiences. Overall, this way of framing the work-chapter four providing story-line description and picture artifacts, and then chapter five presenting interpretation (themes), conclusions, and implications-was brought back to the studio teachers for review, clarification, and mutual growth as a strategy for developing shared meaning and context in the final written analysis.

The context and research experiences have been centered in the Portland State University's Helen Gordon Child Development Center, a full-day laboratory school and childcare program with two ateliers. This school, with its rich 33-year history of 
campus childcare and school experiences, serves a diverse student body, faculty, and staff of Portland State University. Various teachers in this school have been studying the Reggio Approach and attempting to define their values and teaching practices influenced by their recent studies of Reggio Emilia. The two studio teachers have been on a U.S.-Reggio Study Tour in 2002 and have studied the approach on their own through readings and study tours in the U.S., for over five years prior to their trip to Reggio Emilia, Italy. They also work at Helen Gordon Center with over twenty-fiveyears of teaching experiences behind them. They are master teachers whose stories and learning can provide a model to mentor other teachers. My hope is that this phenomenological research study has clearly and dramatically revealed the lived experiences of the studio teachers and researcher as they practiced documentation, collaboration, and reflection in their work.

\section{Data Collection Procedures}

Field observations, field notes, photographs as artifacts, teacher journals, video and audio recordings in the field, and audio recordings of in-depth interviews, conducted over twelve weeks, documented this lived experience research journey (see Table 1). As Creswell (2002) points out, "Qualitative researchers rely on multiple sources of information, and often add new forms of data collection to best understand the phenomenon being explored" (p. 197). The data collection experience lent itself to the complexity of the studio teaching phenomenon. The following table lists this study's underlying research questions, their corresponding methods, and the approaches to each method carried out during the data collection phase. The 
significance of each research question and corresponding method and approaches are divided into sections across the grid to show how they relate.

\section{Table 1}

Research Questions, Methods, Action, and Timeline

Fundamental Research Question: What are studio teachers' experiences of teachinglearning in the atelier as they utilize documentation, collaboration, and reflection as a way to inform their practices?

\begin{tabular}{|c|c|c|}
\hline Research Questions & Method & Action Required (Time Commitment) \\
\hline $\begin{array}{l}\text { When the studio } \\
\text { teachers and the } \\
\text { researcher engage in } \\
\text { the atelier teaching- } \\
\text { learning phenomenon, } \\
\text { what do we experience? }\end{array}$ & $\begin{array}{l}\text { Weekly } \\
\text { Observations } \\
\text { (Monday and } \\
\text { Wednesday } \\
\text { mornings) in } \\
\text { Each Studio }\end{array}$ & $\begin{array}{l}\text { 1. 15-minute observations. } \\
\text { 2. As researcher participant, "Jotted- } \\
\text { down" field notes for 30-minutes } \\
\text { after observations. Photos taken. } \\
\text { 3. 15-minute reflective discussions } \\
\text { with studio teacher after each } \\
\text { session and once children leave the. } \\
\text { studio. } \\
\text { 4. Video record two sessions, one at } \\
\text { first observed session and one six } \\
\text { weeks later. }\end{array}$ \\
\hline $\begin{array}{l}\text { When the studio } \\
\text { teachers and researcher } \\
\text { participant capture } \\
\text { children's learning, } \\
\text { what is our meaning } \\
\text { and understanding of } \\
\text { documentation? }\end{array}$ & $\begin{array}{l}\text { Monthly In- } \\
\text { Depth Interviews }\end{array}$ & $\begin{array}{l}\text { 1. Three interview sessions with each } \\
\text { studio teacher once a month, in week } 2 \text {, } \\
6 \text {, and } 10 \text {. Audio recordings and notes } \\
\text { taken. }\end{array}$ \\
\hline $\begin{array}{l}\text { When the studio } \\
\text { teachers and researcher } \\
\text { get together to discuss } \\
\text { the children's learning } \\
\text { and work, what is our } \\
\text { experience and our } \\
\text { meaning of } \\
\text { collaboration? }\end{array}$ & $\begin{array}{l}\text { Monthly } \\
\text { Collaborative } \\
\text { Sessions }\end{array}$ & $\begin{array}{l}\text { 1. } 3 \text { collaborative sessions with studio } \\
\text { teachers and researcher for } 1 \frac{1 / 2}{2} \\
\text { hours each session, in week } 4,9 \text { and } \\
\text { 12. Audio recording and field notes } \\
\text { taken. } \\
\text { 2. } 15 \text {-minute reflective discussion with } \\
\text { studio teacher after each session and } \\
\text { once children leave studio. }\end{array}$ \\
\hline $\begin{array}{l}\text { When we engage in } \\
\text { teacher reflection, what } \\
\text { are the studio teachers' } \\
\text { experiences of the } \\
\text { meaning of teaching- } \\
\text { learning in the atelier? }\end{array}$ & $\begin{array}{l}\text { E-Journal Write } \\
\& \text { Reflective } \\
\text { disucssions }\end{array}$ & $\begin{array}{l}\text { 1. Each studio teacher emails journal- } \\
\text { write four times to researcher. } \\
\text { 2. 15-minute reflective discussions } \\
\text { after each session once children } \\
\text { leave the studio. }\end{array}$ \\
\hline
\end{tabular}


Observation, Field Notes, and Photographs.

At the beginning of each observation session on Monday and Wednesday mornings in the studios, fifteen-minute observations were made with direct handwritten notes of my remarks split into one minute segments. Each segment sought a description about the teacher experience, language, and interaction with children in the atelier. Additional field notes consisted of my "jotted-down" notes and free-writing during the Monday and Wednesday morning time as a classroom participant. During this time, my primary focus was to contribute in the project and learning and live in the studio-teaching phenomenon. These thirty-minute segments of researcher participant time were conducted directly after the fifteen-minute observations. The "jotted-down" field notes and photos were taken separately from formal field observations as a way to directly inform the research study of my understanding as studio researcher participant. During this more informal time, when I was the studio researcher participant, I kept a running record of the teacher's conversations, my thoughts, and interesting interactions as needed (not in one-minute segments), and photographs as the artifacts. At the end of the observations and researcher participant time, I spent an additional ten-minutes adding a free-write of my experience, rereading my remarks, and making supplementary interpretations. Then, for fifteen-minutes the studio teacher and I engaged in a reflective conversation once the children left the room. I kept notes of this time as well.

We chose Monday morning in Suzy's studio and Wednesday morning in Marsha's studio as the day and time the research data collection would occur. These days and times were selected because they best matched the times each group of 
children who were participating could be present. According to Marsha and Suzy, mornings (from ten to eleven) are the optimal time for bringing small groups of children together for studying a topic or engaging in a research study and observing and interacting with children and teachers.

I looked to observe the studio teachers' interactions with the group of children, the lived experiences of the participants in the studio, and meaning of this complex work. I captured the process of the atelierista catching children's learning and thinking both in writing and in photography. I also aspired to experience the inseparability of teaching-learning, the practices which informed meta-cognition, and the special "aha"-Gestalt-moments in the learning field by engaging as a researcher participant in the studio. How did all of this play out in the daily work experiences of a studio teacher? What meaning did the studio teacher attribute to her/his work experiences in the studio? These were some of the questions I answered as I observed and interacted.

Observational and field notes and photographs taken included time spent in the classrooms during periods when the studio teachers and I were facilitating and capturing teaching-learning experiences. Field notes and photos were also revisited and compared against transcriptions of video or audio recordings. During the weekly 15-minute observation and 30-minutes of field note and picture taking with each studio teacher, two sessions were video-taped, one at the beginning of data collection phase and one in the middle-six weeks later. The video recordings were created in order to revisit the data during the analysis phase for further clarification and better accuracy of written observations of the experience. During video recording days, I did 
not take photos since I was able to take video snapshots utilizing the digital camcorder. All other observation and field note sessions were audio recorded for reference and better accuracy of recorded language.

Field notes and photos were also taken during collaboration meetings, conducted at the end of the $4^{\text {th }}, 9^{\text {th }}$, and $12^{\text {th }}$ week of the study, between the studio teachers and researcher participant to develop shared meaning in our experiences.. These collaborative sessions became the place where documentation (photos, video footage, children's work, their languages, teacher's thoughts, etc.) of the studio experiences were shared, discussed, questioned, and revised outside of the studio time and between the adults. The studio teachers and I set aside time after the studio observation, researcher participant sessions, and reflective discussions for these more specific collaborations to develop a shared context and meaning of our experiences in the studios. In all, field notes were completed and photographs were taken as artifact information throughout the twelve week data collection phase both during classroom time and in our collaborative meetings. They were completed once a month for collaborative meetings between the studio teacher and researcher and once a week on Monday and Wednesday mornings in each studio.

\section{Interviews.}

Interviewing is a complex and important task to consider and plan out before conducting. As Mishler (1986) clearly states, "Although interviewing is commonplace, 'asking and answering questions is at once a simple and subtle affair, and we shall concentrate on the subtleties" (pp. 1-2). The six (three for each studio teacher) audio recorded interviews in week 2,6 , and 10, consisted of initial and then 
more advanced questions to gain a deeper understanding between participants and researcher of the lived experiences in the studio and the meaning of documentation, collaboration, and reflection for the studio teachers. Such questions included: What do you believe your most essential studio teaching role is in the school and how does this affect your experiences in the studio? When you think of the differences between your teaching experiences and those in Reggio Emilia, what similarities and differences come to mind and what meaning does this give to your studio work? Please give details of your best and worst experience capturing children's learning and how this informs your studio experiences? Describe a typical day or episode in the studio and your lived experience in this episode. In the second interview, to build a shared meaning context, I asked: What has been your experience of teacher collaboration in your work as studio teacher? And, documentation? A follow up consisted of, in your experience as studio teacher, what does documentation and collaboration mean for you and your work?

In the third interview session for each studio teacher, as the process of interview became more practiced, more advanced questions considered an artifact or work sample that the studio teacher brought with them to the interview and I asked: What is your experience of reflecting back on this piece of work? What is your experience of learning about your teaching as you revisit children's work and captured languages, pictures, and gestures? What have these experiences meant to you? These questions helped inform specialized categories of studio teaching phenomenon. Interview techniques such as intentional (active) listening and paraphrasing, and 
utilizing empathic statements ("I can imagine that felt like...") were used to help ease the interview process and develop trust with the interviewees.

The interviews were dissected from process, content, and relationship standpoint to inform the meaning of the lived experience. In the interview, the process for me included utilizing the pedagogy of listening and living presently in the moment with the respondent. The content incorporated the facts, knowledge, and interest in the studio teaching-learning phenomenon and viewpoints and this content informed the research objectives. The relationship, which was the narrative between, around, and within the interviewee and the interviewer, developed a rapport of trust, communication, and mutual understanding. As described in a spring 2004 Portland State University course, Research and Resources in Curriculum and Instruction, Dr. Dannelle Stevens suggests that interviewers can utilize content, process, and relationship to clarify thinking about the general idea of interviewing and the specific aspects of experience, understanding, and meaning-making (Personal communication, May 22, 2004). Experience, understanding, and meaning-making passed through the studio teachers' and my precious dialogue about our experiences in the studio as the questions provoked our thinking in the direction of the studio teaching phenomenon.

The three interview sessions for each studio teacher were transcribed from audio recordings to express studio teacher experiences, their thoughts, and concepts related to personal and professional work-life through capturing and interpreting children's work as seen in the graphic languages. In-depth interviews were carried out three times during the data collection phase —once a month—for each teacher, to uncover and track teachers' lived experiences as Reggio-inspired studio teachers. 
They were also a holistic tool to capture the thinking, reflections, and insights of the teachers' stories in this study and to portray themselves in their purest forms as direct quotes within the research. Description and interpretations were added by the researcher to clarify and create points of unity in overall thinking and story-telling of this research phenomenon.

\section{Electronic Journals.}

Teachers kept an electronic email journal and interacted with the researcher over email with personal and professional reflections of teaching-learning experiences throughout the study. On four occasions, weeks $1,3,5$, and 9 , there was a prompt on email from me (as the researcher) to the two studio teachers asking them to reflect their ideas of teaching-learning over the week. The prompt consisted of a single reminder question to motivate the studio teachers to reflect back over their weeklong experiences with children. The question was, "What did you learn and experience through teaching in the studio this week?" The electronic journal exercise created efficiency in the data collection process from teacher reflections and aided in direct teacher interpretation of researcher-witnessed events of the week. These journals were printed out for record keeping and electronically discarded at the end of the data analysis and interpretations phase of the study.

\section{Summary.}

I have chosen these methods for their provocative nature in gathering lived experiences records and because they informed the research of the studio teaching phenomenon in a deeply contextualized way, unifying them to a scenic narrative in the write up of the experience. Over time, the interviews represented the lived 
experiences of the studio teachers and their thinking and considerations into the meaning of documentation, collaboration, and reflection. Not all questions were utilized as text in the results write-up; rather the most essential concepts were considered and woven into the narrative to inform the research questions.

Photos were used to add a visual experience to the overall narrative. At times, photos were chosen to help develop a stronger meaning of the text and used as the artifacts of the experience. Other times, photographs were added to provoke the reader into their own understanding of an event. In this case, photos were not a part of the storyline; they became the gallery, telling a unique story of gestures in the studio.

The weekly observations, field notes, reflective discussions, and reflections informed this research about the lived experiences of two studio teachers and a researcher participant enmeshed in a culture of the Reggio Approach. The observations, notes, discussions, and reflections also provided an opportunity to gather field work, describe the experiences through the words of the participants, interpret and clarify our experiences, and form conclusions regarding the findings.

\section{Data Analysis and Procedures}

Once I collected enough data to begin-in the first weeks of the study-I began looking for emerging themes in the studio teaching lived experience. As a . researcher, I lived in the tension (paradox) of wanting to emerge with the surprise of lived experience and the feeling that I knew what was to come in the data I collected. Heidegger (1988) explores this idea in his Hegel's Phenomenology of Spirit.

According to its intention and inner mission - and from the beginning - the Phenomenology moves within the element of absolute knowledge; and only 
because of this is it capable of venturing to 'prepare for' this element. But should one not say then that Hegel already at the beginning of his work presupposes and anticipates what he wants to achieve only at the end?

Certainly this must be said...We must repeat again and again that Hegel presupposes already at the beginning what he achieves at the end. But we ought not to bring this up as objection to the work. (p. 30)

Thus I looked for meaning in the lived experience before, through, and after the experiences. "In phenomenological research the emphasis is always on the meaning of lived experience. The point of phenomenological research is to 'borrow' other people's experiences and their reflections on their experiences in order to better be able to come to an understanding of the deeper meaning or significance of an aspect of human experience" (Van Manen, 1990, p. 62). As the researcher collecting data, I sought to share the understanding and meaning in the experiences and work of studio teachers. This shared meaning-making research created an arduous and thought provoking phenomenological research analysis process.

The data were analyzed and revisited each month using a distillation of the transcribed observations and interviews to create detailed portrayals of individuals, their experiences, each classroom context, and the artifacts. The observational notes, interviews, and work samples were physically segmented into various categories of "incidental and essential themes" (Van Manen, 1990, p. 106) for examination at the end of this research study. "Phenomenological themes are not objects or generalizations; metaphorically speaking they are more like knots in the webs of our experiences, around which certain lived experiences are spun and thus lived through as 
meaningful wholes" (Van Manen,1990, p. 90). I reported the data in the results and discussion chapter as it occurred over time and then described the essential themes and determined conclusions and future implications in the final chapter.

As Van Manen (1990) states, "In determining the universal or essential quality of a theme our concern is to discover aspects or qualities that make a phenomenon what it is and without which the phenomenon could not be what it is" (p. 107). Once the essential themes were uncovered by asking "is this phenomenon still the same if we imaginatively change or delete this theme from the phenomenon?" (Van Manen, 1990, p. 107), they created an overall structure for data interpretation. In the end, themes emerged and I foresaw data coming through the lived experience that rested in the conceptual frameworks of documentation, collaboration, reflection, and teachinglearning.

In interpretation, I formulated conclusions regarding the research. Theoretical underpinnings such as intersubjectivity, scaffolding, social constructivism, and teacher teaching-learning came to life through the narration of the experiences, which created the culminating points of interest in the results and discussion of this research study. Exploration of the theoretical links to data has led the research to emerging ideas. Some data were categorized in incidental themes outside of the scope of this research and were not chosen for follow up in the themes, conclusions, and future implications chapter.

As I used intentional listening techniques-paying $100 \%$ attention with my ears, eyes, nose, touch, and feelings-during interviews and observations, I captured lucid -streams of consciousness—data, which required dialogue with participants to 
follow up meaning and intention. "Indeed, it is in these shared moments of comparison of ideas and discussion (which are not always easy) that interpretive theories and hypotheses are generated. Those advance not only knowledge of the group but also the more general theories of reference" (Edwards et al., 1998, p. 121). The collaborative make up of data analysis in the study made the coding process arduous but the data more accessible to the end reader. To demonstrate that the participating studio teachers understood the research through the building and coding of themes in dialogue and collaboration with them lent further credibility to the study and added a meta-cognitive framework for participants in the research process.

Additionally, the studio teachers and I have chosen a particular photo gallery of artifacts of teacher and children's work that seemed to need little added interpretation. We hope that the artifact layout describes itself to the viewer-" "this picture says a thousand words" idea. This photo gallery of artifacts contains a heading and the description of how we chose the photos. This was purposeful to keep to minimal narration and allow for reader interpretation. The gallery was decided and agreed upon by the pedagogical team-studio teachers and researcher-in the collaboration meetings. They remain a photo gallery of artifacts which describe themselves to the reader through their display rather than through the narrative. The purpose of this photo gallery of artifacts was to create as direct as possible a link between reader and studio teachers' thinking and learning with minimized researcher (middleman) context through written narrative.

This photo gallery of artifacts was created to devise a purposeful and intersubjective relationship between reader and studio teacher embedded in the work; 
to champion the teaching-learning connection between reader and studio teacher and to develop an interchangeable link between them with only certain influences (the photo choice, gallery layout, and the general heading) put on this work. The gallery was meant to provoke the thinking of the viewer into their own desire for subjective understanding. As Crossley (1996) points out about Hegel's thinking on intersubjectivity between people and through objects, "Relations with 'things' are said to be mediated, in many instances, by relation with others (they are intersubjectively mediated), whilst relations with others are said, in some instances, to be mediated by relations with things" (p. 19). This photo gallery of artifacts display was chosen as a way to create desire for knowing the other through understanding and coming to one's own conclusions about their work. "Our desire for objects and artifacts, for example, may often be a sublimated desire for the desire of others" (Crossley, 1996, p. 19). Other photo work samples and artifacts were chosen and displayed in the research as well. They were given considerable interpretive meaning and narrative for clarity and integration into the results and discussion.

I have chosen the data analysis methods such as distilling observations and interviews and finding the essential themes because they merged well with the philosophy of the Reggio Approach to education and a phenomenological approach to research. Just as I was collecting and analyzing the teacher's work samples and declarations of lived experiences, my observations, and interviews in this research project, Reggio-inspired teachers collect the children's work by closely observing and interviewing them and analyze the work by distilling and creating underlying themes with other teachers and parents in collaboration meetings. The studio teachers 
produced documentation through their analysis process and I was mimicking this behavior on a meta-level in my research. My research (documentation) came through the collaborative analysis process. While the photo gallery of artifacts is minimally explained to allow for meaning-making and interpretation by the reader; others (remaining photo-artifacts) ask for clarity, enhancement, or for an interlacing of ideas. Therefore, the analysis process was delicate and demanded discernment, a quality of intentional listening, and heartfelt care to remain essentially at the core of interpretation of these teachers' thinking and work.

\section{Limitations and Research Propositions}

In all research there are limitations such as threats to research legitimacy, ethical issues surrounding the use of human subjects, and a capacity perimeter. More specifically, this research study has had several challenges which I identified, sought to describe, and planned to manage. In any sound arguments there are multiple ways to see an issue. This places us in the perpetual paradox and forces us to look into the mirror which contains our opposite.

Validity, Ethics, and this Research Capacity.

The Reggio Approach is not a commonly chosen inspired-approach for teachers in the United States. I believe this phenomenon is due to our American untamed images of teachers - the ways they are seen-forcing them into an undervalued position and an exclusively caretaking teacher role. The image of a strong, intelligent, reflective, and capable teacher was critical in this study and has been achievable through this research design. To analyze and describe the work-life and practices of two studio teachers and their role in the school and to widen the scope 
to the more broadly based implications for American classroom teachers remained a challenge in this research.

Primarily, the largest threat in this research rested in the ethical dilemma of conducting this research study in my own school. I chose the Helen Gordon Child Development Center because it houses two studio teachers and ateliers under one roof, which are closely linked to the Reggio Approach. In the Portland, Oregon area there were no other known programs with the structure of two studio teachers in the makeup of the school. The Helen Gordon Center studio teachers have been to Reggio Emilia and studied the approach for several years. After I have helped to conduct seven annual seminars in the Portland, Oregon area and acted in a substantial leadership capacity for the Oregon Reggio Inspiration Network, the Oregon Reggio Alliance, the Oregon Association for the Education of Young Children, and the Oregon Association of Child Care Directors there have been no reported local programs to date emphasizing this aspect of the Reggio Approach.

The challenge in the research process that the studio teachers and I faced together was proximity of work-life and the research (physically being together for long periods of time in study together), relationship burden, and power dynamics. I am one of the directors of the Helen Gordon Child Development Center and both studio teachers report to me in our line of hierarchy. However, one studio teacher was my first director and employer and has been a mentor for me for over eighteen years. The other studio teacher is fifteen years my senior, I look up to her in her work, and we have worked together for over seven years. We frequently assert that she is teaching me and is my life-guru. 
The three of us have been a part of a formal study previously conducted by a doctoral colleague, which examined our collaboration and documentation process over several weeks. This was a successful adventure and experience for me as participant with the two studio teachers. The studio teachers reported the same successful feelings. As well, during the period of the research study, I relinquished my supervisory capacity and the studio teachers were supervised by the co-director of the program. Moreover, since this research study was similar to our current work together, I felt the studio teachers and I were up to the task of overcoming barriers. We mutually saw one another as mentors. Additionally, an authentic collaboration and argumentation of ideas have already taken place within our group meetings with minimal hardship or harm. I was also not seeking a critical type of information that would create a major ethical dilemma such as someone losing their job or reputation due to the study's findings.

I addressed the challenge areas of proximity of work-life, the research and relationship burden, and power dynamics by creating mindful check points throughout the study. (1) Twice during the study, I offered specialized work sessions for the studio teachers to meet and discuss what was not going well, where the challenge areas were, and advice for improvements. As researcher, I stepped aside from this session and allowed them to discuss alone about negative impacts they were experiencing where they could release their fears and tensions of the research work burden. The studio teachers gave me their advice on improvements and I worked with this information to overcome their fears and tension with the goal of making their research experience better by addressing these areas of improvement. The rest of the 
information was maintained by Marsha and Suzy and not reported to me. This setup was designed to equalize and manage the power dynamics between researcher and studio teachers. (2) I alternated times on Mondays and Wednesdays when I visited each studio and I preplanned a timeline of my work sessions so the studio teachers knew when I was video recording, audio recording, or just taking notes in their space and what times of day I was with them as an observer or researcher participant. This plan was put in place to address the proximity and space issues. (3) I relinquished my right to supervise the studio teachers' work and reminded them of this on a weekly basis throughout the data collection phase by handing them a symbolic representation - a hat with the words "director" on it--as a gesture of my different/researcher role with them. During my sessions I wore a button on my shirt that was labeled "researcher." Symbolically and literally, they held my old role of "director" on a hat during our Monday and Wednesday observations, work sessions, and our interviews throughout the data collection and analysis periods and I wore the word "researcher." This is so the studio teachers and researcher maintained a healthier working relationship. (4) Both the studio teachers and the researcher knew that the research project has been signed off by the Co-Director and Dean of the Graduate School of Education. If a serious challenge were to arise during the research phase, any member of the team could have discussed the details of the challenge and sought assistance from either of the department heads (power figures) who were allowing the research to be conducted in the department. The studio teachers also signed a letter indicating that they could stop participation at any time during the research at their request. These simple but important check-in periods, gestures, timelines, and back-up 
plans (department head power and stopping the research) used in the study proved critical to keeping the research project dynamic and vital.

\section{Theoretical and Practical Significance.}

This research study has the potential to create implications for further study of intersubjectivity and practice of the Reggio Approach. Believing that each individual is unique, unrepeatable and yet a part of a collective-a community which is growing and ever-changing-leads educators down a path into the intersubjective life. The teachers' relations with material, subject, and other are invariably joined. Social constructivist theories are likely to be confirmed anew in this analysis, with possible insights about their connections and common threads to phenomenology, and intersubjectivity. I have aspired to find social constructivist practices alive through this research and illuminate them as important factors in early childhood education. This phenomenological research has aimed to promote future emerging themes and data analysis which I hope has worked to resolve fundamental theoretical "holes" in the study and to support future research into Reggio-inspired teaching.

Finally, this educational project has implied and sought to demonstrate that teaching-learning is a unified construct and that teachers who practice analyzing children's graphic language expressions, making children's work visible, and utilizing Reggio-inspired methods for documentation, collaboration, and reflection have experiences to share about the act of teaching-learning. Expressing the studio teachers' experiences in the research engage the reader in a co-learning process with the artifacts, subject matters, and studio teaching work-life more fully. Through lived experience research, studio teachers can begin to live in the "more" of life's lessons 
and life can become more inspired in teaching, reflecting, capturing, analyzing, and learning and then teaching anew. I believe this is the cycle of life chosen by critical teacher-learners and is revealed to be deeply and richly satisfying for all members of the learning community. 
Chapter Four: Research Results and Discussion

"My job is to make the beauty all around us with the children..."

-Atelierista Suzy, Helen Gordon Child Development Center

Capturing the studio teaching experience has awakened my spirit of learning and desire to observe, discover, soak up, and make meaning out of moments in time between me, atelierista, and children. I seem to thrive on the seemingly insignificant precious art studio moments where I've found myself in awe of the two Helen Gordon Center studio teachers, Suzy and Marsha, and of their small group work with children.

Many stories unfold, interweave, and take flight in different tangential directions. To make sense and meaning of the twelve-weeks worth of events; observation of studio experiences, researcher participant time, and reflective discussions; collaboration sessions and interviews; and reflection and e-journal writing, I have sought out and found four overarching stages of development which carry with them many significant experiences retold to the best of my abilities as a researcher and participant in this glorious work.

The four major stages of development flow with our timeline (and the unfolding storyline), and our primary and underlying research questions are explored over twelve weeks in this results and discussion section. Again, our primary research question is: What are studio teachers' experiences of teaching-learning in the atelier as they utilize documentation, collaboration, and reflection as a way to inform their practices? We noticed that as we walked through the experiences week by week several essential phases of development in the project appear that must be retold. They are: (1) Knots in the web of studio experiences; (2) Why do we document?; (3) 
The meaning of pedagogical collaboration; (4) And, reflecting: the meaning of atelier (studio) experience. The following four major areas frame the results and discussion of our research expedition together in the ateliers. They start with our journey into this work and stories along the way in the "knots in the web of studio experiences." They move through documentation of our work as we begin to study what we have done together in "why do we document?" The documentation phase engages us in our collaboration sessions and we commence our study into the meaning of pedagogical collaboration. Finally, we land on our ability to reflect back toward the end of our project and we begin to uncover reflecting: the meaning of the atelier experience. Many stories, journeys, experiences, shared meaning-making sessions, and times of frustration, great joy, awe, bewilderment and laughter appear within the framework of this research study in chapter four. Our investigation of the meaning of the lived studio experience finds its way onto the pages of these lived-research episodes one week at a time and in very specific moments of existence. Then, in chapter five, we will discuss the emerging themes, conclusions, and future implications that arise due to the shared understanding in these experiences retold.

Knots in the Web of Studio Experiences

The first stage of development in our twelve-weeks of studio encounters "are more like knots in the webs of our experiences, around which certain lived experiences are spun and thus lived through as meaningful wholes" (Van Manen,1990, p. 90). We have found meaningful wholes in our atelier lived-experiences which include many journeys and happenings causing the research team (studio teachers and 
me as a researcher participant) to pause, reflect on, and move ahead toward our own meaning in the encounters.

In order to start our journey together into these knotted webs, I clearly and strongly use my voice, my emotion, and my experiences in the first three episodes. From this important launching point, we move more noticeably into the work of the studio teachers and the children and end more effectively with studio teachers" reflections and meaning-making. I have found an important step into understanding the studio teachers' role by first walking through my disequilibrium to come to better understand these encounters. As a reader, take in my voice as a starting point into this work.

Also, take note that after the first three stories where I experience personal and deeply profound encounters with this phenomenon, the research data become sincerely focused on the experiences of the studio teachers and me as a researcher participant surfacing my perspective (only once in a while), children's voices, and our meaning of documentation, collaboration, and reflection. However, the descriptions and understandings of the studio teachers' experiences could not have happened without the disequilibrium I faced and illustrated in the first three stories. My experience walks hand-in-hand and is inseparable with the others. It is a knot in the web which binds to the other knots.

Additionally, as a participant in the research study myself, I battled how much of my voice should intermingle with the experiences put forth by the studio teachers in this work. I came to a resolution in the process that I comfortably fit in the midst of the studio experience from a participant perspective, and my viewpoint has been as 
critical to the studio experiences and stories as was Marsha and Suzy's right to be heard.

In the end, under our primary question, what are studio teacher experiences, we maintain our first underlying question; When the studio teachers and the researcher engage in the atelier teaching-learning phenomenon, what do we experience? We shall see what these experiences bring to us in chapter four through the narrative and figures in this section on the knots in the web of studio experiences. Our first experience begins with a story of listening on the opening day of data gathering with Marsha.

The Value of Intentional Listening.

We are nervous. The first encounter in the studio brings many emotions for Marsha and me. We both seem to buzz around busily preparing for our first research experience together and with a group of children. Marsha explains, "I've seen the children interested in nests as one of the families have brought in a bird's nest and story to share with the classroom community. This has piqued our teaching team's interest to study birds through the arts." It is with the graphic mediums that we are planning our expedition, a medium best suited to the atelier where children can engage more specifically with art media and in specified small groups around a subject such as nests. Marsha plans to have the children start by working on making their own nests out of many materials, including paper and black fine-tip markers for drawing and representing their idea of a nest, and twigs, mud, and other supplies for a live rendition of a bird's nest. 
I turn my attention to the video camera and think: you novice! What are you doing? I'm preparing to audio tape children's permission to work with them, video tape the children at work on our first day, and watch Marsha engage in her teachinglearning experiences. Plus I'm planning to jot down notes as we go along? This first experience feels exhilarating and tiring all at once. I notice Marsha seems to be moving quickly and I take a deep breath, look out the window, and watch the heavy rain pour down. I can hear it tap, tap, tap outside the beautiful windows decorated with long, thin, and twirling twigs atop the curtain rods. I think, this place--the atelier-is our nest for the next twelve weeks.

We proceed to digitally record children's yes and no answers to participation in this research study with Marsha and me once families gave permission for their children to participate. After three of the twelve children answer no and go back to join their friends in other activities, we begin our first session in small groups with the nine who joined our expedition. (From this point forward, except for Marsha and Suzy, other names will be pseudonyms as required by Human Subjects Review Committee.) Marsha asks the children to talk with their neighbors about what they know about nests. Marsha turns away from the children to get materials ready. I can tell she is listening closely with her ears to conversations. She slightly turns her body toward a group and interjects, "Tell your neighbor how you know that." I keep watching with baited breath and I.think, "This experience is something to get used to, this level of listening feels foreign to me." I'm an observer, listener, one-hundred percent paying attention to this field of learning. So is Marsha. I ask myself, "What's next?" 
Alternatively, in the first studio experience with Suzy, I feel a bit more at ease. I think this is due to the fact that we team-taught together for five years, albeit fifteenyears ago. I get my camcorder ready and Suzy brings the children into the studio. We have four children in this group, which feels "a bit more intimate" to Suzy. All four say yes to the research participation and we launch into a story reading experience. After a short story on houses and where people live, Suzy guides us to a table to work on building houses.

The children begin by making stairs and levels to their houses. They put beds on each level and talk with one another about their ideas. "My house has three levels and my bed is at the top," says Maggie. Merna and Susan look over and start making levels for their houses. Merna says, "My bed is at the top with a window." She explores this idea of beds for a while and then begins to add people to the beds. Merna also draws her house for Suzy, which includes a door and a small round part near the peak of her roof and right next to her bed. Suzy asks, "Is this your window in your bedroom?" Merna doesn't respond but keeps drawing. Suzy shares with me, "I'm struggling to understand Merna's representation, as well as the others' thinking and work." I agree with her. I share, "I've begun to ask a lot of questions and the children have become non-responsive to me." Suzy says, "I am just patiently listening for their rhythms and today their rhythm says 'let's go'!" She suggests we move to the light table for a Popsicle stick house-making activity as she declares that she sees "restlessness in the children."

Within thirty minutes in Suzy's studio, Suzy and I appear exhausted as the children bounce from area to area. "Suzy, can we paint our houses?" says Maggie. 
Thomas follows behind. She says, "Yes," they wildly paint for two-minutes, and then they ask for another activity. I think to myself, is today a predictor of the sum of our experiences with these children? After the children have gone from the atelier, Suzy suggests that we "help focus their energy to see where this will lead us." She appears optimistic and hopeful that "time and keen listening will reveal our path." I gain a sense of confidence as I sit in absolute wonder at Suzy's natural ability to sooth my nervous energy and remind me, "You have to do a tremendous amount of listening. They'll come around to the languages in the studio. Listen for their truth, Will. It will come."

Meltdown in the Midst of Beauty.

Holistically, week two seems more relaxed than week one. Suzy and Marsha both appear more at ease with my presence in each of their atelier spaces. They each smile and greet me with "are you ready?" Also, I'm not adding to our stress by videorecording the events. Clicking in to the right gears seems to be the best metaphor to explain the week's experience and yet there is something looming in the back of my mind; it is almost disturbing at an unconscious level. I can't seem to put words to this unrest quite yet. I'm taking pictures and writing down what children say. I'm watching the documenter (Suzy and Marsha) document the children's work. I'm acting as a researcher participant the best I can. And, I'm enjoying most of my moments in each atelier, but my questions and actions don't satisfactorily elicit responses from the children and my interactions with them seem artificial.

In Suzy's studio, I ask Susan to describe her house to me. We talk about the levels in her house, but her responses seem contrived and only to please me as a 
teacher. I say, "How many levels does your house have?" Susan shrugs and answers, "I don't know... an upstairs and a downstairs."

Uninterested, she turns away from me to continue playing with the little people she's made for the house and beds (see Figure 1). I feel dumb and dissatisfied as I continue to try and make meaningful conversation which goes nowhere. Suzy asks Thomas to tell her about his house and prompts him, "Remember, I want you to make this house like your real house." Thomas talks about his pretend bunk bed he's made from a bunch of corks. "It feels squishy and soft," he says.

During the same week in Marsha's studio, I

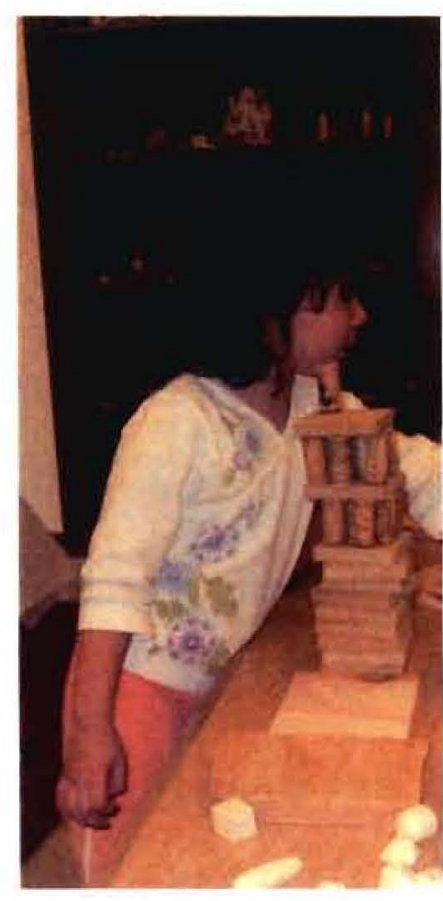

Figure 1. Susan's house with levels and beds.

notice that some children have connected to Marsha for help on their work. She has

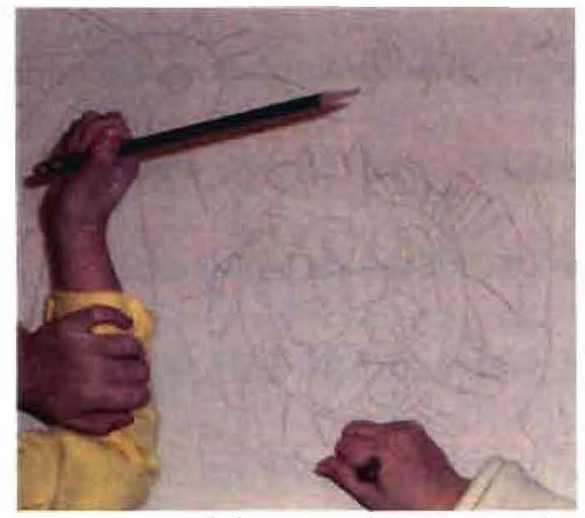

Figure 2. Children drawing together in Marsha's studio. children engage in drawing their bird's nest again this week before they begin to create a life-like nest from sticks, mud, brown paper, and feathers. Marsha queries, "What can you do with a pencil that is better than a pen?" and Lauren suggests, "You can be very, very detailed." This conversation excites Marsha and me. We give each other a glance as if to say we approve of this line of questioning. Marsha continues, "Shall we draw together?" Lauren jumps in, "Are we going to make the nests on one big paper or our own?" Marsha suggests, "On one big paper, yes, I want you to work together" (see Figure 2). 
Their conversation carries on as I jump in with helping children. I find a real bird's nest from a display area in the room and show this to the children. I ask them to touch the mud and feel the twigs. Again, I am hit with a large amount of disinterest. I think that maybe they don't trust me yet or maybe I don't trust them-their capabilities? I .just can't figure out why I encounter "shut down" when I try to engage with the children. I tell Marsha, "I feel like a fraud in the studio." My thinking spirals downward as I begin to believe that I have no idea of what I'm doing with children. I try claiming my right to ignorance in the studio, but it is disparaging and disheartening to me. I think of myself as a person who is good at what I do, an expert in my field. I generally hold an attitude of confidence, but not in these moments. I become so upset and consumed with worry that I visit Suzy as a confidant and longtime friend and I find myself crying and confused. I tell her that "I feel like a fraud...like no one in Reggio Emilia would hire me to work with children because I don't know how to work with them in this way! It just seems so hard to understand what to do or say with these children in the studio."

\section{Light at the end of Week Two's Tunnel.}

During her first interview, Suzy suggests, "I see my job is to make the beauty all around us with to the children." How incredible a statement! And, it seems so true for the atelierista. As I act as a studio participant with the children, it makes me think about our experience and how I'm trying to force the intervals of events into something I want instead of letting the phenomenon unfold and happen naturally. This doesn't feel beautiful "I have been so frustrated, Suzy, what do you think has been my goal in these studio experiences? I think I'm too controlling? How do you 
go about experiencing studio teaching?” I ask. Suzy looks at me lovingly and says, "You know what you are doing Will, just breathe! Relax and breathe. Yes, you are a little too controlling and you just need to relearn how to 'be' with the children. Just be with them." I decide it is time to follow the leader. I firmly resolve to watch Marsha and Suzy's lead and follow how they work. I believe that in this listening and mindful way I can come to understand the studio experience more deeply. The focus has to be put on Marsha, Suzy, and their work with children.

With renewed energy and enthusiasm, I persist and actively engage in listening to the studio rhythms and how Marsha and Suzy work. From the first set of interviews I find out so much more about what the studio experience is like for Marsha and Suzy. They divulge truly personal information about their work in the program and this act makes them vulnerable in the research reporting of their experiences. Living between the visions of the studio teachers (shared in the interviews) and their daily work (researcher participant experiences), I begin to move more deeply into making meaning out of this studio teaching-learning phenomenon.

\section{Atelierista Frustration in the Work.}

The first set of interviews thread a common weave. They are conducted separately; however there are certain similarities from each Atelierista. Marsha shares, "Teachers around you can create a negative influence with their attitude toward the studio and I didn't see this in Reggio Emilia. I think they know what the Atelier is all about in Reggio." Later, Suzy discloses that "Everything revolves around the experiences. It can affect us positively or negatively. Everyday, I have to think what am I doing? Why do it? Do the teachers care?" As I fish out the meaning behind 
these words during our subsequent sessions in the studio, I begin to understand a common and school-wide issue. Both Marsha and Suzy report to me that they feel their role "is misunderstood by teachers." There is confusion about what they are supposed to be doing with children and in these spaces, which both agree, as Suzy says, "Feels like a lack of respect for us." Ultimately, the studio teachers' roles in the school appear to be misread or not cultivated in a way to bring about their importance in the life of the school and each child's experiences at the Helen Gordon Center. This misinterpretation seems to be one of the biggest problems for them.

Marsha reports to me that "when the children come to the studio and have a sense of familiarity with the art materials, the languages to use the materials, and the group project rhythm, then we can engage the children to work toward deeper meaning in their thinking." Suzy agrees with this sentiment and shares, "I think that as the classroom teachers take the time to collaborate on their work with us and vice versa, we all grow in how to share materials, tools, and applying them within the classroom and the studio." The theory seems to be that it takes a combined effort put forth by the teaching team to learn to utilize the languages and materials of the studio. "Children can gain more experience working in a studio way in various spaces across the school including in the classrooms. And, the community formulates a deeper understanding of the research project or study," Marsha shares. I don't see this happening at present as I work in the studios with Marsha and Suzy. Perhaps this lack is due to the misunderstood role of the atelier and studio teachers?

The dwelling project with Suzy and the Ladybug classroom is as an example of this disconnection between classroom experiences and studio work. In her interview, I 
ask Suzy to give details about her best and worst experiences capturing children's learning. She tells me, "The houses project with the Bumblebee classroom has been the best because of what they said and did. The teacher and I work closely together already and she understands what I am trying to accomplish in the studio because I understand what she is accomplishing in the classroom. There is a strong relationship between the Bumblebee classroom and the studio, just look in their classroom and you'll see our shared work. If the teacher is studying houses, then I am furthering the study of houses in the studio." In the end, the language of houses comes to life in the classroom, studio, and sometimes in the hallways of the school and at home when the teachers and atelierista work together. The atelierista can carry the work from the classroom into the visual arts, down the hallways, to other classrooms, into the parents' hands, and out to the community around the school.

However, Suzy shares, "The detachment I feel from the Ladybug room teachers and the classroom curriculum makes me frustrated." At one point, I note that "the teachers in the Ladybug room are literally just too busy to engage with our research project and are unfortunately missing giant developmental milestones happening in the studio with our small group from their classroom. If only they could slow down and engage the children similarly to the way we do in the studio, some of their classroom discipline and attention span problems may disappear." I read this to Suzy as it is in my notes and Suzy agrees and says, "With the Bumblebee classroom I feel a part of community, seeing our center as a whole, where we all work together to create something new. This is why I started the dwellings project in the Ladybug classroom. I wanted that same feelings with these teachers, children, and parents to be 
across the school." Suzy further declares, "In the end what matters to me is that I have to get back to a certain level of questions for myself anyway. What did those children say and do? What did I learn? Is this fitting with the classroom curriculum? And, what's next?" She ends the interview by saying, "Apparently, building houses are not the solution to the Ladybug classroom and studio problems." Suzy trails off with, "We'll have to keep searching for a way in..." We walk away.

Marsha echoes Suzy's sentiments about connection and teacher collaboration in a slightly different way. Marsha muses, "Having other places where people in the school who do the work with you makes the studio experience recognized in a larger way." She takes the idea of studio into a more expanded view of importance in the life of the school. Marsha says, "This year, children really embrace longer periods of time to study a subject in the studio and back in the classrooms. Their attention span is elongated due to their confidence level with the art materials, my encouragement of art integration into the home, and maintaining a relaxed atmosphere in what other teachers think about the flow of the day between classroom and studio. This is not easy work!" Marsha shares with me that conflicts do happen in the teaching team in regard to the daily flow, the curriculum planning, and the discussions around the curriculum and project decisions. "Project planning comes slowly in a larger group of teachers and I try to include parents in the process," Marsha discloses. She rounds out her remarks by saying that "there is this kind of spiritual thing about it. I feel that in the Reggio schools and here too. Where it is just out of love and everyone is doing their best. You just have to love everyone. I mean, you're going to have your bad and good days, but it's just all out of love." 
While the frustration of bumping into one another's "rough edges" appears to happen in the daily experience of studio teaching, it is the larger issue of knowing and understanding the atelier and atelierista role that makes the biggest difference to Suzy and Marsha. They both communicated with me that they now feel heard about the underdeveloped meaning of their important and integral role in the school and assure me that in the upcoming fall we will introduce their role in a new and mindful way to the other staff and parents.

\section{Engaging Children in the Studio: Laboratory of Learning Experiences.}

Week three brings with it a renewed sense of confidence. The level of attention span seems expanded for everyone, the children, Marsha, Suzy, and for me. In Suzy's studio we start by visiting the school's outdoor playhouse before we begin to build our own dwellings out of small wooded pieces, unit blocks, wooden beads, and other materials. I suggested to Suzy that we visit the playhouse because I have seen the children play in the house and wanted to know if this would help them represent their own idea of their houses and build a common language. Suzy supports this idea in the beginning but shares that she felt it was a bit contrived by the end. She says that "the children seem excitable and wanted to get back to the studio table to work on their own ideas of houses."

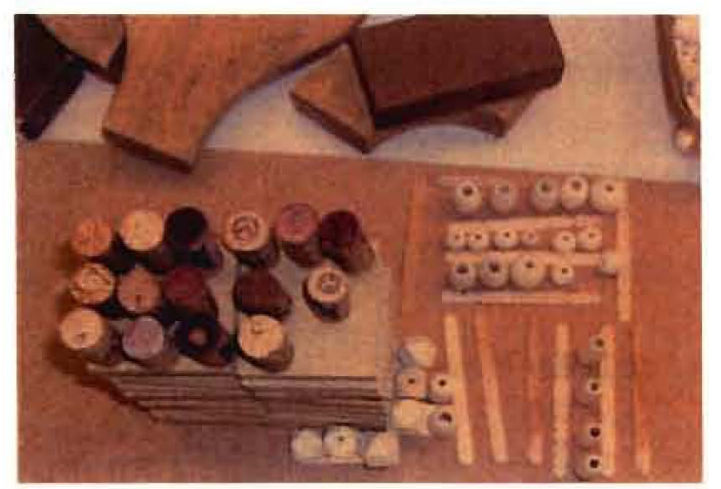

Figure 3. Merna makes a family party.

We notice Merna has chosen to build a house full of people and make the people into "a family party" in the very crowded house (see Figure 3). This becomes 
important as our research unfolds due to the fact that Suzy begins to see "a connection between the houses and families" and later we decide to move the project toward representing family rather than houses. Thomas begins to build his house by stacking the same pressboard block pieces one next to the other and surrounding two gothic arches with blocked doorways. (I did not take a photo of this experience.) He shares with Suzy that his house has a front and back door, with people in it. Maggie is out today and we do observe a shift in the energy from four children to three. Suzy says that "it feels as if a link in the chain of thinking is gone." Susan also continues from the previous week's work. She builds her stairs, her beds, and her people in the "levels" of her house. All the children seem to talk more about their family members in the constructions they are building.

Somewhere in the middle of this thinking-energy, Thomas interjects softly, "Suzy, my mom forgot to bring the picture of my real house." The others chime in, "Oh yeah! We forgot again, too!" Suzy had invited the children's parents to join our expedition and bring in a picture of their home and where they live. She suggests we invite them "so we could compare and give new language and tools to the project and see if the teachers will engage, too." As we suspect, the emerging language appears to be about family members. After all, Suzy has now invited family members to join the project by sharing a picture of their family home. At the end of the work session with the children, Suzy and I imagine that the parents more specifically ask the children about their studio work. Then, Suzy suggests, "We should follow up on that as we begin to refocus our project starting next week [week four]." 
Week three with Marsha appears to be about provocation. Provocation is a term we use which means to fan the flames of the children's learning experiences with some unknown element(s). This concept tends to advance the inquiry, interject new theories and ideas, and generate energy into the project. In order to move the group along, Marsha and I discuss several ideas about adding different research elements into the project and expanding the tools, journey, and study into a larger framework. Marsha thinks of these additions this way in her e-journal, "The film Winged Migration brings in a visual experience that could otherwise not have been presented. If only the children could have gone to Sauvie's Island to see the migratory birds in person. I think it is important that the small group always pass on their experiences and knowledge to others. Showing the film to the whole group gives all the children an opportunity to have the provocation and general background knowledge that the film provides." Marsha has come up with the idea of showing a piece of the movie Winged Migration to the entire preschool and observing what our small group does in the studio with this added information.

We wonder how this movie experience will change the course of the children's work in the studio. I think aloud to Marsha, "The teacher's ability to listen must change to meet the needs of the children's growth and the development of the project. This seems to be our process in the group experience, don't you think?" Marsha responds, "I think the experience of coming to know birds and nests is about simplicity." As we start to explore this idea, the children arrive and Marsha begins our session with small group discussions about what the children saw in the movie. "Choose a part of the movie you want to act out together. Like a play, go slow and not 
silly," Marsha suggests. Marsha has asked them to act out what they saw because she is seeking a full-body experience where the children viscerally symbolize the images they see. She explains that "to pretend to become a powerful creature such as the birds they've just seen in Winged Migration seems to build on the language of birds and help the children develop their skills of communicating concepts of what they've witnessed."

Morgan and Marvin go in front of the group and begin. As he moves his arms slowly, Morgan says, "All the big birds were slow, but not the little ones, they were too fast." Marvin chimes in as he is moving his arms rapidly up and down, "The big

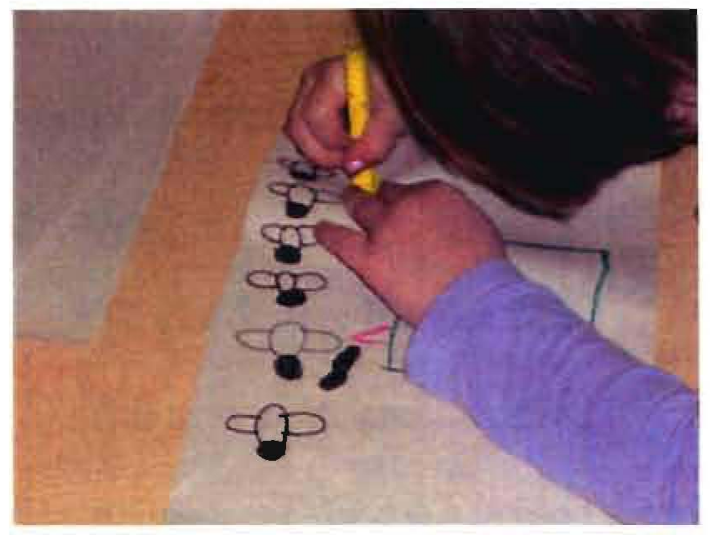

Figure 4. Representing birds migrating from the Winged Migration movie. bird goes really slow. And, the little bird goes fast... and this green is the nest part." Other children take a turn acting out their group's thoughts and then paint and draw their ideas, mostly making lots of "little" birds flying in rows, "migrating" as they called it (see Figure 4).

It is in week three that Suzy and Marsha begin speaking about and using resource materials to further a central theme. The studio experience includes a concept of presenting research ideas in a unique and unfamiliar manner to my teaching background. These "resources" as Suzy and Marsha call them include items such as reference books, magazines, movies, puppetry, and other live and representational media which tie to a central research project. They play a role in making meaning out of the study in their presentation and application. These resources elicit new or 
recalled vocabulary and take the study to a profound level of awareness, exploration, inquiry, and utilization. Suzy talks about it this way, "I like to read books to start out our experience so the children have some context." Marsha explains, "I want the movie to give the children new perspective that I couldn't do alone. They might see something that jogs their memory or see something new that excites them."

It appears that these tools become the research materials from which the atelierista and children draw most of their information together. This seems to make a tremendous difference in the way the studio teachers work with children all around. The atelierista studies along side of the children and purposely brings their voices, thoughts, ideas, and theories to the forefront of the work as she listens for and responds to their co-construction of knowledge, creativity, visual artistry, and imagination.

\section{Oh, The Stories We Can Tell.}

This next experience is called "living with the cracked egg." In week four, Marsha prepares me for egg hatching theories from the children. She suggests, "Do you remember how the children were so interested in the two coconut shells being eggs in their first nest representations? Well, Winged Migration has a section on eggs hatching." The children come directly to the studio from watching another small episode in the movie Winged Migration. In this clip, they experience watching a bird hatch out of a nest. Serendipitously, earlier in the week, I had sent Marsha a webpage slide-show link where someone had digitally recorded two humming birds hatch from their eggs in a nest. Unbeknown to me, Marsha has shared this website with the children, too. 
Our small group seems well prepared to represent what they think they know about hatching birds. All the while, I thought we would be looking at hummingbirds and instead, we are focused on representing the hatching of eggs. "In general, we go where the children are most interested," Marsha shares. In small groups, Marsha has the children work together to find hatching birds in the books she's borrowed from the library. Their task is to share an imaginative story about the bird they find. Marsha believes that "if the children draw and share a made up story with one another about birds, then their expressions will more deeply connect them to the study and understanding of hatching eggs." Marsha thinks that this creative act of spontaneous story-sharing is similar to the tool she used in acting out the birds they saw in Winged Migration. "This is a way for children to acknowledge their own developmental understanding of the study and to see where they are in their thinking," she affirms.

A parent has joined us for the egg hatching theory session and Marsha notices his level of discomfort around his unspoken role within the activity. He hovers over his child and the small group he's joined. On their own and as usual, the other groups warm up slowly but do begin to tell their stories, make up funny tales, and laugh with one another. Marsha and I take notice of the way the group of children with the hovering adult is laughing and talking, but not really "telling" each other stories because, as Marsha later shares, "The parent was interjecting, hovering, and leading the group way too much."

This parent fairly abruptly leaves the studio without any interaction with Marsha and me and we feel this is unusual. Marsha turns to me, "Adults don't know what to do! Not just teachers! Adults." I agree with Marsha, "I didn't know what to do 
with Suzy in the studio two weeks ago. Boy was I in crisis for a while. It feels better for me now, but still a bit nerve-wracking at times." Marsha suggests, "He'll get there if he pays one-hundred percent attention, watches the children, and listens for the rhythm of the studio." I interject, "I feel like I am hatching from my egg! It's a long process." After we mull over this thought of hatching, we go back to our work with the children.

There is a pendulum that swings between Marsha and me as we gently hold our breath at intervals in the midst of making general decisions. We discuss this feeling at the end of our morning. It appears that we maintained minimal interaction with the children and none with the parent helper. Marsha suggests that we have to think about, "What do we say? How do we say it? We speak to the children about the eggs, what they've seen, and what they are drawing." We discuss how Andrea appeared to be struggling with what to draw. Using a technique I've learned from watching Marsha, I asked Estelle, "Can you share your drawing with Andrea of the bird coming from an egg?" (see Figure 5). They got excited to join one another and worked together to draw and talk. In defaulting to Marsha's expertise, I checked

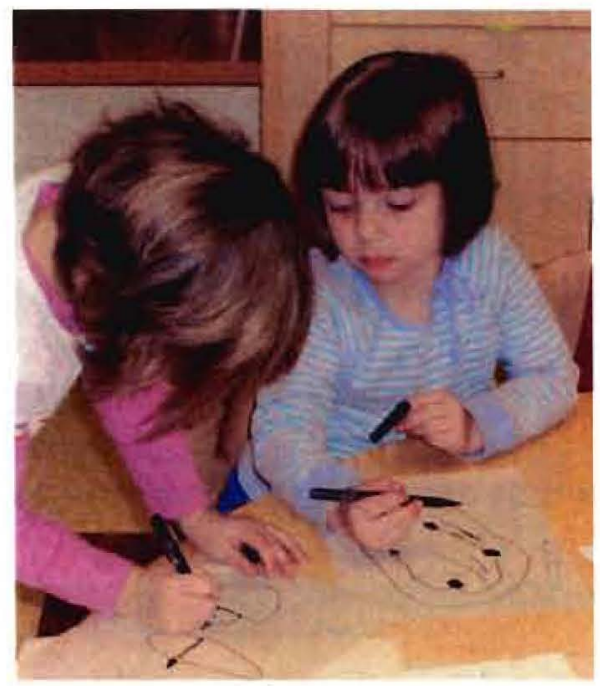

Figure 5. Sharing egg drawings in Marsha's studio. in with her, "I wouldn't have just joined anybody together like that. They seemed ready?" Marsha agreed with my decision and affirms, "The hum of the morning felt good." Maybe we are shedding our shells and becoming something new with our 
experiences? And, I wonder, "Maybe we have not quite figured out how to do this work with the other adults and parents yet?"

In Suzy's studio, Suzy asks if it is okay to redesign our dwellings projects after listening to the children during the past three weeks. "They were not exploring houses nearly as much as the families in them," She suggests. I agree with her decision. This experience is called "The people in the house: A leap in identity." Suzy has placed out new materials on the table based on a conversation she had with the children. They are interested in working with clay, not with the blocks or paper anymore. Suzy has informed me, "I am planning to do some deep breathing exercises with the children after reading them a couple of books on families to frame their thinking." Also, she shares, "I have only planned one space in the room for the materials and work today. Let's see how they do." Her idea is to "slow us down and lose our previous sense of pace in the studio." She decides, "I want to have the children draw and begin to represent their own families in their houses." Who lives with you in your house and what do they look like? This is the question Suzy asks the children to think about more deeply.

As the children sit down to draw, Suzy and I notice Maggie starts to scribble all over her paper. She is bouncing in her chair and acting silly. For a five-year-old, her behavior begins to spiral out of control and her actions are showing us that the studio work might not suit her energy today. "This not only felt like a lack of interest on Maggie's part, but also of self-discipline," Suzy suggests later. However, in this bizarre moment with Maggie I think, "I wonder how Suzy can promptly turn this around?" Suzy looks at me and gestures for me to interact since I am the closest to 
Maggie. I leap in quickly to make a change in Maggie's energy. I feel as if I'm taking a big risk and my heart races, but I try to mimic ideas I've seen Suzy utilize. "Maggie, now that you've been able to do whatever you want with the marking pen, I'm going to remove this piece of paper and I want you to work with making your family faces.. . drawing your family." Suzy and I look at one another as I say this to Maggie and gently hold her hands in mine. Maggie says, "Okay!" and begins to draw her family.

At the end of the time with the children, Suzy and I muse about this occurrence, "She got intricate with her faces and the drawings. I kept saying look at my face. What's on my face? And, she'd say 'eyelashes' and she'd draw those." Suzy noticed that "Maggie got stuck in a couple of places," but then realizes that "Maggie took a developmental leap today in her representative work." Maggie had said, "I don't know how to draw ears." Suzy suggested she look at Thomas's drawing (see Figure 6). This was intriguing to us both since Thomas had the shortest attention span in the group and has only been able to draw straight lines using an imaginary representation of his ideas. I ask Suzy, "I wonder if the classroom teachers are able to

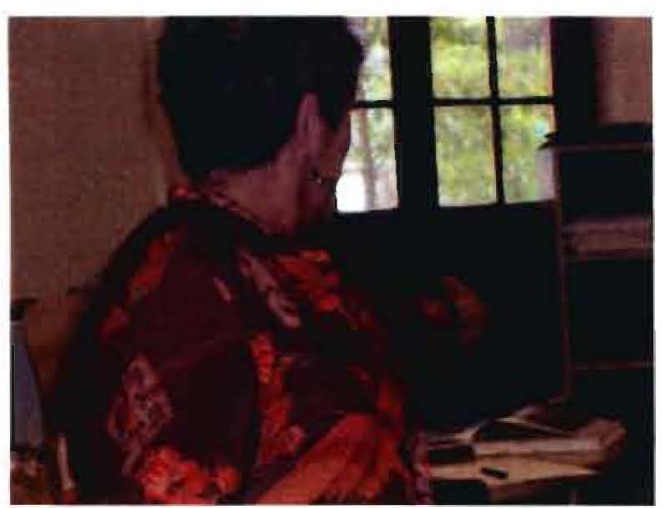

Figure 6. Suzy suggesting that children look at Thomas's drawing. afford the time to work so closely with each child as we can in the studio?"

Maggie and Thomas worked together and Merna, Suzy and Susan helped each other with their drawings. This experience felt exciting to Suzy and me even though Suzy was still sensing the children were "just

lost!" At the end of the morning, we figure out next steps for the following week. 
Suzy suggests that we change our direction. "I think we should move away from the houses, and stick with the idea of families," Suzy recommends. "As I've been listening, it seems that the children's ideas about family members and their relation to the family are emerging." I agree with Suzy's observations and we look over our incredible story between Suzy and Maggie on Maggie's family drawings. The leaps we feel that we are making with the children lead us toward an exploration of identity, clay, and self-portraits in the weeks to come, thanks to Maggie's bravery and willingness to turn her attention to a representation of self and family identity.

Seeing in Whole Rather Than in Parts.

The morning of week five, I enter Marsha's studio late. She is engaged in a puppet show with the children. Reinfred the owl has joined our study group to introduce the children to the concept of owls and where and how they live. Reinfred is the owl puppet adopted by the kindergarteners who are studying birds and owls at the same time as our group's study. The preschoolers have seen Reinfred around the school and Marsha thought it was a good time to introduce this aspect of birds to the children. Marsha e-journal writes, "The concept of 'habitat' can be too large for a child (or adult) to grasp. In past years, I noticed that the plight of the spotted owl helped the general populace to embrace the immediacy of the problem of lost habitat. Reinfreid was engaging enough to draw the children into his story. I also feel that when characters and stories are shared between classrooms, there is a unifying effect." As our group hears talk of Reinfred, there is an excitement that she has come to visit them in our space. 
"This particular owl is a snowy owl," Marsha tells the children. Reinfred introduces words such as tree, grip, claws, predator, prey, and habitat. The children use writing tools to practice write several words such as snowy owl and tree. Then, the children are asked to use Cray Pas to draw and color what they see in the books on owls. I overhear Marsha tell the children to "remember to think of a story of your owl. What's the owl thinking? Doing? Exchange ideas with your neighbors." I can only guess that Marsha has asked the children to make up stories before I arrive. Usually she starts the morning with the larger group split into small groups of three. "This way, they can more intimately talk and come up with stories on their own," Marsha tells me.

As I turn toward Marvin, I hear him say, "Okay Marsha, but this is hard to do!" He is referring to Marsha's request of drawing and coloring an owl picture. This statement makes me think of Thomas in Suzy's studio. Thomas had the same sentiment earlier this week in Suzy's studio experience with clay. He declares that he cannot make his sister's face because he doesn't know how. Suzy provokes Thomas with "What would you make first?" Similarly to Suzy and Thomas's conversation, Marsha suggests to Marvin, "You can do this Marvin, I'm here to help."

In both cases, a precious moment between the studio teacher and the struggling child develops, making way for them to courageously step into their higher creative selves. This rhythm of working together takes negotiation and expertise for both to become teacher-learner. The studio teacher must learn where the child is and the child must teach the atelierista what they do and do not understand and where they are willing to grow and make meaning. Looking for growth in Marvin, Marsha moves her 
propositions of Marvin to a new level as she asks, "Are you going to try to draw an owl on the other page of your book? I'm going to bring the book with a picture of an owl on it closer to your work so you can see how to do it." Marvin practices his drawing. Marsha helps by encouraging Marvin with ideas, "And they have those little circles around their eyes." Their conversation continues and fades for me as I begin to help Terrey.

Terrey is working with the silver and gold Cray Pas to make a picture of some sort. He is in the middle of complete concentration where I actually notice his tongue sticking out slightly as he thinks really hard and surveys his current work (see Figure 7). I think out loud, "I wonder what you are making?" Terrey doesn't respond due to his intense concentration. Besides that, I make note of the fact that he spent a great deal of time talking earlier and goofing around; I decide not to interrupt his process too much. In this moment of a making my decision to watch and listen silently, I felt as if my brain and eyes rapidly come to focus_-similarly to an out-of-focus film reel

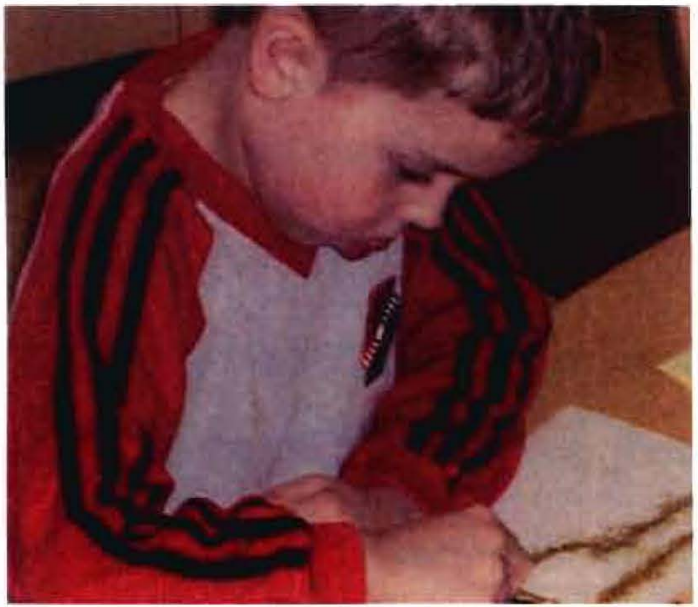

Figure 7. Drawing an owl with tremendous concentration. or a fuzzy picture when suddenly unblurred.

I take a step back from Terrey's work as I finally see his consideration of the owl in whole rather than in parts. I see Terrey, a book with a flying owl picture, with the left wing spread out and I notice a sketched-out golden circle with a large

oblong-shaped golden outline stretched out to the left. Terrey is drawing an incredible 
portrait of this picture of a flying owl. I simply stand there in amazement unable to respond at first. Then I grab my camera and take several pictures and ask Marsha to come over and see Terrey's work.

My "double take" leads Marsha to a new vision in Terrey's work as well as to some serious discussion between Marsha and me about where the project is headed. It seems to Marsha that "we have grown in our study from the nests, which has turned to birds, eggs, and now owls." In our reflective discussion after the studio experience, Marsha and I begin to make meaning of our rich five weeks of study and look for where to move next in the research. "We seem to be noticing the bigger picture and seeing in wholes rather than just moving through the parts of the experiences,"I suggest. As we develop a plan, Marsha declares that "studying urban bird life makes sense due to the trajectory of conversation and storytelling" of our mostly inner city children. "I think this is where the children are headed and we had better follow," Marsha ponders.

Our Own Sense of Time.

Suzy starts the morning of week five with a book You be Me and I'll be You by Pili Mandelbaum. In the midst of the preparing to read the book, Suzy suggests that the children each draw in three deep breaths and then slowly let them go. She calls them "belly breaths." She also asks them to do a yoga pose while she counts as they hold the pose. This seems to calm the bouncy and excitable energy of the children. After they all seem satisfied and focused, Suzy reads the story and they all sit very quietly listening almost as if they hadn't been paying attention before now. Once the 
story is over and the children discuss the reading, our conversation takes a turn toward the project work.

Suzy talks with the children about our idea of working in clay for several sessions to make family figurines and our own faces. "Our dwellings project seems to be taking a turn and heading down a road of more carefully representing the people in your families," Suzy explains. She continues, "This idea of making families seems to be what's next in our studio time together." Later she adds, "I think this move is appearing out of our deep listening to the children's work on getting to know their family members in the houses. The focus in the children's work has been on family members and their relation to each family member in the home." Suzy has explained this to the children and she told them, "We've noticed that you seem more interested in playing with your little people as family members while you built and drew your houses." Suzy informs the children that she has captured many of these conversations about family members as we watched them work over the first couple of weeks.

Suzy reads some of the children's quotes from the previous week about Merna's play and her family interest. She explains later that she had done this "to spark their memory and get the children to think more deeply about the actual focus of their study." I remind Maggie that she and Thomas had been talking about their family members and who was in each bedroom of the houses. We reminisce, "Remember how Susan has had her family in her house and her story of who lived on what level and what they did in the house?" Suzy also stated to the children that she overheard them talk about wanting to use the clay. "Is this alright with you if we work on making our families and ourselves out of clay?" Suzy asks. The "yes" response 
was overwhelming and clear and we knew that we were about to head down a much more inviting and complex road with this study.

At the end of the session, I write down that I have really enjoyed this day in the studio. The session felt like a lot of shared decision-making, negotiating, and talking through what we had observed. In our reflective discussion after the session, Suzy and I contemplate why the day felt so good and land on two essential ideas related to this good sensation in our work that day. The first idea Suzy suggests is that "the children had intentional time to relax and come to the studio with a sensibility to the materials, space, and thinking." Suzy declares that she "will continue to offer a moment of relaxation and belly breathing for the children as they first arrive to our day because they are coming from a hard classroom transition between morning meeting and classroom exploration. Mainly, it's potty-time when I go and get them." She then adds, "I think it will bring a different level of meaning to their work to remember to deeply breathe before we begin."

Additionally in the same reflective discussion after the session, Suzy and I uncover new meaning in our concept around a sense of time. I say, "While time seemed to pass quickly, we enjoyed ourselves immensely and this sense of time felt elongated, don't you think?" Suzy agrees, "I see that the children left satisfied as if their bellies were full of good food." One even smiled and said to me, "Goodbye Will, thanks for the studio time." Others chimed in with camaraderie, "Yeah, it was great!"

Suzy shares, "They really focused on their time with us, really making their family faces!" We talk about how focused they got with their work and this seems to be the first time where time "ran away" with the project. Suzy shares, "We could 
really breathe and feel the rhythm of the children." Suzy captures children's learning for the first time. As I bring this up to her just after the children leave, she says, "I felt like I had enough time to get to all of the work today." I suggest that "we were in the flow" and we both agree that it felt like a gift of precious and beautiful moments in time with our newfound friends and co-learners. In Edwards (1998) there is a statement about the way we feel toward this episode's sense of time.

The measure of the clock is false. It is certainly false concerning the time of children-for situations in which true teaching and learning take place, for the subjective experience of childhood. One has to respect the time of...tools of doing and understanding; of the full, slow, extravagant, lucid, and everchanging emergence of children's capacities; it is a measure of cultural and biological wisdom. (p. 80)

The children are teaching us so much about what they can $d o$ in the studio and who they are as strategic thinkers, capable of bringing their ideas through the medium of this newly explored earth substance-slowly molding their clay over time. Why Do We Document?

In this section we are working to explore and reveal the second underlying research question: When the studio teachers and researcher participant capture children's learning, what is our meaning and understanding of documentation? Suzy reveals, "I am doing documentation for this reason, I want to see the children grow and have them teach me what they know. I want to know if we are both on the same level of the work." She adds that she turned a corner this year in her documentation. "I used to think that I needed to show all of the children's art, and that's almost one- 
hundred children. Now I know I can happily show one or two of the children and their learning about a project in the studio and talk with others about it." Creating beautiful documentation which demonstrates the thinking and work in the studio is a critical component of the studio teachers' work-life. Knowing this information, I asked Suzy and Marsha to share with me their experiences of teacher documentation in their second interviews with me.

Marsha discloses that documentation is a "connector to families." She believes that families could "bring more documentation home and back, which would bring families in to the thinking of the project and build relationships between the school and the home." Additionally, in the studio researcher participant time we also see experiences unfold which relate directly to the notion of documenting children's learning. Several of the experiences relate to week six and seven as well as to the second collaboration session where Marsha, Suzy, and I stumble upon numerous gifts of magical moments in our meaning making of documentation. The following stories reveal the meaning we made in documenting children's and our learning experiences. What Happens to our Experiences as we document them? The Eyes of an Owl. Week six brings with it a second video session. At this point, Marsha and I feel so secure in knowing that our part of the work is only a portion of the events in the studio. This understanding allows me to spend more time behind the video camera, watching the children explore owls and making an owl on their own. Marsha starts out the session with Sophie asking to leave. I capture this on video as it seems so important to Sophie. Marsha suggests to Sophie, "You can take a rest from coming to the studio at other times in the week and focus your energy on this research 
project." Sophie says, "I don't want to be in groups always." Marsha responds, "First you can look through the book and find something you want to make. We have lots of materials. Maybe you can make something on your own today."

Marsha seems to choose a different path to help Sophie make her decision to stay by suggesting that she not come in at other times of the day and that she work on something by herself for the day. Sophie does stay and she is very careful about what she wants to make. She takes her time as she develops a couple of theories with Marsha about making an owl. As a side note, the classroom teachers share with Marsha and me that they've observed Sophie's obsession with the veterinary clinic the children have developed in the home-living dress up area. One teacher proclaims, "It is good for Sophie to find other creative outlets and remember the connections

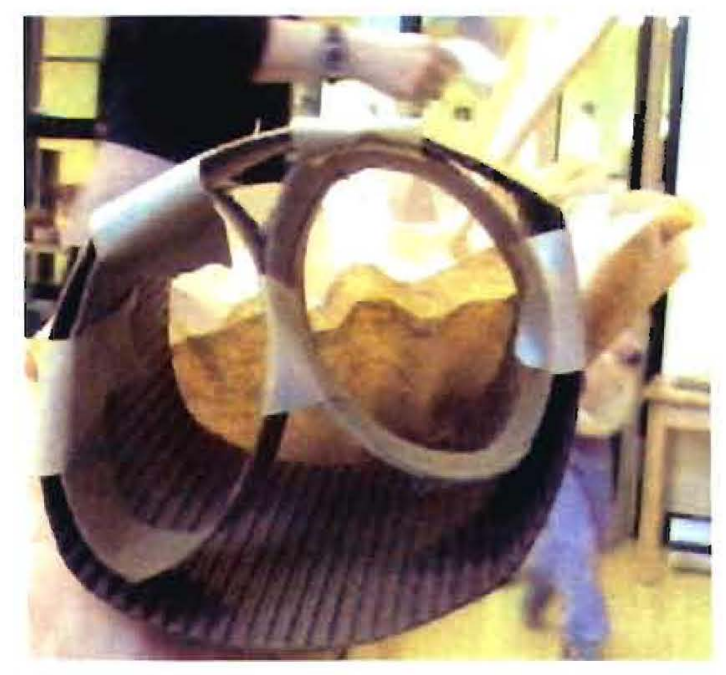

Figure 8. Sophie flying her owl creation toward the camera. between the birds in the studio and the veterinary clinic in the classroom. The two spaces are interconnected for her exploration and to develop her creative drive."

In the collaboration session with Suzy and Marsha, I share my experiences of Sophie's owl creation from the day she carefully flies her owl toward the camera

and brings the eyes of the owl directly to the camera lens (see Figure 8). We watch the video camera lcd screen and we talk about what happened with Sophie and Marsha through the process. Marsha tells us more about Sophie's choices in her owl creation 
such as the "stirrer which turns the goop inside of the bird. This helps to make and feed the babies," Marsha mimics. I remember that I took careful footage of Sophie's owl and that Sophie explained much of this to me via the camera.

Since I captured Sophie's learning experiences on film, Suzy and Marsha feel privileged to revisit this reenactment of Sophie's studio experience with me. As I share this film with Marsha and Suzy, we see that the bird's eyes are made from two pieces of rolled corrugated cardboard and attach to a bowl-shaped brown body. There is a corn husk sticking up from the bowl (it looks like a cereal bowl with a straw spoon in it). The corn husk is maneuverable and as Sophie moves it back and forth she talks about the gooey mess inside of the bird. Her theory is that "worms live inside of the bird and get stirred up into goop which helps the eggs grow into birdies." I wonder aloud to Marsha and Suzy, "How could we document this to share with the parents and the other teachers? We'll have to design a panel with Sophie to showcase her work and her theory." Marsha suggests, "This is a great idea and then we can make meaning out of her theories together with her."

Hidden Meanings in documentation: Understanding Symbols.

In the early weeks of our studio experiences together, Suzy and I struggle to understand Merna's drawings and house representative work. Suzy shares with Marsha, "Merna kept drawing peaks in the house with a round thingy near the top. We just didn't understand her idea." This representation seemed natural to our experiences of children drawing symbolic representations of houses; much like clip art would look of a house. However, near the peak, Merna would place a round shape. Suzy and I would both probe Merna with questions. Suzy would ask her, "Is this a 
window in your bedroom?" In one version of her drawing, she had traced her bed in the second story of the house and then she draws this round shape next to the bed. She can not seem to explain to us what the round shape is, but she knows that it is not a window.

These moments with Merna must have seemed profound to Suzy and me

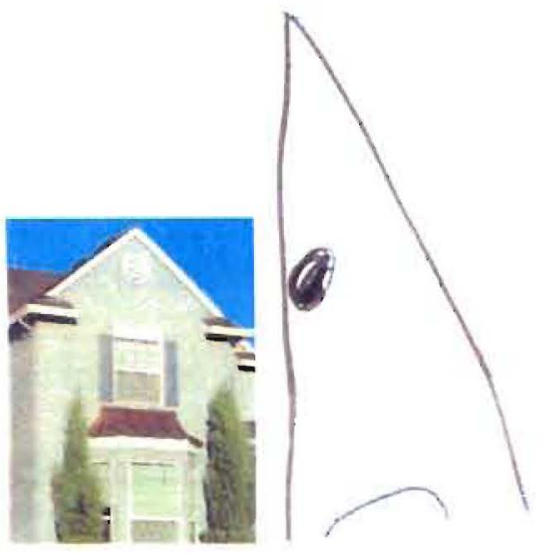

Figure 9. First drawing of the peak of Merna's house which shows the mysterious round near the top. because although we moved on and seemingly forgot about them, when the memory returned to us they were shocking and resurfaced due to the look on our faces. I felt an instantaneous jolt as I walked into Suzy's studio with Marsha and we prepared for the last half of our second collaboration session. We had decided to conduct the collaboration sessions in both studios with gathered materials from each project displayed for all of us to see and discuss. Uniquely, as we enter Suzy's space, the first documented piece Suzy has to share with us is about Merna's drawing (see Figure 9). Suzy says, "Will, look what Merna's dad brought in?" I scan the table and see a picture of a driveway leading to a house with a sharp peak at the top of the house. Near the top of the peak is a small circular shape, perhaps a vent of some sort from the attic. I instantly recognize the shapes of the house and recollect our conversations with Merna. Suzy explains our journey with Merna's drawings to Marsha and we happily smile and laugh. I say, "Our connections to her symbolic work were way off. I just couldn't understand what she was trying to draw, over and over!" I ask the group, "Was this symbolic for Merna or 
was it her most accurate representation?" This is a good question to take in and think about for all of us. Finally, after some silent thought and hard stares at Merna's drawing and picture, we move to other conversations.

Documenting the Documenter: Silly Gestures.

In week seven there is an unspoken silliness in the studio with Suzy and me. We seem to keep gesturing to one another with our faces. Suzy moves her eyebrows up while talking with Susan and her face stays steadily on Susan while her eyeballs move up toward me as if to say, "Look at what is going on here!" I pay closer attention to the interactions and slightly giggle with my hand covering my mouth so as to not make noise. Maggie catches us! She says, "Hey, why are you two laughing?" I almost cannot contain my joy and heartily respond, "We are just having so much fun in here with you all." Suzy adds, "We love you so!" Maggie slowly looks down at her work and verifies our goofy behavior, "You two are just silly."

I take a picture of our moment after the fact and wish I had a video camera rolling of this event. We miss the moment and I think it feels important to share the joy with others. I am truly enjoying myself and Suzy agrees. "We are having such a good time now; do you think you'll continue to come into the studio even after the research is finished?" I ponder this question a lot and realize how important all of this work feels for the school, the children, my own development, and how this must feel for Suzy. Again, we wish we could have captured this fleeting moment. It has filled me with such wonder and amazement, my heart wants to burst in the presence of such great joy. I'm learning that we can't capture everything and some moments are better left as memories to cherish. 
In week eight, I've written in my notes that the children and Marsha are making both physical and mental gestures in Marsha's studio. We have moved into pretending to be the birds as we study birds, eggs, and their habitats. As I enter the room, Marsha has asked the children, "Think about urban birds and living in the city. Can you talk with your neighbor about this?" I think this is provocative since most of our families in the school live in the city. I wonder to myself, how will the children relate the urban life of birds to their own life? Marsha thinks aloud, "Does anybody remember anything about birds living in a city?" Apparently, Marsha is referring to Winged Migration once again or perhaps another resource material she's shared with the children while I was away. Laurel puts her hand out palm side up as if to say, I've got something to offer. She pronounces, "It is hard for birds." Marsha agrees and offers back with her hand mirroring Laurel, "What do they worry about?" Terrey jumps in by placing both hands on the table and standing up as he declares, "It could blow away."

Marsha has grabbed a clip board, taps the pen on the paper several times, and starts writing down responses as she asks again, "What could happen to birds in the city?" Marvin responds mildly, "Birds could fly away. They could escape and get away and their eggs could get eaten." This conversation feels satisfying, but I realize that I'm not capturing all that I could with the gestures including children thinking with their elbow on the table and their hand holding their chin. Marsha's tapping with the pen as if to say, "I'm ready to write!" Children mimicking the movements of birds in their explanations. Marsha writing madly, looking up intermittently, quietly pondering, and returning to the writing. The large group conversation comes to a 
close as Marsha asks, "Could people scare the birds?" Someone replies, "We're all good tẹachers, so we know not to scare them." Marsha finishes, "We're going to make the buildings for birds to roost. What does roost mean?" Lauren interjects, "To make its home!" The children begin to gather the materials-bubble wrap, foam pieces, cardboard, plastics, and the like-which are placed all over the room. Marsha passes out tape.

Marsha declares, "In two minutes, I'm coming to get your ideas." She points around the room as if to say she wants to hear what children have been working on and thinking about as they have represented their urban birds and their roosts. There has been a flurry of activity and incredible creations are made all over the room. Children have shared their ideas aloud, pointing, making gestures to support meaning, cutting, ripping, dramatizing the events to make meaning of their concepts of roost.

I think to myself, I must ask Marsha about the concept of schema or our internal representation of the world. It appears that building shared meaning of one's schema is developed in this room through interaction, hand-action, and gestures of all sorts. This feels like the way children make meaning in the studio so often with Marsha. I share with Marsha, "It seems ingenious to have the children act out their idea or move about to get their concepts across to others." Marsha responds, "The children gesture to make meaning with one another and me as a way to get their internal ideas out into the creativity of the room. At least, to me it feels creative." Photo Gallery of Artifacts.

It has taken us a long time to choose the photo gallery of artifacts we want to share in this venue. From the beginning of our data collection, we have chewed on the 
issue of how to frame the gallery which best portrays its own story within our structure of working together. I think we have learned through choosing these photos that we are making a value statement and purposeful judgment on what to share from our experiences in the studio. Marsha reports, "So many people see the studios and what goes on in them in a purely visual way. Because of this, I feel that what is written and said about the studio work is of the utmost importance. However, the gallery of studio images does produce a strong connection to those who view them."

Suzy agrees with Marsha's sentiments about the strong visual connection. She intimates, "We have to engage others through the work and we do this with photos, lots of photos and verbal thoughts from the children. Creating this gallery is documenting the work." I imagine that our process of selecting the gallery of photos is similar to teachers collaborating on any documented project in the school. These photos remain a gallery of artifacts which gives a visual experience to the reader through their display. Again, the purpose of this photo gallery of artifacts is to create as direct as possible a link and between reader and studio teachers' work with minimized researcher context through written narrative. In week nine, we realize that we have only spent about ten minutes in each collaboration session generating and brainstorming ideas such as "let's show listening" or "what about children's hands and work?" With so many pictures, we decide this may be enough time to formulate our decision after all.

In the second collaboration session, we finally land on a decision after these repeated conversations, mostly due to prior hallway exchanges. I suggest that "we concentrate on pictures of teachers using the value of listening with children." Marsha 
and Suzy do not protest, and we seem to walk away with a solution in hands. A week later, I write in my journal, "We are still searching out meaning in our photo gallery of artifacts." Marsha had wondered in a passing hallway comment, "What is it that we supposed to show in the gallery again? I'm not sure we have enough to demonstrate our idea of listening to children in the photos."

As we prolong this big undertaking until we have time to meet again, we come back to the teachers' and children's interactions in the photos. The photo gallery appears to monopolize my thinking until in one instant; Marsha declares something out of the ordinary and well demonstrated in our photos. She suggests, "Why don't we show a series of gestures." Afterall, we are writing a story about silly gestures and we have a lot of gestures in our pictures. "It will be like watching a silent movie of our experiences together," I write in my journal. I share this with Suzy who seems excited by the news. "Gestures, yes we have a lot of photos which tell their own story about gestures, don't we? I think that the reader can understand such a story without many words, maybe we should call it gestures making meaning in the ateliers," Suzy proposes.

With the issue of the photo gallery decided, we move forward (see Figure 10). We wonder what the readers will see, think, feel, ponder, and decide about our precious work and experiences. Through careful selection and an intentional lookback, gestures become the underlying meaning in this photo gallery of artifacts. This gallery in figure 10 is what we have come up with to share with our readers. 
Figure 10. Gestures Making Meaning in the Ateliers.
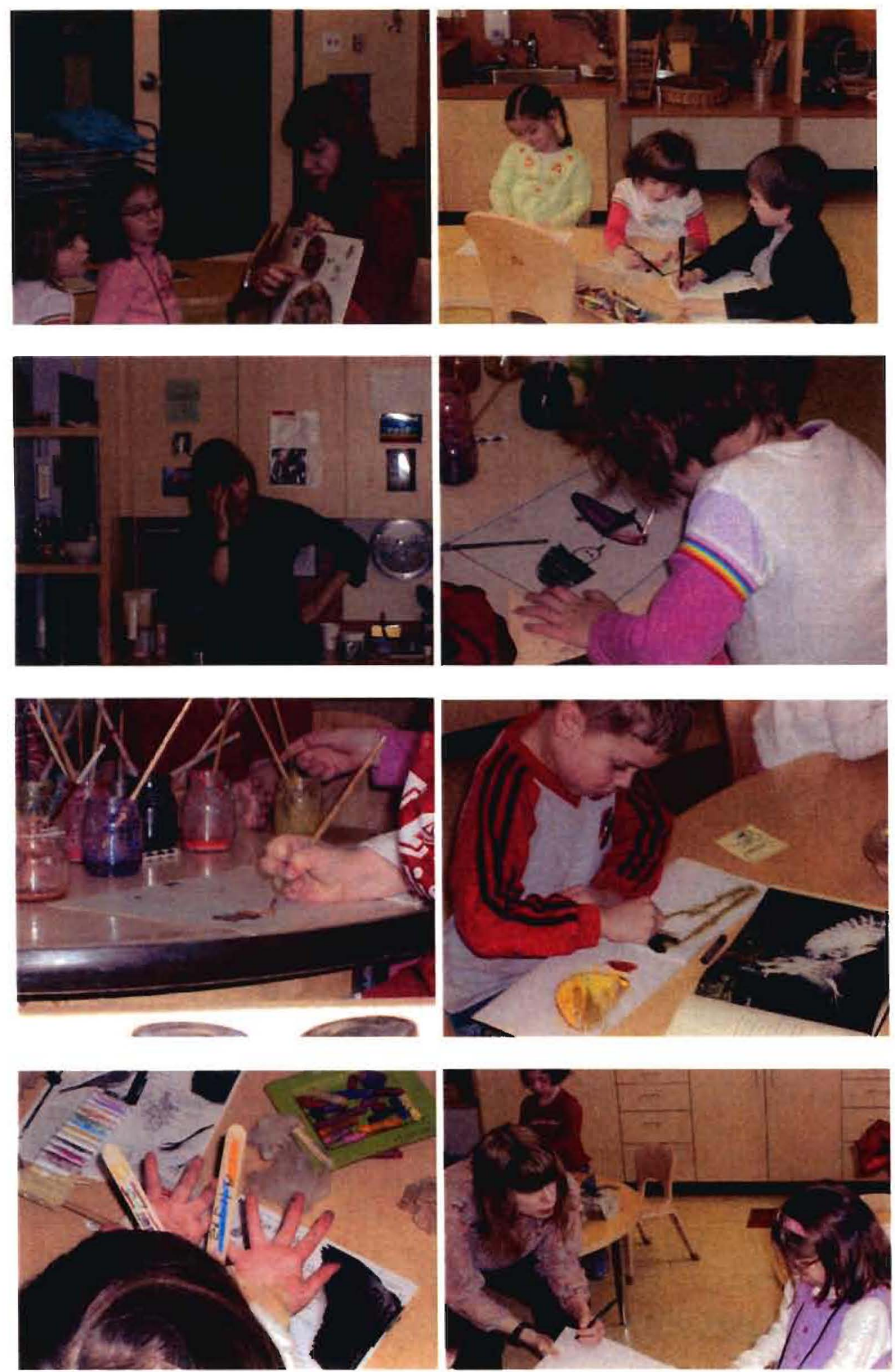
Figure 10. Gestures Making Meaning in the Ateliers continued.
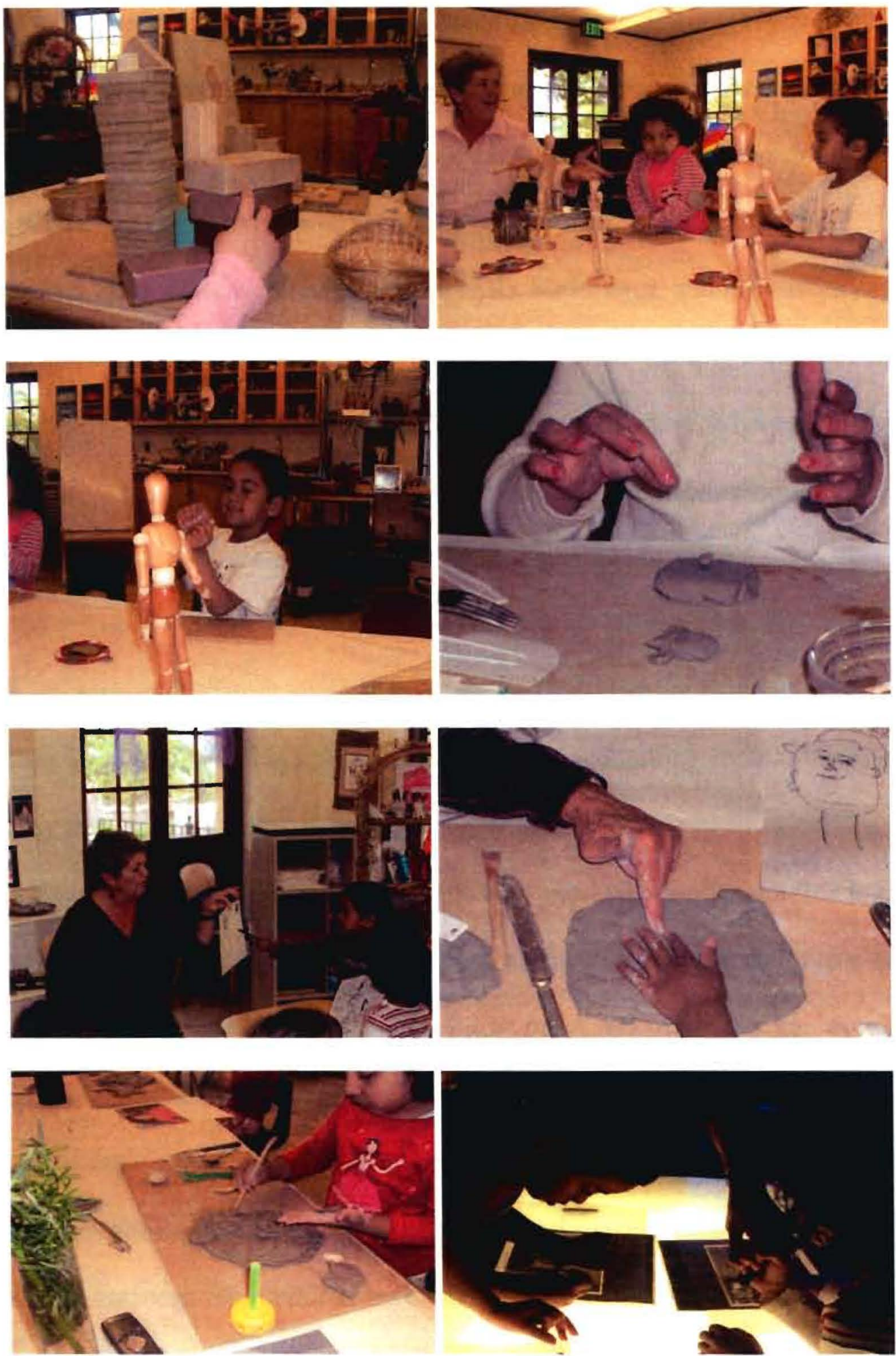
The Meaning of Pedagogical Collaboration

In this section we are looking to answer the third underlying research question: When the studio teachers and researcher get together to discuss the children's learning and work, what is our experience and our meaning of collaboration? So we begin to develop our answers after week ten when Marsha and I discuss the possibilities for next steps in our project on nests, birds, eggs, and now urban roosts. Marsha and I seem to be in a groove of collaborating and reflecting back after each studio session where one of us will ask, "What happened today? Where are we going next? What do we want to prepare for our next session?" Marsha responds after week ten that she would like to see the urban roost idea continue in some fashion. She says, "The teachers have shared with me that the children are talking a lot about urban roosts and making their own habitats in the Butterfly classroom around the tent that is up. They appear to be making 'homes' with the tent and talking about urban roosts. This may be a connection between ways of living."

Marsha shares with me that "it would be a good idea for the children to engage the images in the movie Winged Migration more. They could grow their theories of what they see in the movie about habitats, bird's nests, and roosts in some way from the movie." She tosses the ping-pong ball to me with the thought of asking the children to draw a large rendition of an urban roost and bird from a still clip of the Winged Migration movie. I throw it back to her and suggest, "How about we transfer this week's drawings [the children have already made] onto transparencies and enlarge them onto a wall. We could then trace them on the larger scale." The children seem to be working on a larger scale in the Butterfly classroom with a similar idea of 
making a "roost" for themselves in dramatic play. Marsha agrees, we have a plan, and we metaphorically continue to toss the ping-pong ball about other issues of the day. We feel enthusiastic in our work together and the energy builds on itself from one session to the next. I wonder if there is culmination in the process of collaboration and when we may come to this peak.

In our final interview session between Marsha and me, Marsha explains that "good conversation brings awareness and a shared emotional experience allows teachers to go somewhere. It opens doors and creates possibilities." She shares these ideas with me as I ask what her experiences of teacher collaboration have been like so far. She also believes that for "Helen Gordon Center, collaboration has given us a viewpoint of more professionalized teaching, showcasing our experiences." Similarly, in Suzy's final interview, she suggests that collaboration "brings about our future. We can talk about our ideas. It feels hard with so many teachers and children but it is such a positive contribution to the school."

Marsha, Suzy and I continue to explore collaboration ideas in our reflective discussions after each studio experience, but the difficulty in getting the teachers involved with Suzy's project has been immense. As Marsha says, "In our wing upstairs, we have weekly meetings where we discuss, argue, and come up with where to go next in our big project such as the birds and urban roost study. This is not easy work." These ideas about creating a collaborative feeling between the work in the classrooms and the studio finish in a desire to develop a plan of action for the following school year to make this process and communication better. Intentional collaboration seems pretty poor for Suzy's teaching team and much better for 
Marsha's team. Marsha works in a select wing of five teachers where her glass walls are adjoining to the classroom spaces. The team meets often and sees each other throughout the day. As Suzy has said, "I feel my studio is invisible, way back in the corner behind the kitchen, downstairs and around the corner from the Ladybugs." She tells me, "I meet with the teachers when we can, but it doesn't feel like a priority has been set up for us. I also don't get to connect with parents living so far away from the classroom."

As well, we continue to seek solutions for our present circumstances with Suzy's situation. For our current work, Suzy and I fantasize about the classroom teachers' participation in our project around the dwellings and now family faces. I suggest, "How would it look if Merna, Maggie, Susan, and Thomas had the opportunity to work on their studio theories in the classroom in-between our sessions? What if the studio work was directly related to the classroom ideas?" Like in the Bumble Bee classroom, a language of artistic expression would appear between the spaces and in the hallways. "Learning would be reciprocal and grow between parents, teachers, me and the children," Suzy proposes.

Furthermore, Marsha explains that the concept of "morning meeting" has helped to create a collegial atmosphere between the five teachers in the wing. "Morning meeting and the weekly teachers' meetings engage the whole teaching team in collegial and pedagogical collaboration," Marsha declares. Marsha, Suzy, and I continue to grasp for ideas around teacher and studio co-creation, reciprocity, and general relationship building and well-being as a means to our school's collaboration efforts. We wait to see what else bubbles to the surface in our shared thinking. 
Isolation in the Studio: Gifts for Others.

In week eleven, Suzy and I share a flash of insight during our reflective discussion after the studio session. Since we have been grappling with this notion of teacher collaboration as a well-being gesture between teachers-a way to figuratively say 'we're working together'-I suggest that we "give Teacher Julianne and Teacher Jackie in the Ladybug classroom a gift from the children and the studio. It would be a way to imprint their identity into the studio work as the children's identity shows up in the classroom." Suzy runs with this idea and proposes creating Julianne and Jackie's faces out of clay to the children, in the same manner and using the same tools as they have for making their family and self portraits. I suggest to the children that we can call this our "school-family project" to see what reaction we get from them.

"You have pictures of your faces up in the room that the teachers helped to create. How would you like to create their faces to hang in your classroom?" The children's faces become excited. Merna says, "Yes! I would love to make our teachers' faces." Maggie says, "You mean, make teacher Jackie out of clay or something?" And Thomas chimes in with, "Yeah, that's what they mean, Maggie. Let's do it." And he nods at Maggie up close and in her face while touching her shoulders. Maggie nods back, but brushes Thomas's hands away. I didn't catch Susan's response, but she seems enthusiastic and wants to get started as she is the first to move to the drawing table.

To get other teachers in the school involved, Suzy and I ask around for pictures of Julianne's and Jackie's faces. We tell folks about our project and ask them to keep it as quiet as possible so Julianne and Jackie can be somewhat surprised. "We 
understand that the children will talk about their studio experiences in their daily morning meeting in the Ladybug room as they usually do, but we know that the overall surprise is still worth giving to the teachers even though they'll know," Suzy shares. Overall, we share our process with other teachers so they become familiar with what we've been working on with the Ladybugs and how we are proceeding with this idea of reinventing and representing the homeroom teachers with our small group of children.

During our final week and once the children are present in the studio, we ask them to come to the drawing table and individually draw a picture of teacher Julianne and Teacher Jackie. Suzy has purposefully chosen to split the group into two smaller groups of two. This group-making feels familiar to the teachers' work in Reggio Emilia as described in Making Learning Visible. "The teachers often form pairs with one child more oriented toward the verbal language and the other more oriented toward action. Interest is also a distinct factor" (Guidici, Rinaldi, \& Krechevsky, 2001, p. 249). Merna and Susan are to work on Jackie's face and Thomas and Maggie are to study and recreate Julianne's face. We all agree on how to proceed as Suzy suggests, "We thought that Merna and Susan could work on Jackie's face and Thomas and Maggie could work on Julianne's face. What do you think about this?" The children respond by nodding one to another. I ask Suzy later, "This group feels pretty flexible, don't you agree?" She concurs and says that "other groups could have required some negotiation around who was to work with whom and on what teacher's face. Yes indeed, a flexible and loving group, l'd say!" 
After the children have drawn their teacher's face, they are asked to join me at the light table set up for tracing faces. They each trace their teacher's face (the face they will study in clay) and at this point Suzy announces that the group will now work in their smaller pairs to create the clay figure of the teachers' faces. Suzy intentionally proclaims this collaborative effort "to see if the children will react as they work to finish their tracing." Merna looks over at Susan's tracing and Thomas at Maggie's. We figure that Maggie and Susan are seen as stronger tracers and more sophisticated drawers than the other two. As Suzy says, "We've spend time with all four of the children talking about their work. We're pretty open about șaying how something looks for each one of us and who has more practice at what." Suzy clarifies, "It isn't about being mean or criticizing each other's work; it's just about forming ideas that are stronger than our previous representations. The children generally seem to get this and are really nice with one another when they state their opinions about the work we're making."

We conclude that Thomas and Merna see this same difference in their partner's level of drawing as we do, but we are only speculating on this point because of their simple acknowledgment of eye-contact with the other's work. Since we didn't follow up with them on this particular point, Suzy and I wonder what they were thinking. We speculate together in our e-journals, "Do these children have the same issues of collaboration and vulnerability we face as adults in the school? How will they respond and react to one another's work, thinking, ideas, and gifts of exchange?" These questions and many more lay in the horizon if we continue our work with them beyond our final day of research and data gathering for this study. Since this is our 
final day together and we didn't follow up in the moment, our questions seem just beyond our grasp. In our reflective session after the studio time, Suzy points out, "We should revisit this moment and our questions of the children. It felt as if we were moving so fast again - like in the beginning - and it is good to recognize when we need to slow down and reflect on what is important with the children." I interject, "If the research study were to continue beyond today, I think that we would have some answers as to this exchange between Thomas and Merna's glance at the tracings and our wonderings of small group collaboration. We could bring back the photos I took of this episode and talk with them more about our choices?" Then, Suzy and I reflect back over the final moments of the day, at the time when the clay work begins.

We arrive at a moment of marvel when we move to our final task for the day where the children work in their small groups we've chosen. The co-creation of teachers" faces out of clay feels like a long minute of holding our breath. "We wait to engage, we listen in so many ways, and we watch the children using the techniques of the camera," Suzy suggests. The children sit together and talk about their ideas; who is going to make the nose, the eyes, eyebrows; how the hair will look; and what shape the ears will be. Suzy has set up the space with the original pictures, the tracings, and the drawings around a single large slab of clay resting on a clay board. There is enough space for two children at each clay board and the children stand rather than sit.

The children's hands begin to move in orchestration and Suzy and I offer simple statements such as, "Does that look like the nose on the picture or in your tracing?" The tracings seem sophisticated enough to refer back to for guidance. They provide us with a tool from each child as a map to guide us to our destination. I notice 
that Thomas and Maggie begin to each make a set of eyes separately. "You have to decide together how the eyes will look," I offer to Thomas and Maggie so that they'll begin to work together. They look at one another and Maggie says, "I know, I'll make the eyes and you make the eyebrows?" Thomas jumps in by taking his two little balls of clay (presumably eyes) and squishing them together. He starts to roll the clay in his hand as if to make a worm or snake. Maggie forms the eyes and Thomas puts the eyebrows directly above them, squishing them down onto the eyeballs themselves. I pick up the picture of the teacher and suggest, "Look Thomas, is this how her eyebrow sits in the picture? Is it touching the eye itself?" Thomas fiddles with the eyebrow but doesn't ever seem to understand this concept fully as he keeps pressing it closer to the eyeball itself, until Maggie jumps in and moves them up above the eyeballs and says, "Here, like this" and she moves them up and away from the eyeball.

I take note that Suzy and I have split off and we concentrate on one group's work without worrying about the other. We appear to be working in harmony, as if our melody is tuned and softly playing Mozart's concerto. This moment feels ideal and I take a deep breath as I watch Thomas and Maggie struggle with the tip and bridge of the clay nose. I propose to them, "Can you feel each others' noses to see where the bridge and tip of the nose is. Here feel mine, too." I then ask them, "Do you think you can make the bridge and the tip of teacher Julianne's nose?" They take water and a ball of clay and begin. Once they finish I say to them, "I think your nose looks pretty real to the picture you have." Maggie looks at the clay face and says, "Hey! It's a nose alright." We continue our negotiation, scaffolding, and co-creating process. I share with Suzy later, "While at times this studio teaching session felt like a brain- 
teaser and really hard as to how to negotiate big concepts [such how to make hair or cheeks, who will create what, how to refine an area of the face or revisit a piece that seemed already complete], overall this studio time felt satisfying and deeply engaging for me." I couldn't tell if Suzy agreed and found that Suzy had another story to tell all together.

Rough Stones Polishing One Another: Teachers and Children as Co-Learners.

I am jolted back to my seat as I watch a moment of deterioration between Susan, Merna, and Suzy during the clay face-making process of teacher Julianne. I think about this particularly rare and precious moment in time as my heart sinks from a very high place of work with Thomas and Maggie toward Susan's meltdown in front of Suzy and Merna. Thomas and Maggie have finished their rendition (remaking) of teacher Jackie's face. They seem so happy and content with one anther. They took feedback and suggestions well about what to look for and change in their clay work, their tracings, and their original drawings. In fact, they hardly clarified anything with me at all. They just took verbal suggestions from me, non-verbal (and spoken) cues from one another, and then they moved to the next level of their work by incorporating these ideas into their rendition. I notice that their dialogue is with the clay and their hands and write, "Their interchanges are mostly non-verbal." In the end, they wash their hands, put on some of Suzy's lotion, and get ready to leave.

I turn from them as they go to wash up at the sink and I watch the frustration overcome Susan. Susan and Merna's face is not finished and Susan has burst into tears. Suzy explains to Susan, "You and Merna must decide together how the nose will look Susan, you can't do this alone. Merna's right here and wants to help, too." 
Apparently, I had missed a conflict of interest that was ending badly. I try to help and interject, "Susan, you can come back to work this out when you are ready and calm enough to talk with Merna and Suzy." This makes her angrier and more frustrated

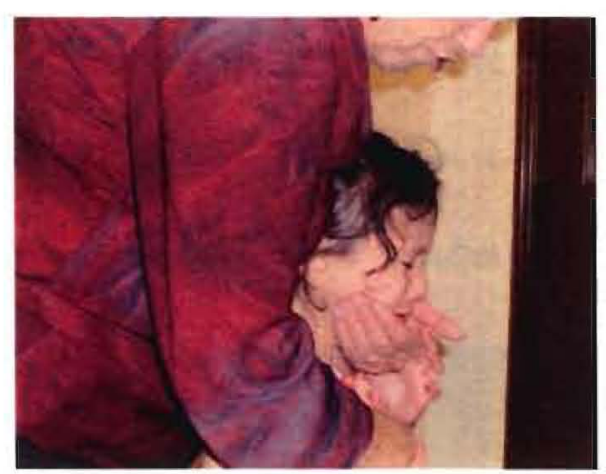

Figure 11. Suzy holding Susan to comfort her as Susan gives way into Suzy's arms. with the work as she looks over at me, grunts, crosses her arms, and stomps her feet harder.

To no avail, Suzy attempts to help calm

Susan until the culmination of Susan's

frustration ends in tears streaming down her

face. Suzy suggests, "Why don't you and

Merna take a break and return to the work at a

later time?" She adds, "It might be a good time to go outside and run off the frustration you're both feeling." As Suzy stands behind Susan and leans over her to see her face, Susan collapses into Suzy's body in relief from the frustration and agony of her disagreement and the sobs subside. Suzy holds Susan tightly as if to say, "I'm here...shhh" (see Figure 11). Merna stands there in disbelief and looks on as the temper tantrum unfolds with Susan (see Figure 12). Suzy explains to me later, "Susan was upset because she wanted to make the nose by herself. Merna was there ready to decide

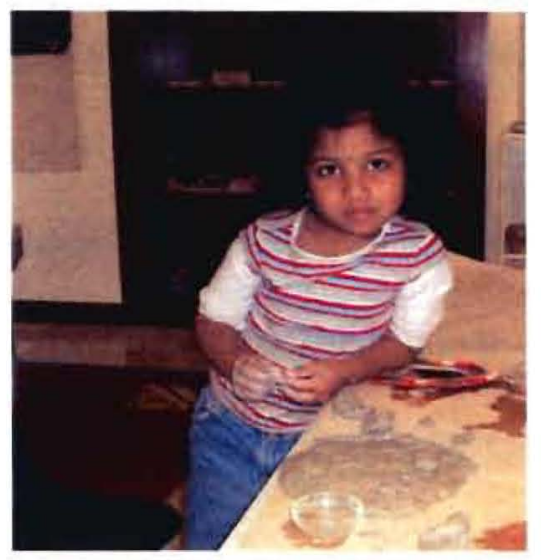

Figure 12. Frustrated Merna looking on as Susan tantrums. how to make the nose. I simply asked them to think about if the nose Susan is making is the same as the nose in the tracing or the photograph of Julianne." I'm assuming 
that Suzy's suggestion and Merna's insistence on co-designing the nose hit a raw nerve with Susan and pushed her over the edge of collaborative possibilities.

\section{Revisit and Reconstruction.}

Suzy comes to me later in the final week and shares several pictures of Susan and Merna working together to finish their face of teacher Julianne. I ask how she got them to cooperate and collaborate to create such an elaborate clay portrait. I look

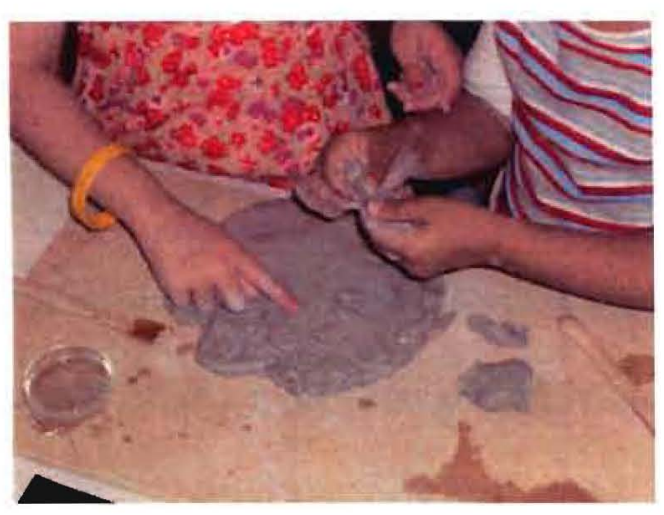

Figure 13. Merna and Susan's hands working together to complete their teacher's face in clay. again at the wonderful curly hair that looks reminiscent of Julianne's true to life form (see Figure 13). My heart begins to sing and I sit in disbelief as Suzy shares Merna, Susan, and her success in overcoming their earlier hardship.

Suzy tells me, "I've apologized to

Susan for making her so upset about the nose." Suzy gives me her voice recorder to hear her conversation in the moment of reconstruction with Susan and Merna. She says, "Susan, I hear that you were mostly angry with me and somewhat with Merna? I'm sorry that you got so upset when I asked you about the look of teacher Jackie's nose." Susan replies, "I know Suzy, I think I overreacted!" Suzy asks Susan and Merna, "Do you think that you can join together again and remake teacher Julianne's face? You'll have to work together this time and we'll keep looking back at the tracing and original picture, but I won't get in the way too much." Suzy reports that they did agree and that this became quite a learning experience for them all. Suzy confirms with me, "Can you believe that Susan used the word "overreacted'? She 
seems so sophisticated at times. It's a mystery how Susan can meltdown like that and then recover with such grace."

Later, Suzy reports to me, "Merna, Susan, and I have worked together more harmoniously than ever before on this final version of teacher Julianne." In this revisit of the face project between them, it seems like a revisit of a friendship and a reconstruction of studio work at the same time. "Revising the project felt good," Suzy states in her e-journal. Suzy also writes, "Susan seems to carefully weigh out each decision as she moved forward with Merna. I was careful as to what I suggested to them, too. I let them work out the details much more." We agree that this is a sharp learning curve for Susan, Merna, and Suzy herself. Suzy has strongly witnessed Susan's artistic expression and individual identity, but she has never seen her cooperatively and synergistically work with another child on such intense collaborative designs until now.

As Suzy and I look back at this experience and I share with her the photo I captured of her holding Susan while Susan is crying. I suggest to Suzy that "revisiting and reinventing (a term I've heard from Lori Gysmar-Ryan of the St. Louis-Reggio Collaborative) is an essential tool of the studio experience. It helps to redevelop the meaning of our past experiences and revitalizes our creative juices of working together toward a common higher good." Suzy says, "And, most importantly, it feels good to go back once in a while and remember to be kind to one another!"

As for teacher Julianne and Jackie's faces, they have been covered with one layer of paint and have been presented to the teachers as a gesture of kindness. More paint layers are to come before the project is fully completed, but the seeds of 
connection between the Ladybug classroom and atelier are now underway. One clear change brought about by this research study is that teachers Julianne and Jackie seem to be paying more attention to the children's work in the studio and one says, "We've displayed their clay face renditions in a prominent location in the classroom for family members, other children, and the general community to take in and ponder." As Suzy reports to me in an e-journal, "Teacher Jackie came to me after a staff meeting and said that she was sorry that she hadn't come to the studio to learn more about our work in there. She was just so busy in her first year of teaching that it escaped her." Suzy also says, "Teacher Jackie wants to plan more meetings between us and co-design the curriculum more. I'm very excited to see where we'll go next. This can affect the children, teachers, and parents, too."

\section{Community Involvement: Parents, Teachers, and Other Children.}

It has been two weeks since Marsha and I were able to reconvene our small group for a final session. In week twelve, my final week with Marsha, we have decided to display the thinking and work about the bird project and see where this reflection and look-back will take us. We have also informed others about our project work display in Marsha's studio and plan to have them come through, look, comment, recreate, make suggestions, and simply join our community of learning experiences.

The air is exciting and Marsha has set up the space in an artful way with the display spread out throughout the studio. Marsha and I envision a deeper understanding of studio work and its importance arriving through this interchange. Marsha asks parents and children to look over the studio display of our work on birds, urban roosts, and the rest of our study and she communicates their responses to me via 
email. I am not available to participate in this exchange, but the work carries on without me. This reality of my absence forces us to think symbolically about our future work. What can carry on about the study of birds in the future as we revisit and continue to engage the community even in my absence? Marsha shares, "I know that answers and more questions are to come through this community process." This is what a parent in our school-community has to say about our work with the children. Sophie's mother reflects back and shares these thoughts with Marsha:

Sophie really seemed to enjoy the group work on birds. She became very aware of birds in the environment. She has always been a feather collector and we have a birdfeeder in the backyard that she enjoys filling. We also have some very noisy crows who seem to be territorial of our yard. Our new house has 3 separate bird nests built in the eaves on the front of the house. Sophie seemed very excited about this. During the bird project we traveled to Central Oregon and we were able to identify some birds that we had not seen in the Valley. We also talked about habitat. The importance of trees and ecosystems to the survival of birds. The way that birds participate in spreading seeds (very exciting to talk about bird poop!) Overall, she seemed to be much more conscious of the presence of birds in her immediate environments. (Personal communication, June 28, 2005)

Another parent had some major reflections to contribute to this community gallery opening as well.

Marvin's experience with the bird study seemed to really open his eyes. We had this science subject to talk about, and the fact that it coincided with a bird 
building a nest above our porch this spring was a great coincidence. We've been able to talk about the work that he did at school, and the whole family has become more aware of the flora and fauna in our surroundings-winged creatures. The other day, several weeks after the study concluded, we happened upon a small lifeless baby bird on the porch. We buried the bird, but not before getting to look at where the feathers would have been and the skeletal form of the bird. Marvin was familiar with the anatomy of the bird as a result of being involved in the project. Marvin's artistic expression seems to have also expanded during this time. I'm real excited about his budding creative expression, and so happy that he has access to the best teaching, the best learning environment, and the best tools and materials in which to create. Thank you for opening his eyes to this beautiful subject, and allowing me too, the opportunity to become more aware of our winged neighbors. (Personal communication, June 28,2005 )

Overall, many parents commented on the importance of this study both to their child and to the rise in quality of time spent within their family's experiences. Other families, whose children were not directly involved in this particular bird project, seemed as interested and commented that their children had picked up on new language (to describe birds and nests) than the parents had ever seen or heard before the onset of the project. Another parent reports to Marsha that she overheard her child talking about the birds he had come to know from listening to the other children in Marsha's group. This parent writes in an email to Marsha: "Why do birds not come to the birdhouse mommy? Why do they not come to eat their food?" and, "What is that 
bird saying? Is it talking to me?" This parent also reports that her child was mimicking the bird's sound in response to the bird singing. Most likely, as Marsha speculates, "This child's awe about birds is due to the movie Winged Migration and the whole preschool wing's exploration of the elements from the film."

In looking back and projecting forward, I think that the visual artistry, the group learning experiences, the tie-in between classroom, parent, child, representative learning, and visual arts with atelierista Marsha is reaching beyond the borders of the school. While I feel the protective membrane between the school and home and the school and community, I know that there is a crossover involving an exchange of ideas, which is shaping the way teachers, children, and families work between these worlds.

Reflecting Back: The Meaning of our Atelier Experiences as a Discussion

"We must reflect with the group in order to arrive at a context that listens." -Atelierista Marsha, Helen Gordon Child Development Center

In this section, we explore our final underlying research question: When we engage in teacher reflection, what are the studio teachers' experiences of the meaning of teaching-learning in the atelier? Answers are revealed in the narrative and the verbal snapshots of the experiences. Teacher reflection is an important factor in informing us, parents, other colleagues, and visitors of our small group's previous thinking and the work in the atelier. As Suzy has stated in her e-journaling, "Teacher reflection is very real. It is a way of getting to know children and families and look at them as individuals." She adds, "I sometimes wonder what they think about Suzy, about me as an individual? I want to see them grow and teach me what they know. At 
times, this makes me feel inadequate." I try to mirror what I am hearing Suzy say, "Reflection can feel scary at times. I wonder if reflection can bring about the vulnerability and listening we need in order to move forward in our work?" We both sit quietly and reflect on these words.

As we continue to explore the ideas of teacher reflection, I notice that Marsha's thinking is on a different path than Suzy's as she responds in her final interview. "To reflect," she pauses, "For me, this makes me think of the value of intentionality." She continues with an example of this intentional listening and explains that is how she selects groups to work together. She listens for their rhythms and their questions about the world around them. Marsha reflects in her e-journal, "Reflection pertains to the child, parent, and the teacher. It forms a better connection with what is going on in the school." Marsha digs even deeper and asks, "How do we expect that parents connect? Without groups and integrated research projects, parents would be hard pressed to understand the visual arts, academics, and socialization of our school context. We must reflect with the group in order to arrive at a context that listens."

Developing a context that listens requires the many venues we have explored already and many more we have yet to try. Currently, Marsha and Suzy tell me that they reflect with the school community by: "Asking parents to review a project and comment on it or to directly experience the project and inform us about their views of it; Meeting with teachers on a weekly basis to reflect back what is happening in the studio and in the classroom; Asking children to explain what they are experiencing in the studios through morning meeting; Documenting commentaries and reviewing 
artifacts and photos as editorial tools; And, by developing both oral and written histories about the work of the atelier, children, atelierista, classroom, home, school and community." As Marsha has stated, "Probably the biggest difference between classroom teacher and me is that I have the time to develop this context. Let's face it; there is a reality that exists for the classroom teacher. Her time is taken up by many daily in-classroom tasks so she should lean on me to develop the community aspects. This is just as I lean on a school coordinator or you to have even more connections outward from the school. It all works in tandem."

After mulling over how to end our time together as researchers, I decide that we need some time to reflect on our work together and live in our context that listens. I give the two studio teachers a chance to read over what I have written in this chapter (they are familiar with my first three chapters already) and in chapter five (themes, conclusions, and future implications). We have come up with a final collaboration session around the stories I have told which include each one of us, separately and in our group dynamic. We have taken the time to review all of the work to date and we shall see where this shared and purposefully developed meaning making session leads us.

\section{Shared Meaning Making.}

We finally sit down together and go over the text I have written. I asked Suzy and Marsha to convene with me one final time to consider our work together and to reflect on the meaning in the stories and text l've retold. As we launch into the conversation I've brought final ideas to throw out to the group to get us thinking. I ask simple questions: What has the text brought to your thinking as your read it? What 
is your experience of reflecting on the text? Suzy begins, "Wow, I can only imagine what must be like for Will. I can only speak for what I feel. The entire chapter four brought tears to my eyes many times. I want to do the project over again. What I mean is I want to apply what I learned from the research. I think what this experience has brought to me is that the parents, the children and the teachers should all be involved in what we are doing! Then, only then, we will be successful!" Marsha continues, "Our school philosophy, including curriculum methods, needs to be fully explained/discussed during orientation and throughout the year, every year." These responses bring about a sense of resolve for me as a researcher participant to continue in some capacity with the studio research. This feels like the will of the studio teachers.

Another idea that comes from this meeting of the minds is around which story is most meaningful and why. Suzy proclaims, "I think the part when I talked about Bumblebee's and Ladybug's room and Marsha talked about the parents. What I see as missing is the parents' input to what I am doing. They are the missing. I don't know how to get them involved when the classroom teachers aren't involved. I think I was more involved in the Bumblebee's room because the classroom teacher was directly linked to what I was doing and vice versa, and the parents were involved in the classroom. I want to directly involve the children, parents, and the classroom teachers. We can work together. We can make it better together...in a new way."

Marsha reflects on this question about the most meaningful story to them and says, "The story of Suzy's feelings on classroom community. It shows the implications of discontinuity/continuity between the studios and classrooms and who contributes to 
the project work and who doesn't." Again, the sentiments and reflections from the studio teachers reinforce the notions put forth in the results and implications of this research. Reflecting back has strengthened the point of view of the research and where the problem areas lay in the make up of the school's ateliers and studio teachers. These problems exist in the system and the research must bring about some ideas for changes through the themes, conclusions, and implications of this work.

\section{Endings, Beginnings, and Continuations.}

At the end of this journey we sit in Marsha's studio with streams of light filtering in down to our table from the clerestory windows above. We discuss the feeling of "being fed and yet unsatisfied at the same time" as our thoughts head down the unknown pathway which lies ahead of us. "It feels like a paradox for us, sad and joyous all at once," someone suggests. We look at one another in silence until Marsha and Suzy ask me about what is next for us. "So, you want me to continue working with you in the studios and also to reframe the meaning of the studio in our school," I think aloud. "This feels like a huge undertaking for us as a group," I say waiting to hear their response and to know their experience as it unfolds between us in the room. Instead, the silence ensues on this topic and we talk about the mundane of our daily lives. One journey is about to come to an end and I think we realize that while we will never be the same three people due to our encounters, a small slice of our work lingers on in the shared meaning of this text. I proclaim, "Somewhere, in the midst of us, it feels as if a larger mind is asking us if maybe we have smoothed our rough edges together?" Marsha suggests, "My learning curve has gone way up due to this research study." Suzy interjects, "I wonder what we'll do next? Marsha and I 
want to work in the Piazza together and create more joyous occasions including the families more." They don't ask me to join them out loud, but I take this to mean that another series of events and more experiences are about to be made into meaning. Is this our ending? Is it a new beginning? Or, is it simply just life continuing on in an ever unfolding web of experience?

Summary: Review of the Research Questions and Results

The initial question for this research study was: What are studio teachers' experiences of teaching-learning in the atelier as they utilize documentation, collaboration, and reflection as a way to inform their practices? As we have demonstrated in the results and discussion chapter, the four areas of development include many experiences retold. They start with knots in the web of experiences, move through the question of why we document and the meaning of pedagogical collaboration, and end with reflecting back on the meaning in the experiences. These areas of development exhibit the experiences outright and answer our broadly framed question through the narratives and photo artifacts.

Informing this primary question are open-ended research provocations. The first underlying question was: When the studio teachers and the researcher engage in the atelier teaching-learning phenomenon, what do we experience? In our first area of development, a strong researcher participant voice is shared and explores disequilibrium in the role of researcher participant in the studio. This voice eventually finds its way to a profound problem through paying closer attention and listening to the two studio teachers during studio sessions. These experiences teach that we can fumble through moments of intense disequilibrium, find research problems such as a 
poorly developed image of the studio teacher in a school, watch children closely and utilize tools to engage them in their learning, come out of our shell and develop relationships, step back to see the teaching-learning experiences more clearly, and develop a different sense of time in the studios.

The second underlying question was: When the studio teachers and researcher participant capture children's learning, what is our meaning and understanding of documentation? Our meaning and understanding of documentation comes through the four narratives retold as experiences in the second area of development. The story of the eyes of an owl conveys that as we document learning, we capture what children are thinking and can help scaffold their learning. We can revisit a way of thinking coming forth from the child and, as Marsha suggests, enact the meta-cognitive field by making "meaning out of her theories together with her." Through this particular story, we come to understand that adults and teachers alike can be co-learners and learn about teaching, about Sophie's ideas of an owl, and about owls in general as we design a panel with the child to showcase her work and her theory.

In the narrative on understanding symbols, the importance of revisiting documents that a child has created comes to light. The studio teachers and researcher participant learn that finding connections in documents over time helps to create a larger understanding of the child's perceptions and representative work. Merna worked to create a drawing of a part of her house. We didn't understand her representation until we saw a picture of her house that her parents gave Suzy. Only by intentionally looking back at Merna's work did we see the connections in her thinking and her representation became clear. In this case, documentation means reviewing 
work and representations over time to develop more complexity in the teachinglearning atmosphere and understand the integrity of the child's work.

In silly gestures, we discover the meaning of letting go as we take photos. We find that we cannot photograph every detail during the experience and that we can only visually capture what we are able and as time and energy permits. The silly gestures felt wonderful between Suzy and me as we made faces at one another and were caught by Maggie. We have captured this moment in our memories, but will not have a visual record of the event. Similarly, in Marsha's studio, I wished I had photographed her tapping the pencil on the clipboard and the children's movements and engagements with one another as they created urban roosts. In order to recapture these moments, we would need to revisit them and play act them out to take pictures of the events since these moments are visually lost to my inability to take pictures quickly enough in the original moment. We learned that sometimes the act of documenting becomes unmanageable in the moment and that revisiting is essential to determine what is important in the events and what can remain unrecorded.

In the photo gallery, documentation came to mean giving ourselves time to collaborate on and think about what we were creating from the learning we had seen. Documentation also came to mean that we can frame studio teaching-learning and experiences in so many complex ways given the documents we had before us and that we must remain flexible about ideas we generate. Gestures in the studio became important and we encountered anxiety as we hoped to share something we deemed meaningful with others. 
The third underlying question was: When the studio teachers and researcher get together to discuss the children's learning and work, what is our experience and our meaning of collaboration? Collaboration was a struggle from the beginning of this study on many levels ranging from child-to-child, teacher-to-child, parent-toteacher, and teacher-to-teacher. The studio teachers' and researcher's meaning of collaboration stemmed from our work and deliberate time commitments we held to over the course of the study. The studio teachers felt they were rough stones polishing one another as they worked with other staff, children, and parents.

First, Suzy reported feeling isolated from the classrooms and other teachers and parents with the Ladybug experiences. She shared this with us in each of our collaboration sessions. Then, she struggled with Merna and Susan to make a connection between the three of them and also between the classroom and studio. Finally, as Merna, Suzy, and Susan kept revisiting their relationship and experiences, they succeeded in a communication breakthrough and moved toward a collaborative spirit. Merna, Suzy and Susan were able to reconstruct their face project together through apologies, commitment to the work, and open communication. Suzy and the Ladybug teachers developed an interest in each others work and began to listen and discuss possibilities of collaboration slowly and over time.

Other meanings of collaboration came through the parent and teacher interactions and events that were shared by Marsha and me in our collaborative sessions and in our reflective discussions after studio sessions. Marsha and I struggled with a parent and witnessed a need to open the doors of communication between the parent and us to establish trust and relationship around working in the studio. Marsha 
also invited parents and other community members to reflect on their understanding of the research events, even those who were not directly involved with our project. Marsha, Suzy and I learned that by asking questions, taking the time to come together, listening deeply, making kind gestures, and continuing to revisit our collaborative work together as a small group to articulate the challenges, we developed our meaning of collaboration.

The fourth and final underlying question was: When we engage in teacher reflection, what are the studio teachers' experiences of the meaning of teachinglearning in the atelier? This research study purposefully engaged the two studio teachers and researcher participant in teacher reflection and shared meaning making. An early version of chapters four and five were distributed among the three research participants and then we came together to collaborate and reflect back the meaning in the experiences. In our reflections, we learned that we could develop shared meanings, and that endings are sometimes new beginnings or simply continuations of an event.

The experiences of the meaning of teaching-learning in the atelier became clear as Suzy shares, "What I see as missing is the parents' input into what I'm doing. I don't know how to get them involved when the classroom teachers aren't involved. I want to directly involve the children, parents, and the classroom teachers. We can work together." It takes all of us, parents, teachers, and children to engage in the teaching-learning process. What we learn through our experiences of documenting, collaborating on, and reflecting about is what we teach. What we teach is what we learn about in the atelier. These two notions become central concepts of our meaning together. Reflecting on our time and experiences has helped us to remember the 
importance of our teaching-learning project and we can see the thread of possibilities into future creative research endeavors.

In sum, studying the experiences of studio teaching and the four underlying questions about experience, documentation, collaboration, and reflection have provoked a powerful revisit of the lived experience phenomenon with Suzy, Marsha and me. In clarifying the narratives and finding answers to our questions, we uncover the themes, conclusions, and implications to this research study. Our lives are forevermore changed by the results of this phenomenological research. Our endings bubble up many essential themes of the results, possibilities for future research, and conclusions spilling into future dramatic events in the life of the studios and the school. We now know that experiences are not something to just sit back and watch but to engage in and make more life out of them, and to remember that living this way creates wonder in the events. 
Chapter Five: Themes, Conclusions, and Future Implications

The experiences and meaning-making in the studios have brought Marsha, Suzy and me much closer together in our thinking. We are clear about our ideal that the studios must begin to play a strong role of in the life of the school. We wish for the ateliers and studio teachers to act as connectors to the classroom, outdoor, theater, reuse center, and central piazza experiences as well as to all other neighboring spaces through the documentation, collaboration, and reflection, engaging all people in the school. We uncover a yearning for the atelier to be the hub to the spokes on the school wheel and the studio teachers to bring forth the visual and aesthetics arts and to promote inquiry and theory-building across the school. Yet our experiences conclude that the studio and studio teachers are not currently considered that way in the life of the school and this brings forth other problematic findings and strategic implications.

We have uncovered revealing essential themes, which are central to our work as atelieriste and researchers of young children's work and thinking as we have journeyed through the art studio encounters. Throughout our many experiences, we have come upon several conclusions and implications for future study. These conclusions and implications appear through the essential themes in our research study: life eats entropy; serendipity and synergy; the image of the child as a connection to all images in the school; engagement in the studio-engagement in the classrooms; scaffolding and social constructivism; intersubjectivity, phenomenology, and the meaning of wholes; and the role of the atelierista, pedagogista and school organization. This is the moment of departure from the current study of studio 
experiences into the unknown that propels us toward the conclusions and implications in these essential themes.

The studio teachers and I leave the precious moments of our time together in the background and move toward a more profound existence-forever-more changed. I see Marsha, Suzy, and I jumping off of the edge of all that we have known before us. As we leap, I remember one key phrase I've learned along the way of my life's passage. As we bound into the unknown, faith is knowing one of two things will happen, we will land on solid ground or we will be taught how to fly. Here are key patterns (themes) which lead us toward our next flying adventures. The patterns are a trajectory built from remembering and revisiting our past experiences and moving towards more life and a generosity of experiences.

\section{Life Eats Entropy}

I have recently listened to an old cassette tape about the future of our humanity as described by Barbara Marx Hubbard (1997), author of Revelations and 1984 candidate for vice president of the United States of America. Her interpretation of life is that it eats entropy (the random disorder and deterioration) we sometimes encounter. "Life eats entropy," (Cassette Tape, side A) she states twice in her microphone from her 1997 speech on conscious evolution. Something in this statement seems profoundly interesting to my work in the studios with Marsha and Suzy. I have encountered random disorder time and again in this research study and I have watched it turn into experiences full of meaning. With this thought in mind, I search out my copy of the book, A Simpler Way, by Wheatley and Kellner-Rogers (1996). I open it directly to the page on the complexity of order in life where the word emergence is 
significant. There is something familiar in this book to the statement of "life eats entropy" by Hubbard (1997) and it is framed around order or the emergence of life.

Emergence is a common phenomenon found everywhere in life. Social insects are a particularly stunning example. The tower-building termites of Africa and Australia accomplish little when they act alone; they dig only lowly piles of dirt. But as they attract other termites to their vicinity, a collective forms. As a group, they become builders of immense towers. (p. 68).

We wish for the studio to become the heart and hearth of the school and a place where the work occurs in relationship with others as a group study. This group work creates order and more complexity in our researching experiences. Through the messy work of our small assembly of children and teachers studying nests or dwellings, we find a higher order of thinking. In our journey we moved toward a full life experience of birds, the eggs, hatching, food, mamas, and home, or dwellings, family, self, and school, and much more in an artistic and visual way. Did we know this is where we would go in the beginning? I think we found ourselves on a journey, with backpacks full of goodies (studio'tools, applications, and ideas), plotting our course as we walked our pathway (documenting), stopping to look over our work (collaborating), and reviewing where we came from (reflection) to map where we were going next (projection of the project). The energy of our work has built on itself and through many minds (intersubjectively) organized around a central concept. The life of our project has devoured the random disorder.

Additionally, as I started my studio experiences confused and lost, I finally came through it by way of beauty, time, and deep listening or by the experience itself 
organizing into higher order. Life ate entropy in my personal journey of studio involvement and of coming to meaning-making in the studio. It seems important to remember this simple concept of life eating entropy as a way to reformulate all of our muddled human experiences when we are living in the mess of disequilibrium. The studio teachers and I are finding this moment of disequilibrium (of where the ateliers and studio teachers fit and don't fit in the larger vision of the school) a challenge to our sense of growth, well-being, and psyches.

However, we have made meaning by organizing with one another around a subject matter -the experiences in the studios. We have found this problem of the studio teachers' misunderstood role and underdeveloped image in the school and are seeking solutions and desiring to watch life eat entropy. Our sense of the subject we studied - the experiences of studio teaching utilizing documentation, collaboration, and reflection - came to life in our mind's eye, more and more as we visited and revisited a study of something great such as nests (birds, eggs, etc.), dwellings (family, identity, self, clay, and school), and the studio teachers' experiences (beauty, time, deep listening). Palmer's (1998) idea in The Courage to Teach of sitting at the round table as a co-learner studying a subject (studio teaching experiences) together becomes vital to our work as we look back over and make sense and meaning of our experiences. We constructed meaning together and we developed a capacity to listen and understand the subject and each other more profoundly. We may be in crisis with the identity and role of the studio and its teachers, but we are listening deeply and finding the emergence of the studio teacher's meaning in the life of the school. 
Serendipity and Synergy

In planning for each of the interviews as a way to construct thoughtful meaning together, I anticipated different responses from each studio teacher. Without any prompting and a great deal of listening, what I found was such a similarity between Marsha and Suzy's response in regard to their frustration and the image of the atelierista and atelier from other staff. Moments of chance (serendipity) are fundamental to a phenomenological research approach and to capturing these studio teachers' experiences. Serendipity happens as we look for something else but find what we need at the precise moment we are ready to accept its gift. Suzy, Marsha, and I found what we needed at the particular moment in our study just as if it were called forth for us to unearth.

Early in the research gathering, Marsha and Suzy separately explored the notion of a current unsatisfactory design in their studio teacher role as I asked them to share their experiences of studio teaching. Marsha shares, "Teachers around you can create a negative influence with their attitude toward the studio." Suzy agrees, "Everything revolves around the experiences. It can affect us positively or negatively. Do the teachers care? It feels like a lack of respect for us." As we expanded on this concept together throughout the data gathering phase, we realized that we had the power to redesign and more clearly state our intentions and vision behind the ateliers and the studio teachers' function in the life of the school. We also realized that this can take some heavy collaborative work with others to not only set the stage for a new emergence of the atelier/atelierista roles, but also to follow through on this vision together, knowing that we'll grow and make mistakes along the way. 
Due to the unexpected events in the interviews, a gift of synergy for the school vision occurred. Through Suzy and Marsha's separate disclosure and overtly spoken frustration with the school's treatment (non-recognition of importance) of the ateliers and the studio teachers, we bonded, discussed, brainstormed on, and re-envisioned the priority that the school places on these laboratories of learning.

This research into recognizing serendipitous moments and acting on them synergistically has far reaching consequences for the children, teachers, families, and all of us at the center. Profound conclusions came about as we honed a deeper meaning through coming together as researchers, finding our voices in the stories, and making meaning of the lessons of the studio experiences. In the simple acts of finding moments of clarity between minds and beginning to use synergy to develop ourselves into teacher researchers, we have experienced the desire for the atelier to become a central character in the life of the school for teachers, parents, and children and we have come to recognize the gloomy frustration that the atelier is not yet developed this way.

Thus, through reflective practices, documentation, and collaboration, our meaning-making has formulated an unexplored role for the significance of a laboratory of learning. These practices have shown us a way toward a different type of laboratory space (the atelier) where children, teachers, and parents' group work can come together under community learning, shared meaning-making, and the visual arts. This concept is fundamentally different than a classroom space where children and teachers live their days and ordinary moments and explore both broad and specific theories of childhood. The studio is designed as a space away to learn to play with and 
represent everyday theories more specifically through the visual arts. We must begin to make this focused laboratory a living reality in all parts of the school, where theorybuilding and creative languages emerge in addition to the everyday and ordinary moments of typical classroom life. We aspire to reformulate the studio teachers into a conduit of these practices which flow between the classrooms, hallways, and homes so that the community can learn together around a provocative subject.

As I come to the conclusion of my research experience with Marsha and Suzy, a newly published book written about Reggio-inspired studios comes across my desk. I grasp for the perfect words to say about how big the studio experiences have felt for the three principal investigators of this study, Suzy, Marsha and me. Instead, on the first page of this most important and new work, the words are already spoken for me. In The Spirit of the Studio (2005), Loris Malaguzzi is best quoted as saying:

I will not hide from you how much hope we invested in the introduction of the atelier. We knew it would be impossible to ask for anything more. Yet, if we could have done so we would have gone further still by creating a school made entirely of laboratories similar to the atelier. We would have constructed a new type of school made of spaces where the hands of children could be active for messing about. With no possibility of boredom, hands and minds would engage each other with great, liberating merriment in a way ordained by biology and evolution. (p. 1)

I find Malaguzzi's quote comes to us at the best of moments and inspires us to courageously continue on the journey of seeking out the unexpected. Serendipity is at its finest hour in the life of this research project. Reading Malaguzzi's words about 
the school and atelier relationship, we can find our big idea (albeit currently unrealized) represented and it feels similar to Bateson's (1994) "coming-home" experience for me. I revel in Malaguzzi's expressions and think, how will his vision propel me and who will take the next journey with me? I can feel the synergy building up all around the school as we take flight into our unknown laboratories of learning. The Labybug teachers (and others) have asked how they can help to clarify Suzy's, Marsha's, and the studios' roles to make Malaguzzi's vision a reality. They have asked, "Where do we begin to make these changes?" They are seeking new possibilities together as we come to closure in this research project. The Image of the Child as a Connection to All Images in School

What is unknown about childhood? How much do we understand about the images we carry around in our heads related to life and learning of children? One of the largest impacts of this studio teacher study comes from witnessing and discussing the work of the atelierista and the children together. Working from a place of only seeking out the commonplace experiences to then refocusing on the important and sometimes invisible elephant in the room, involved a process of listening to and learning from the children's everyday and common moments with us in the studio. Midway through our data collection phase, Marsha and Suzy both redirected two children who saw themselves as incapable of accomplishing what they thought was their "studio task." In Marsha and Suzy's view, both Thomas and Marvin possessed the quality of mind to move into their own creative expressions of the work and ideas that were offered to them. I had to ask myself what it must feel like to be a teacher standing in front of competent children. Additionally, how can we sustain this 
practice of listening and balance when to speak up and make suggestions to children? I then realized that as we reframe our view and know that we teach from a place of believing in the capabilities of the "other," we change how we respond and react in our moments with our co-learners. We teach one another as we listen to our grandest desire to want to know how-how to draw a bird, how to make a face in clay, and how to experience the atelier as the atelierista does.

The image of the competent child changes the substance of the image of the teacher. As we take note of children's competence, we (teachers) reframe our approach and engagement in their school-work, materials usage, what we ask them to look for, think about, and create. We also slow ourselves down enough to pay attention to our own thoughts, words, and commitments of the day. These notions make me think of Marsha's and my experience with Terrey and the owl wing he colored out of Cray Pas. In slowing down to listen, we had a focused moment. I decided not to interrupt his process too much. In the moment of making my decision to watch and listen silently, I felt as if my brain and eyes rapidly come to focussimilar to an out-of-focus film reel or a fuzzy picture when suddenly un-blurred. I take a step back from Terrey's work as I finally see his consideration of the owl in whole rather than in parts. I see Terrey, a book with a flying owl picture, with the left wing spread out and I notice a sketched-out golden circle with a large oblongshaped golden outline stretched out to the left. Terrey is drawing an incredible portrait of this picture of a flying owl. I simply stand there in amazement unable to respond at first. Then I grab my camera and take several pictures and ask Marsha to come over 
and see Terrey's work. With a double-take and profound stare, we found Terrey's elephant in the middle of the room, silently gazing at us and asking to be seen.

At the Opal School Symposium, Judy Graves informs me that she sees children as "conduits of energy and ideas, rather than empty vessels seeking knowledge" (Personal communication, June 24, 2005). If this is a more authentic expression of the image of the child in schools, we have to think about what the image of the teacher must be. It must include a researcher, a co-learner, a listener, a documenter, collaborator, and person who reflects on the teaching-learning. What of the other images? The image of the parent, the school, the society, and the image of the atelier? These questions must be examined and answered in many ways through the considerate act of listening carefully for the precious moments in the everyday experiences with these characters and in these spaces.

This way of listening in our teaching-learning experiences is hard work and not something that we can accomplish over night. We cannot expect to always be in this zone of listening in our everyday practices. However, if we see the child as competent in front of us, then we can act, respond, and relate in solidarity and competence as a teacher-learner ourselves. We must ask ourselves, "How can we listen even when it is hard to stay focused?" This is an important question because our image of the child will shift our image as teacher when we practice and engage the act of listening and looking deeply for the extra-ordinary in the ordinary moments.

\section{Engagement in the Studio-Engagement in the Classrooms}

Through this body of work, the studio teachers and I hope others can see the importance of studying the role and image of the atelier and atelierista as these sacred 
spaces are created in other schools. The interconnectedness of the studio and atelierista to the rest of the school remains to be seen, even for us. We know it exists and early in the investigation we uncovered elements of the studio teachers' frustration of the interpretation of their role as it relates to the classrooms in our school. The separation between studio and classroom (and atelierista and classroom teacher) is still strong, but it can diminish as the school's faculty plan to vision a new "way" of working through collaboration and a clear revisit of the atelier and atelierista role. Cadwell's (2003) idea of polishing our rough edges to create smooth stones bodes well in this study. Rodgers, Anderson, Conley, LeVasseur, and Turpin (1993) have suggested, "In addition to creating a safe place to grow, I wanted to dissolve the membrane of isolation I knew new faculty operated behind." In our school we are all five-years new to this central concept of collaboration as a way to dissolve our separation. We thought that we were teachers who worked on our own islands and mostly still practice in this way. We hope that through the atelier and atelierista we can provide a shift in this individualist way of thinking and working. We know that we can not continue teaching-learning practices in isolation and flourish a school. Schools exist so the collective mind can grow and diversify its thinking and patterns of living.

At this time, it is important for the school faculty to engage the families, other staff members, and us all in a strong cause for relationship. Teachers, atelierista, family members, and children must collaborate to formulate a school experience. It takes one-hundred, one million languages to explore the meaning of school-life and to study in-depth about such important topics as birds, urban roosts, families, dwellings, 
and identity and so forth. How do we recognize ourselves as participators in this ever unfolding web of experiences? In our understanding, we know that we powerfully make our meaning together and through visual arts and representative work. We must look for the knots in the web of experiences melodiously and we recognize that we must work through conflict and the pain of isolation, as in Suzy's case. We are a collective mind engaged in a process of studio teaching ways which shall someday spill themselves back and forth from classroom and studio to hallway and home. As this vision has yet to actualize in our program, we recognize that more research and seeking out problems are in order. To capitalize on our documents and images could propel us toward meaning making and deeper shared understanding of the studio teaching experiences and phenomenon.

\section{Scaffolding and Social Constructivism}

Suzy, Marsha and I worked to form study groups within our larger groups as they sometimes do in Reggio Emilia. "Reggio Educators frequently set up initial exploration of a topic in which they can observe which children show the greatest interest and enthusiasm before forming a learning group" (Giudici, Rinaldi, \& Krechevsky, 2001, p. 291). This concept of choosing certain groups of children to engage seems to be about scaffolding and level of interest for Suzy and Marsha. We have sought out ways to pin one child's expertise to another child's interest in growth when we observe that they are not doing this on their own or naturally. Again, as Hendrick (1997) points out, a collaborative approach to learning utilizes "Vygotsky's perspective emphasizing the use of guidance and modeling in a social setting" (p. 82). 
As in the final face project with Suzy where we constructed the teachers' faces, we managed to consider, ponder, and design the project around the individuals who were taking the journey with one another and us. The questions we had to ask ourselves again and again were: "What strengths did the children have when we reflected on the materials we were about to ask them to explore? Which child(ren) needed help coming to understand this way of working together and functioning with the available tools? Would it serve the learning best to have them self-select into smaller groups for completing this work or could we optimize the experience by more formal selection of small groups from our observations?" These questions are not lightly taken into consideration when completing group work with children. In Suzy's case with Merna and Susan, a big question was, "Did Suzy make the right choice to select the children into subgroups without asking for their ideas of who could work together and why?" The answer seems to rest within both the process and the results of the group project and comes after the fact. This may be problematic and something for which the studio teachers and classroom teachers need to consider developing a protocol.

It was clear we did not foresee the struggle between Susan, Suzy, and Merna about how to work together and make the clay nose and how to accept feedback, but this incident was such a learning lesson for us all. To make meaning of this event, we reflect back on a fundamental construct set forth by Malaguzzi. "It is important for pedagogy not to be the prisoner of too much certainty, but instead to be aware of both the relativity of its powers and the difficulties of translating its ideals into practice" (Edwards et al., 1993, p. 51). Susan had been able to create with the artistic media we 
had been supplying, but her work was always alone and in isolation. While she had picked up bits and pieces of tools and applications for her own process of working the blocks in the dwellings and the clay in the face project, she was more of the demonstrator for others to follow. She was a leader and it seemed difficult for her to let others (Merna and Suzy) have a voice, and for her to take feedback from Suzy and Merna. Scaffolding her ability to work as a team member was a goal for Suzy and me. The social constructivist perspective which staggered us became Susan's disequilibrium and subsequent tantrum when trying to construct knowledge in an overtly social way. Her anger with Suzy's suggestions and her inability to continue the work with Merna got in her way of communicating and co-constructing ideas and the features of the face.

In the end, was Suzy right to interject her ideas and ask Susan to rethink her theory of the nose and hair? The studio teachers have walked a fine line in knowing when to act, when to collaborate with a child and their theories, and when to let them just be in the moment with the materials. Merna was seeking some help in coauthoring and co-designing the face and Susan was not used to being a listener and coproducer. Suzy felt bad for interrupting their process, but also felt the necessity to help Merna and Susan to find another way to share ideas. She felt like she was walking "a fine line" and I see this type of choice as a critical paradox in studio teaching.

In this research study, the questions of scaffolding and social constructivism revolve around the interpretation and meaning in each of our experiences. Our consideration of theory rests in the notion that we must understand broad theoretical 
implications of the learning theorists and educators such as Piaget, Vygotsky, Dewey, Malaguzzi, Ciari, and others. And, we need to keep an ever widening eye on the children themselves. Malaguzzi best states this theoretical perspective this way, "A unifying theory of education that sums up all the phenomena of educating does not (and never will) exist" (Edwards et al., 1993, p. 81). For in the children, we will find the surprise that exists inside of the theory, which may move us beyond the original theory's borders, suggesting ideas far greater than we have ever known before in our experiences. For Merna, Susan, and Suzy, we have to ask ourselves, what was the surprise in their teaching-learning experience? The data show that they learn to overcome barriers, that they see Suzy's frailties, and that they can forgive and move on to collaborate at new levels of the work. What happened for Susan, Merna, and Suzy in this experience? Is it that they all become co-learners, learning and teaching one another? I think the answers move us beyond theory and into the meaning of the particular experience as it unfolded for the participants.

Intersubjectivity, Phenomenology, and the Meaning of Wholes

Intersubjectivity and phenomenology walk arm-in-arm in this study. What meaning did we construct through the experiences we encountered? The data show a strong connection between participants in making shared meaning of our experiences. We worked to build a capacity to move toward a third mind that was greater than any one mind alone. We felt that this endeavor must be our group teaching-learning process in schools today. "Each subject, then, is a construction (self-constructed and socially constructed) that is defined with a specific context and culture" (Giudici, Rinaldi, \& Krechevsky, 2001, p. 39). 
We understand that we all have differences in the way we come to know and how we express ourselves. This matter of intersubjectivity is not a problem of difference; difference in and of itself is just what it is, a diverse perspective, a way of being or knowing the world, and a way of coming to the work. It is how the society or school treats the difference and the person to which the difference belongs that concerns our experience. It is the treatment of the person as a whole subject with their own life story through which we can share and make meaning together that matters.

If our questions of research fundamentally seek our and share experiences and to make meaning of them (phenomenology), then our schools must treat the differences we encounter as a context or whole-meaning experience and not decontextualized into only parts of a meaning. When we learn to let experience between people grow into full meaning based on intersubjective understanding (rather than look at it as fragments, we create third mindedness), we more fully arrive at an intersubjective understanding between participants. To conduct ourselves in this way means that we maintain the powerful connection between us as human subjects by collaborating, listening, documenting, and revisiting. Our experiences become framed in more complete wholes and not splinters of the experience.

As in the case with the parent who visited the atelier with Marsha and me, we did not come to know him and maintained only parts of the meaning of our encounter. A parent joined us for the egg hatching theory session and Marsha noticed his level of discomfort around his unspoken role within the activity. He hovered over his child and the small group he joined. Marsha and I took notice of the way the group of children with this hovering adult was laughing and talking, but not really "telling" 
each other stories because, as Marsha later shared, "The parent was interjecting, hovering, and leading the group way too much." This parent fairly abruptly left the studio without any interaction with Marsha and me and we felt this was unusual. Marsha turned to me and said, "Adults don't know what to do! Not just teachers! Adults."

In this encounter, Marsha and I did not maintain a powerful connection between us and the parent who abruptly left the room. We wonder what he thinks of this encounter and until we know his story, we will only carry with us a fragment of the experience. An experience that is not revisited and reviewed between teachers and parent is one which forms a feeling of disconnection and causes a dense fog around our relationship with them. This disengagement is not a good feeling in the school and it helps maintain the isolation and fragmentation between spaces, learning, and groups or individual protagonists.

Another case in this study where experiences become framed in more complete wholes and not splinters includes the encounter between Merna, Susan, and Suzy. As they worked together, struggled to understand each others' meaning of the facemaking experience, fell apart and could no longer talk to work out their differences in ideas, took a break, came back together, revisited their experience of frustration and hurt feelings, and reconstructed their project, they grew an idea of "thirdness" which began to exist inside and between them mentally as they revisited their experience. They developed a mutual sharing of meanings and built shared contextualized understandings of their work-coming to know the other more fully. 
Moreover, it is in my ability to share this work with Suzy and Marsha that we construct meaning. We build a deeper understanding of our work together this way. This meaning-making process of sharing is similar to the story of Marsha and the parents whom we hear from in the reflections of the bird project. The parent gives Marsha meaning of the child's learning experiences of birds from home. As in the case with Marvin's mother, she states, "Thank you for opening his eyes to this beautiful subject, and allowing me too, the opportunity to become more aware of our winged neighbors" (Personal communication, June 28, 2005). Parents walked away from the bird project with their own understanding looking through their child's eyes. This level of reflection, interpretation, and collaboration between parent and teacher changes the images we carry of the child, the studio teacher, and of the parent.

Additionally, if the reader were not reading this material, these words would serve no purpose. They build meaning because the reader gives meaning to the set of words, ergo intersubjectivity at work between reader and researcher mediated through the text. Every reader also takes away their own interpretation of the reading because they came to read these pages through their own lens of experiences. Thus, these interactions construct third-mindedness. This belief in intersubjectivity (thirdmindedness) is the reason why we forged a gallery of photos and belabored the issue of what to share from our experience in the photographs. We can only hope the reader experiences the photos as a way to their own meaning-making of our events. In this way, the phenomenon remains unique and more than what was known before it at the same time. 
Through the built-in organizational tools of documentation, collaboration and especially reflection we find that we can come to a new existence and help others to see the importance of the visual arts, group and co-learning events, connection with parents, and community building as they appear through the atelier and are authored by the studio teachers and community around them. Therefore, documenting experiences and collaborating and reflecting on the phenomenon allow the image of the studio and studio teachers to take form. Imagine the implication of hundreds of schools documenting, collaborating, and reflecting on the process of learning in a school-context willing to listen to the voices of its participants. It would all look different based on the context, but it would have an overall significance greater than what we experience now. This utopia would mean not only for the pedagogical image of school but also for our broader societal image of the child, teacher, atelierista, parent, and school, that we could grow with children toward new and creative ways of seeing, understanding and representing the world.

The Role of the Atelierista, Pedagogista and School Organization Currently, the Helen Gordon Child Development Center has a host of administrative functions performed by many folks directly in the school. In Reggio Emilia, the administrative duties of the Municipal schools such as enrollment, hiring, budgeting, and staffing are centrally completed and separated from the daily functioning of the schools themselves. The organizational structure of the Municipal preprimary schools in Reggio Emilia include co-teachers, an atelierista, cooks, housekeepers, and parents at each school. A pedagogical coordinator moves between 
several schools and collaborates with the teachers, atelierista, and parents on school curriculum each month.

Organizationally speaking, there is not a central pedagogical role that hones the theoretical framework of Helen Gordon Child Development Center's vision through the participation of many voices (teachers, parents, children, atelierista, etc.) in the school. This is completed more randomly and by many separate voices. One major implication for the local community in which this research was situated rests in a role found in the preprimary schools of Reggio Emilia and performed by the Pedagogista. This central protagonist's function in the school merits research and formal study as much as the atelierista's role has received.

The pedagogista (pedagogical coordinator of services) serves as liaison between parents, teachers, atelierista, and the work of the children. "We have a team of Pedagogisti to facilitate interpersonal connection and to consider both the overall ideas and the details" (Edwards et al., 1998, p. 64). As researcher, I believe that I played out a part of this pedagogical role in our research study. Uncovering collaborative elements of the studio teachers' experiences such as the communications between staff, atelierista, and parent was paramount in this research study. As well, I found myself envisioning the project work with the studio teachers and children, researching the experiences, and documenting the documenter. I think the idea of a pedagogical role working across several schools warrants more investigation.

Suzy and Marsha asked me on several occasions to continue to study with them even after this study is over. The implication at Helen Gordon Center and in the greater Portland early childhood community is immeasurable for an expanded version 
of the pedagogical role I played, which would include parent-work and communicate the images and visions put forth by the classrooms, studios, and other shared spaces within the school as well as forge a vision between schools and in the larger community. Helen Gordon Center could benefit in immeasurable ways by organizing itself around the central concepts of the work put forth in this document such as documentation, collaboration, and reflection on teaching-learning. It could also prosper from a continuous revisit and re-search of the studio teacher experiences, which could lead to many other central concepts to actualize such as this notion of pedagogista.

The organization of a school, ranging from how materials are presented and placed to which person plays what role in the living and breathing experience of school is a fundamental value in determining the length of life of an atelier entity or any space, vision, protagonist, or idea in the school.

The school, for us, is a place where, first and foremost, values are transmitted, discussed, and constructed. The term education is therefore closely correlated with the concept of values, where 'to educate' also means - and in certain respects primarily means--to educate the intrinsic values of each individual and each culture, in order to make these values extrinsic, visible, conscious, and shareable. (Giudici, Rinaldi, \& Krechevsky, 2001, p. 38) The value of school organization is a broad subject matter and deserves detailed attention from both the participants who inhabit the school and the community members who surround this sacred place for children. 
I have come to believe that the atelier and atelierista deserve central billing in the organizational structure of a school which practices documentation, collaboration, and reflection as a set of values strongly held in the center of the roundtable. As the results indicate, teaching-learning can become paramount not only in the studio spaces and classrooms, but all over the school and in the children's homes and surroundings. In The Spirit of the Studio (2005), Carla Rinaldi states:

The atelier brought another difference into the school and pushed the idea of diversity to the utmost, encouraging a new pedagogy that would highlight the subjectivity [and interconnectivity] of the child. Considering the atelier as a metaphor, I like to say (and I'm not the only one) that the whole school has to be a large atelier, where children and adults find their voices in a school that is transformed into a great laboratory of research and reflection. (p. 170) These words ring out as a valuable construct for organizing the next stages of growth at the Helen Gordon Child Development Center. This work would clearly imply a group effort and participation on many levels and it moves the organization away from fragmentation, isolation, and separation between classrooms, "shared spaces," and the studio. It is not solely the studio teachers' charge to construct a deep and meaningful group learning experiences; this must appear in concert with each school participant, child, parent, teacher, administrator, cooks, housekeeper, and studio teacher and in each school space.

As Suzy and I found in the faces (identity) gift and Marsha and I came to in the Winged Migration sharing, when we work together mindfully to try and engage and connect with others we begin to find the rewards of connection. In the moments of 
sharing the experience of face making with Suzy and the children, I quietly thought, "Is this collaboration between the children the gift to the teachers and the children, or is the clay face a gift to the school?" And, when Marsha was gathering parent feedback about the study of birds, I wondered, "How can we engage the parents and teachers even more in these studies and projects?" Maybe, in effect, the studio is the gift which brings forth documentation, collaboration, reflection, and research problems of the classroom teacher, parents, and studio teacher's work together with children. It feels like the birthing of a new era in the school for Suzy and Marsha as they suggest to me casually that we lead the center in this pedagogical vision of collaboration, reflection, and documentation to further the rights of children and move away from our isolation.

\section{Closing Reflections}

As we develop our school context, a school that listens for the rhythms of the children's thinking and work, as well as to the needs and desires of the teachers and parents work and thinking, we become something more than we were before. The implications of this body of research and the many valuable stories herein presented bring forth more deliberation. We deserve the time to think about our journey and the theories we build as teachers of young children. We must not waiver from an ecosystem which stimulates "a sort of psychic skin, an energy-giving second skin made of writings, images, materials, objects, and colors, which reveals the presence of the children [staff, parents, community] even in their absence" (Ceppi \& Zinni, 1998, p. 16). And, we must carve out our "third mind" spaces for meeting up to work within 
each others' thinking, and grapple and toil in the labor of loving children and school community.

Our implications are vast and varied, but all connect centrally to taking care of our work within a children's school. We must think about the competence of children and their rights to be citizens from the time they are born. When teachers turn their attention to this, we begin to see a more matured understanding of the invisible elephant standing in the middle of the room. It makes us prepare the space for the image of teaching-learning and learning-teaching. We become competent teachers standing in front of competent children and this competence shifts the problematic image of the teacher, child, and school. We grow to be the teachers we always wanted standing before us when we were children. We were once children in the moment of digging up worms, thinking about how birdies grow in their mama's bellies, and developing our eyes, noses, mouths, ears, hair, chins, cheeks, and eyebrows. Our identity begins to take hold of us and soars our teaching and learning self into the unknown as we practice creative acts of love using techniques, ideas, and wonderings from the experiences of a researcher participant, two studio teachers, and their ateliers. 
References

Administration for Children and Families. (2001). Head Start FACES: Longitudinal findings on program performance: Third Progress Report, U.S. Department of Health and Human Services. Retrieved November 11, 2004, from http://www.acf.hhs.gov/programs/core/pubs_reports/faces/PMC3rdReport.pdf

Barazzoni, R. (2000). Brick by brick (Reggio Children, Trans.). Reggio Emilia, Italy: Reggio Children. (Original work published 1995)

Bateson, M.C. (1994). Peripheral visions: Learning along the way. New York: Harper Collins Publishers.

Berk, L., \& Winsler A. (1995). Scaffolding children's learning: Vygotsky and early childhood education. Washington, DC: National Association for the Education of Young Children.

Blakely, E., \& Spence, S. (1990). Developing metacognition. Syracuse, NY: ERIC Clearinghouse on Information Resources. (ERIC Document Reproduction Services No. ED327218)

Bullard, J., \& Bullock, J.R. (2002) Modeling collaboration, in-depth projects, and cognitive discourse: A Reggio Emilia and project approach course. Early Childhood Research and Practice, 4(2), 1-20.

Byrne, M. (2001, April). Understanding life experiences through a phenomenological approach to research. The Association of PeriOperative Registered Nurses, 4(73). Retrieved April 5, 2005, from http://www.aorn.org/journal/2001/aprrc.htm

Cadwell, L. (1997). Bringing Reggio home. New York: Teachers College Press.

Cadwell, L. (2003). Bringing learning to life. New York: Teachers College Press.

Campbell, B. (n.d.). Phenomenology as a research method. Retrieved April 5, 2005, from http://www.staff.vu.edu.au/syed/alrnnv/papers/bev.html

Canfield, A. (n.d.). Body, identity and interaction: interpreting non-verbal communication. Retrieved April 4, 2005, from http://canfield.etext.net/

Ceppi, G., \& Zini, M. (Eds.). (1998). Children, spaces, relations: Metaproject for an environment for young children. Reggio Emilia, Italy: Reggio Children.

Chaillé, C., \& Britain, L. (2003). The young child as scientist : A constructivist approach to early childhood science education. $\left(3^{\text {rd }} \mathrm{ed}\right.$.). New York: Longman. 
Chalmers, D.J. (1996). The conscious mind: In search of a fundamental theory. New York: Oxford University Press.

Charlesworth, R. (1999). Understanding child development. ( $5^{\text {th }}$ ed.). Clifton Park, NY: Delmar Thomson Learning.

Clements, D. H. (1997). (Mis?)Constructing Constructivism. Teaching Children Mathematics ${ }_{2}$ 4, 198-200.

Coulter, J. (1979). The social construction of mind. London: Macmillan.

Creswell, J.W. (2002). Educational research: Planning, conducting and evaluating quantitative and qualitative research. Upper Saddle River, NJ: Pearson Education, Inc.

Crossley, N. (1996). Intersubjectivity: The fabric of social becoming. London: Sage Publications, Ltd.

Curtis, D., \& Carter, M. (2000). The art of awareness: How observation can transform your teaching. Minnesota: Redleaf Press.

Dahlberg, G., Moss, P., \& Pence, A. (1999). Beyond quality in early childhood education and care: Postmodern perspectives. Philadelphia, PA: Falmer Press, Taylor \& Francis, Inc. (ERIC Document Reproduction Service No. ED433943)

Davies, T. (2002). Changing schools of thought: Back to the future. Research in Education, 1(71), 9-16.

Desforges, C. (1995). How does experience affect theoretical knowledge for teaching? Learning and Instruction, 5, 385-400.

DeVries, R. (2004). Why the child's construction of relationships is fundamentally important to constructivist teachers. Prospects, 34(4), 411-22.

Dewey, J. (1963). Experience and education. New York: Macmillan. (Original work published 1938)

Dewey, J. (1933). How we think: A restatement of the relation of reflective thinking to the educative process. Boston: D.C. Heath and Company.

Dewey, J. (1963). The school and society (Rev. ed.). Chicago, Ill: The University of Chicago Press. 
Denzin, N. K., \& Lincoln, Y. S. (Eds.). (1994). Handbook of qualitative research. Newbury Park, CA: Sage.

Dolloff, L.A. (1999). Imaging ourselves as teachers: The development of teacher identity in music teacher education. Music Education Research, 1(2), 191-207.

Edwards, C., Gandini, L., \& Forman, G. (1993). The hundred languages of children. Norwood, NJ: Ablex Publishing Corporation.

Edwards, C., Gandini, L., \& Forman, G. (1998). The hundred languages of children. $\left(2^{\text {nd }}\right.$ ed.). Norwood, NJ: Ablex Publishing Corporation.

Erlich, B., \& Bhavnagri, N. (1994). Teacher change using effective practice when attempting to move toward a Reggio Emilia approach. St. Louis, MO: ERIC Clearinghouse on Elementary and Early Childhood Education. (ERIC Document Reproduction Service No. ED386295)

Ernest, P. (1994). Varieties of constructivism: Their metaphors, epistemologies and pedagogical implications. Hiroshima Journal of Mathematics Education, 2, 114.

Ewing Marion Kauffman Foundation (2002). Financing child care. Kansas City, MO: ERIC Clearinghouse on Elementary and Early Childhood Education. (ERIC Document Reproduction Service No. ED464702)

Findlay, J. (1977). In 'Hegel's phenomenology of spirit'. (A.V. Miller, Trans.). Oxford: Oxford University. (Original work published 1807)

Flavell, J. H. (1976). Metacognitive aspects of problem solving. In L. B. Resnick (Ed.), The nature of intelligence (pp.231-236). Hillsdale, NJ: Erlbaum.

Freire, P. (2001). Pedagogy of freedom (Patrick Clarke, Trans.). Linham: MD: Rowman \& Littlefield. (Original work published 1998)

Fullan, M. G. (1991). The new meaning of educational change. New York: Teachers College Press.

Gandini, L., \& Edwards, C. (2001). Bambini: The Italian approach to infant/toddler care. New York: Teachers College Press.

Gandini, L., Cadwell, L., Hill, L., \& Schwall, C. (Eds.). (2005). In the spirit of the studio: Learning from the atelier of Reggio Emilia. New York: Teachers College Press. 
Gedin, M. (1998). About listening... Discovering the inquisitive child. Stockholm, Sweden: Reggio Emilia Institute.

Glassman, M. (2001). Dewey and Vygotsky: Society, experience, and inquiry in educational practice. Educational Researcher, 30(4), 3-14.

Guidici, C., Rinaldi, C., \& Krechevsky, M. (Eds.). (2001). Making learning visible: Children as individual and group learners. Reggio Emilia, Italy: Reggio Children.

Guskey, T. R., \& Sparks, D. (1991). What to consider when evaluating staff development. Educational Leadership, 49(3), 73-76.

Habermas, J. (1987a). The theory of communicative action, vol. two: System and lifeworld. Cambridge, Polity.

Habermas, J. (1991a). The theory of communicative action, vol. one: Reason and the rationalization of society. Cambridge, Polity.

Hegel, G. (1979). The phenomenology of spirit. Oxford, Claredon.

Heidegger, (1988). Hegel's phenomenology of spirit. Bloomington and Indianapolis: Indiana University Press.

Hendrick, J. (Ed.). (1997). First steps toward teaching the Reggio way. Upper Saddle River, NJ: Prentice-Hall, Inc.

Herbert, E. (1997). Schools for everyone: A new perspective on inclusion. San Francisco, CA: Jossey Bass.

Hertzog, N.B. (2001). Reflections and impressions from Reggio Emilia: "It's not about art!" Champaign, IL: Early Childhood Research and Practice: An Internet Journal on the Care, Development and Education of Young Children. (ERIC Document Reproduction Service No. ED453002)

Hesslefors-Arktoft, E. (1996). By word and action: The meaning of "using pupil experiences. " Göteborg, Sweden: Göteborg University. Retrieved April 10, 2005, from http://www.ped.gu.se/biorn/diss.sum/hesslef.html

Hillman, J. (1996). The soul's code: In search of character and calling. New York: Random House Publishing, Inc.

Hubbard, B.M. (speaker). (1997). Conscious evolution: The path of the co-creator. [Cassette Recording]. Wilsonville, OR: LEC Productions. 
Huitt, W. (1997). Metacognition. Educational Psychology Interactive. Valdosta, GA: Valdosta State University. Retrieved November 1, 2004, from http://chiron.valdosta.edu/whuitt/col/cogsys/metacogn.html

Joyce, B., \& Showers, B. (1983). Power in staff development through research on training. Arlington, VA: Association for Supervision and Curriculum Development.

Karoly, L, Greenwood, P.W., Everingham, S.S., Hoube, J., Kilburn, R., Rydel, C.P., Sanders, M., \& Chiesa, J. (1998). Investing in our children: What we know and don't know about the costs and benefits of early childhood interventions. Retrieved November 11, 2002, from http://www.rand.org/publications/MR/MR898

Katz, L.G., \& Cesarone, B. (1994). Reflections on the Reggio Emilia approach [monograph series]. Pennsylvania, IL: Eric Clearinghouse on Elementary \& Early Childhood Education.

Lambert, L. (1988). Staff development redesigned. Educational Leadership, 45(8), 665-668.

Lee, VE, \& Burkam, DT. (2002). Inequality at the starting gate: Social background differences in achievement as children begin school. Washington D.C.: The Economic Policy Institute.

Lieberman, A., \& Miller, L. (1979). Staff development: New demands, new realities, new perspectives. New York: Teachers College Press.

Lincoln, Y.S., \& Guba, E.G. (1985). Naturalistic inquiry. Beverly Hills, CA: Sage Publications, Inc.

Livingston, J. (1997). Metacognition: An overview. Buffalo, NY: University at Buffalo. Retrieved November 1, 2004, from http://www.gse.buffalo.edu/fas/shuell/cep564/Metacog.htm

McClellend, J., Dahlberg, K., \& Plihal, J. (2002) Learning in the ivory tower: Students' embodied experiences. College Teaching, 50(1), 4-8.

Mezirow, J. (2000). Learning as transformation. San Francisco, CA: Jossey-Bass.

Mishler, E.G. (1986). Research interviewing: Context and narrative. Cambridge, MA: Harvard University Press

Munn, P. (1998). Parental influence on school policy: Some evidence from research, Journal of Education Policy 13(3), 379-394. 
New, R.S. (1993). Reggio Emilia: Some lessons for U.S. educators (Report No. EDOPS-93-3). Champaign, IL: ERIC Clearinghouse on Elementary and Early Childhood Education. (ERIC Document Reproduction Service No. ED354988)

New, R.S. (1999). Why should children learn? Making choices and taking chances. Early Childhood Research \& Practice, 1. Retrieved November 11, 2002, from http://ecrp.uiuc.edu/v1n2/print/new.html

New, R.S. (2000), Reggio Emilia: Catalyst for change and conversation (Report No. EDO-PS-00-15). Washington, DC: Office of Educational Research and Improvement. (ERIC Document Reproduction Service No. ED447971)

Olds, A. (1998). Quality in child care designs. Paper presented at the National Campus Child Care Coalition conference, San Francisco, CA.

Oregon Psychoanalytic Center. (2005). Working through impasses with the intersubjective third [Brochure]. Portland, OR: Dr. Jessica Benjamin.

Palmer, P.J. (1998). The courage to teach: Exploring the inner landscape of a teacher's life. San Francisco, CA: Jossey-Bass.

Patton, M. Q. (1990) Qualitative evaluation and research methods, ( ${ }^{\text {nd }}$ Ed.). Newbury Park CA: Sage.

Phillips, D.C. (1996). Response to Ernst von Glasersfeld. Educational Researcher, $25(6), 20$.

Phillips, D.C., \& Soltis, J.F. (1998). Perspectives on learning (3 ${ }^{\text {rd }}$ ed.). New York: Teachers College Press.

Perfect, T.J., \& Schwartz, B.L. (2002). Applied metacognition. Cambridge, UK: Cambridge University Press.

Piaget, J. (1932). The moral judgment of the child. London: Routledge \& Kegan Paul.

Piaget, J. (1995). Comments on Vygotsky's critical remarks concerning the language and thought of the child and judgment and reasoning in the child. (Ed. \& Trans.), New Ideas in Psychology, 13(3), 325-340. Lancaster, UK: Department of Educational Research. (Original work published in 1962)

Piaget, J. (1970). Structuralism. New York: Basic Books.

Reyes, X.A., \& Rios, D.I. (2003). Imaging teachers: In fact and in the mass media. Journal of Latinos and Education, 2(1), 3-11. 
Reggio Children (Eds.). (n.d.). A document of three rights. Reggio Emilia, Italy: Reggio Children.

Reggio Children (Eds.). (1996). Catalogue of the exhibit the hundred languages of children. Reggio Emilia, Italy: Reggio Children.

Reggio Children (Eds.). (2004). Rechild: Reggio children newsletter. Reggio Emilia, Italy: Reggio Children. Retrieved January 29, 2005, from http://zerosei.comune.re.it/pdfs/rechild06.pdf

Reggio Children (Eds.). (2005). 100 languages of chidren. Reggio Emilia, Italy: Reggio Children. Retrieved June 6, 2005, from http://zerosei.comune.re.it/inter/100exhibit.htm

Rockel, J. (2003, November 3). Interpreting documentation [Msg 1]. Message posted to Early Childhood and Parenting Collaborative electronic mailing list, archived at http://listarchives.crc.uiuc.edu/reggioaskeric/2003/Nov_2003/index.html

Rodgers, C.R., Anderson M., Conley W., LeVasseur P., \& Turpin, L. (1993). Mentoring each other: Teacher educators as learners of teaching. Brattleboro, VT: The MAT Program of The School for International Training.

Rosenthal, S. \& Bourgeois, P. (1991). Mead and Merleau-Ponty: Toward a common vision. New York: State University of New York Press.

Sassalos, M.C. (1999). Discovering Reggio Emilia: Building connections between learning and art. (Report No. PS028-024). Champaign, IL: Eric Clearinghouse on Elementary and Early Childhood Education. (ERIC Document Reproduction Service No. ED456890)

Schon, D.A. (1987). Educating the reflective practitioner: Toward a new design for teaching and learning in the professions. San Francisco: Jossey:Bass Publishers.

Schon, D.A. (1983). The reflective practitioner: How professionals think in action. New York: Basic books, Inc., Publishers.

Segal, L. (2001). The dream of reality: Heinz von Foerster's constructivism. ( $2^{\text {nd }}$ ed.). London, England; Springer Verlag.

Silva, A., (2001). LOs and metanoia - reflective practice. Retrieved April 4, 2005, from http://www.learning-org.com/01.07/0052.html 
Sosniak, L.A. (1987). The nature of change in successful learning. Teachers College Record, 88(4), 519-535.

Sparks, G.M. (1983). Synthesis of research on staff development for effective teaching. Educational Leadership, 41(3), 65-72.

St. Louis-Reggio Collaborative (2001). Conversations with directors and RE [Brochure]. St. Louis, MO: Ashley Cadwell.

Swetnam, L.A. (1992). Media distortion of the teacher image. Clearing House, 66(1), 30-32. Retrieved August 8, 2004, from EBSCOhost Academic Search Premier.

Taylor, K., Marienau, C., \& Fiddler, M. (2000). Developing adult learners: Strategies for teachers and trainers. San Francisco: Jossey-Bass.

U.S. Department of Education Office of Public Affiars. President Bush's plan to prepare children for kindergarten. (2003, February 3). Retrieved May 26, 2003, from http://www.ed.gov/PressReleases/02-2003/02032003d.html

U.S. Department of Health and Human Services. Administration for Children and Families. (2001, Jan 21). Retrieved May 24, 2003, from http://www.acf.dhhs.gov/programs/opa/facts/headst.htm

Van Hoorn, J., Nourot, P.M., Scales, B., \& Alward, K.R. (2002). Play at the center of curriculum $\left(3^{\text {rd }}\right.$ ed.). Upper Saddle River, NJ: Pearson Education.

Valli, L. (1997). Listening to other voices: A description of teacher reflection in the United States. Peabody Journal of Education. 72(1), 67-88.

Van Manen, M. (1990). Researching lived experience: Human science for an action sensitive pedagogy. Albany, NY: State University of New York Press.

Von Glaserfeld, E. (1995). Radical constructivism: A way of knowing and learning. London, England: Falmer Press.

Vygotsky, L.S. (1980). Mind in society: The development of higher psychological processes. Cambridge, MA: Harvard University Press.

Wheatley, M., \& Kellner-Rogers, M. (1996). A simpler way. San Francisco: BerrettKoehler Publishers, Inc.

Wideen, M.F., \& Andrews, I. (Eds.). (1987). Staff development for school improvement: A focus on the teacher. New York: The Falmer Press. 
Williams, R.R. (1992). Recognition: Hegel and Fichte on the other. Albany, NY: State University of New York Press.

Xiang, Z, \& Schweinhart, LJ. (2002). Effects five years later: The Michigan school readiness program evaluation through age 10 . Retrieved November 11,2002 , from http://www.highscope.org/Research/MsrpEvaluation/msrp-Age 10-2.pdf

Yun, E. (2000). The project approach as a way of making life meaningful in the classroom. Champaign, IL: ERIC Clearinghouse on Elementary and Early Childhood Education. (ERIC document Reproduction Service No. ED470896) 